University of Louisville ThinkIR: The University of Louisville's Institutional Repository

Electronic Theses and Dissertations

$8-2016$

\title{
The impact of the Patient Protection and Affordable Care Act's risk adjustment program on adverse selection : first year case study.
}

Steven K. Zimmerman

University of Louisville

Follow this and additional works at: https://ir.library.louisville.edu/etd

Part of the Public Health Commons

\section{Recommended Citation}

Zimmerman, Steven K., "The impact of the Patient Protection and Affordable Care Act's risk adjustment program on adverse selection : first year case study." (2016). Electronic Theses and Dissertations. Paper 2512.

https://doi.org/10.18297/etd/2512

This Doctoral Dissertation is brought to you for free and open access by ThinkIR: The University of Louisville's Institutional Repository. It has been accepted for inclusion in Electronic Theses and Dissertations by an authorized administrator of ThinkIR: The University of Louisville's Institutional Repository. This title appears here courtesy of the author, who has retained all other copyrights. For more information, please contact thinkir@louisville.edu. 
THE IMPACT OF THE PATIENT PROTECTION AND AFFORDABLE CARE ACT'S RISK ADJUSTMENT PROGRAM ON ADVERSE SELECTION: FIRST YEAR CASE STUDY

By

Steven K. Zimmerman, M.C.S.

\author{
A Dissertation \\ Submitted to the Faculty of the \\ School of Public Health and Information Sciences of the \\ University of Louisville in Partial Fulfillment of the \\ Requirements of the Degree of \\ Doctor of Philosophy in Public Health Sciences \\ Department of Health Management and System Sciences \\ University of Louisville \\ Louisville, Kentucky
}

August 2016 



\title{
THE IMPACT OF THE PATIENT PROTECTION AND AFFORDABLE CARE ACT'S RISK ADJUSTMENT PROGRAM ON ADVERSE SELECTION: FIRST YEAR CASE STUDY
}

\author{
Steven K. Zimmerman, M.C.S.
}

A Dissertation Approved on

21 July 2016

By the following Dissertation Committee

Dissertation Director

Robert Esterhay, M.D.

Bert Little, Ph.D.

Michael Mills, Ph.D.

Karunarathna Kulasekera, Ph.D. 


\section{DEDICATION}

This is dedicated to Dominique, Dallas and Davis. I hope they have learned as much from me as I have from them. 


\section{ACKNOWLEDGEMENTS}

My journey toward this goal would not be possible without the help of many

people. First, I would like to thank Dr. Bob Esterhay for his continued and valued encouragement and support throughout my entire time in the program. I would like to thank Dr. Ray Austin, my advisor, for his guidance through the early years and getting me started in the program. I am also grateful to the rest of my committee: Dr. Bert Little for pushing me to do a little more each time we visited; Dr. Michael Mills for asking questions in a way that made me think differently; and Dr. KB Kulasekera for his feedback.

I would like to thank my family for their support, especially Cindy who never complained about the amount of time I was unavailable while I was working towards this goal. Thanks to Susan Kirk, my grandmother, for helping to shape me into the person I am today.

Finally, I would like to thank my friends and colleagues who supported me and helped me over the last several years, most notably of which are Scott Bagley, Bob Frey, Lisa Geyer, and David Malin 


\title{
ABSTRACT \\ THE IMPACT OF THE PATIENT PROTECTION AND AFFORDABLE CARE ACT'S RISK ADJUSTMENT PROGRAM ON ADVERSE SELECTION: FIRST YEAR CASE STUDY
}

\author{
Steven K. Zimmerman
}

July 21,2016

In 2014 the Patient Protection and Affordable Care Act (ACA) implemented a risk adjustment program to stabilize premiums and neutralize premiums in the individual health insurance marketplace. This dissertation will examine the impact of the ACA risk adjustment program on adverse selection for one insurer during 2014. This study utilized enrollment and claims data for one insurer and employs graphical analysis to test for adverse selection. Previous studies have been unable to utilize actual insurer data to test for adverse selection in under the ACA risk adjustment program.

Until the implementation of the ACA, insurers relied on underwriting methods to avoid being adversely selected. The ACA has removed the underwriting model by requiring insurers to move to a community rated model for pricing plans. This approach, along with risk adjustment was intended, by the Department of Health and Human Services (HHS), to attract insurers to participate in the individual health insurance marketplaces. Unfortunately, not all states enjoyed a large contingent of participating insurers which consequently had a dramatic financial impact on certain insurers being adversely selected. This dissertation discusses the potential drivers of adverse selection. 
In addition, the study examines potential improvements to help balance the risk pool and move toward the intended goal of risk adjustment. 


\section{TABLE OF CONTENTS}

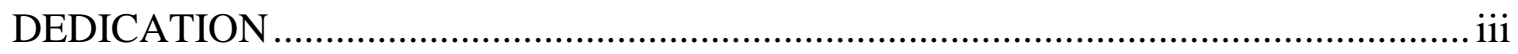

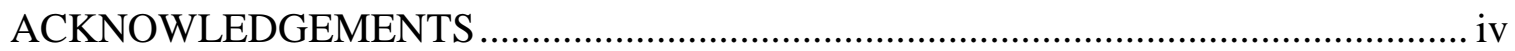

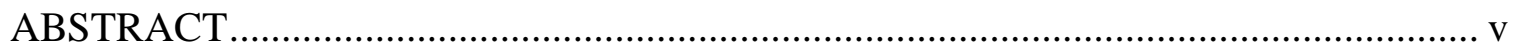

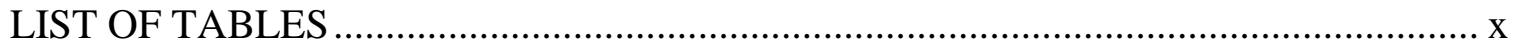

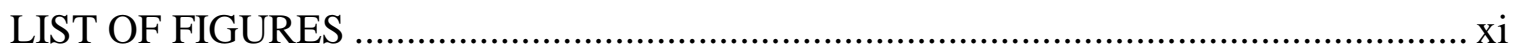

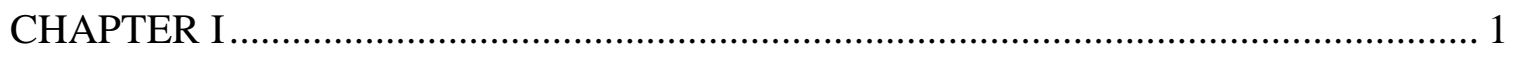

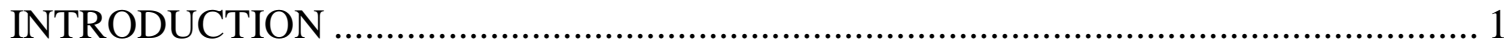

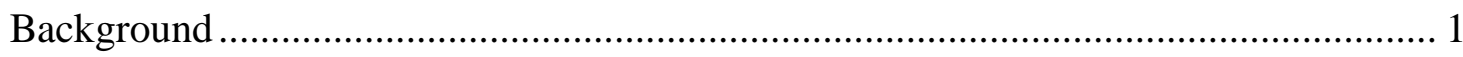

Adverse Selection ............................................................................................ 2

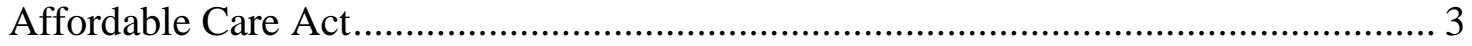

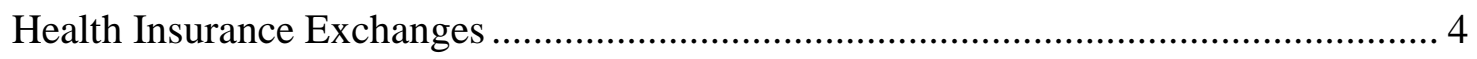

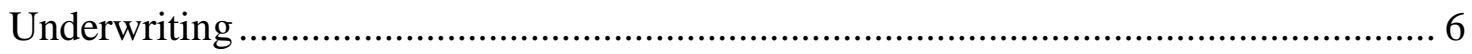

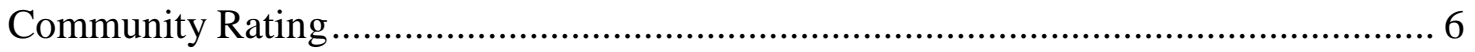

Premium Stabilization Components .................................................................... 7

Risk Adjustment History................................................................................ 10

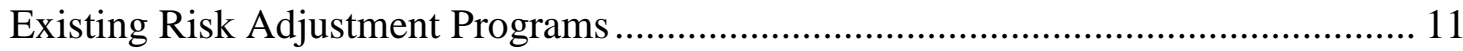

Affordable Care Act Risk Score Components and Calculation ................................ 12

Risk Adjustment Payment Transfer ..................................................................... 15

Risk Adjustment's Role in Public Health .................................................................... 24

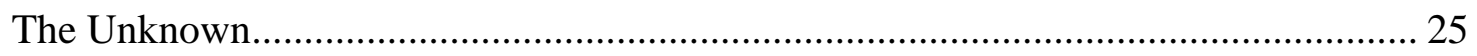

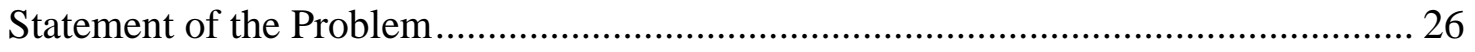

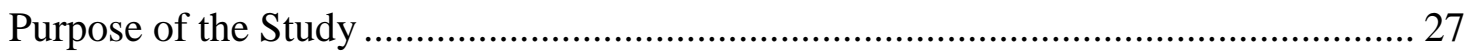

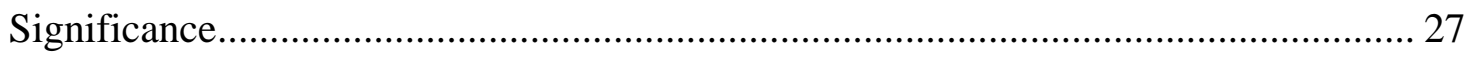

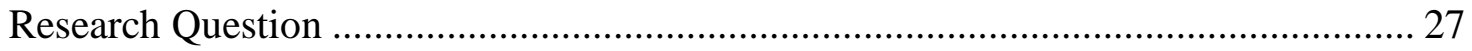

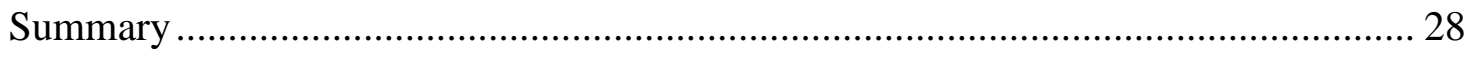

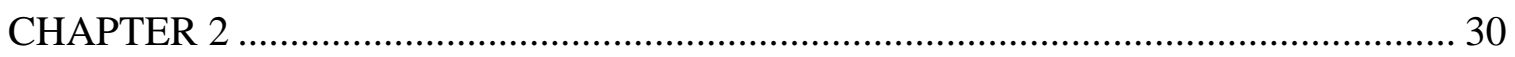




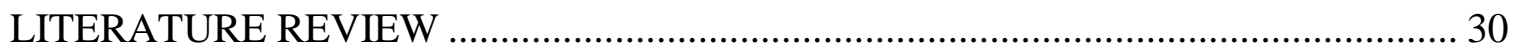

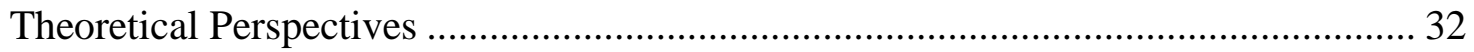

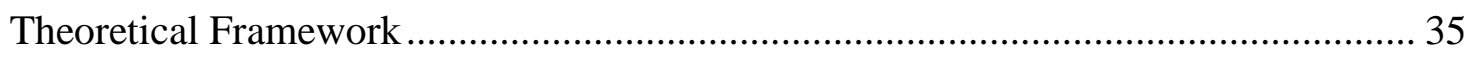

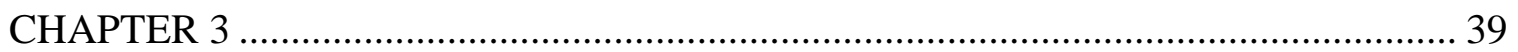

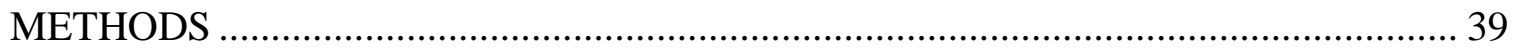

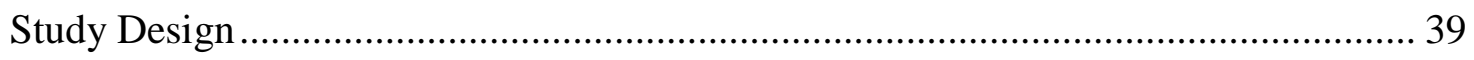

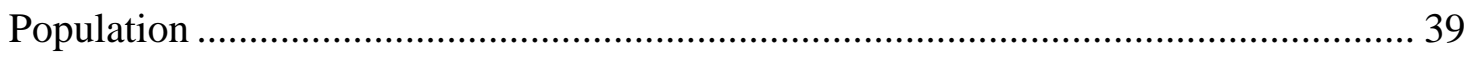

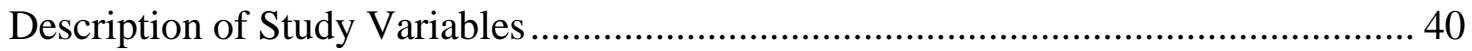

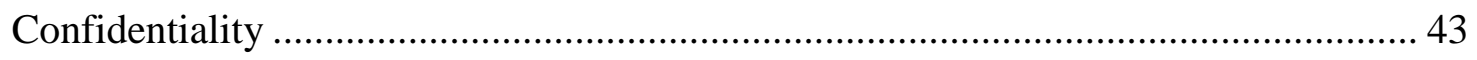

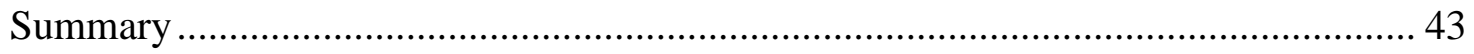

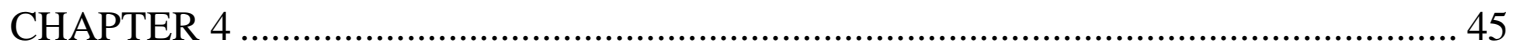

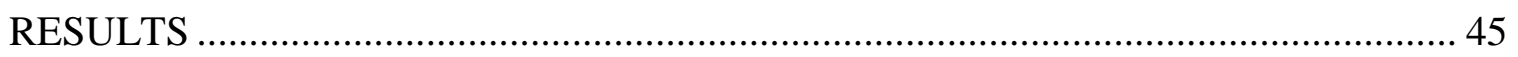

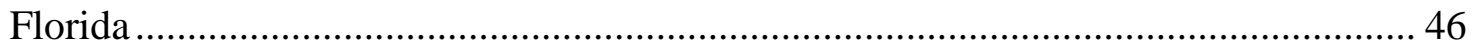

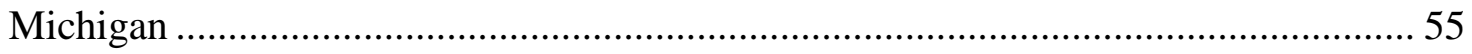

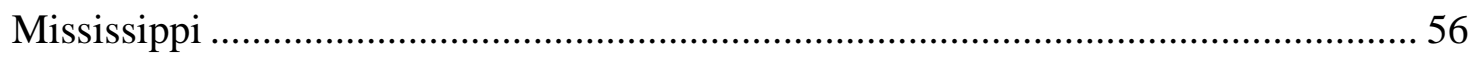

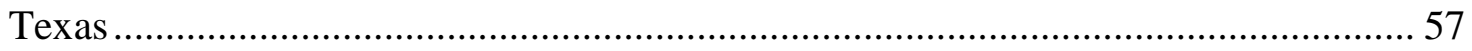

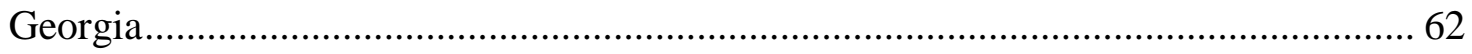

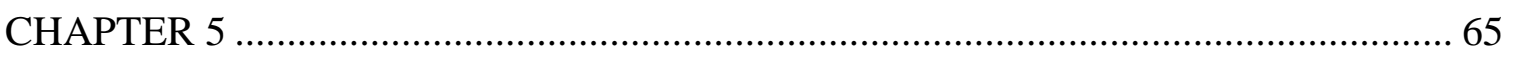

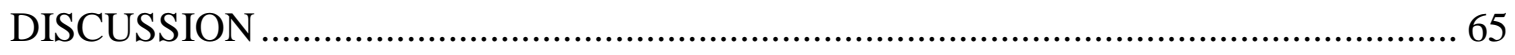

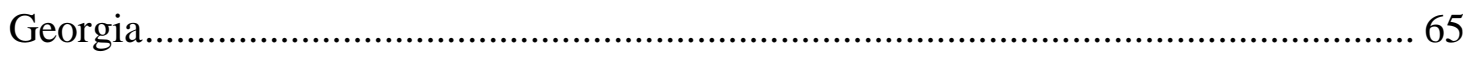

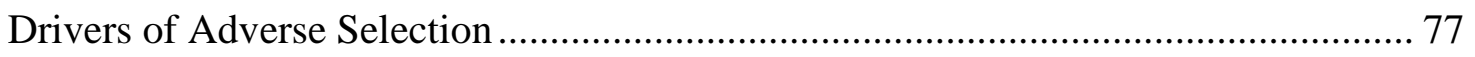

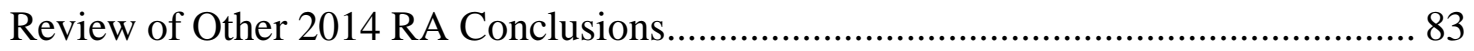

The Case for a Concurrent Model........................................................................... 89

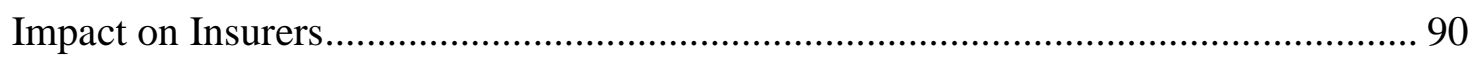

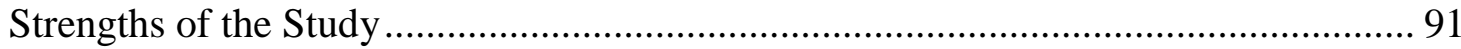

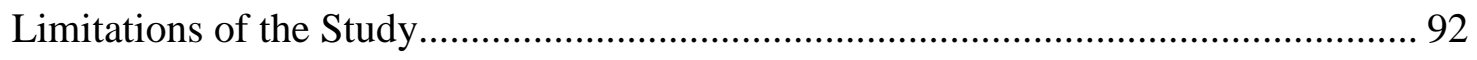

Recommendations for Future Research ................................................................. 93

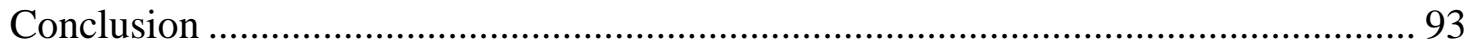

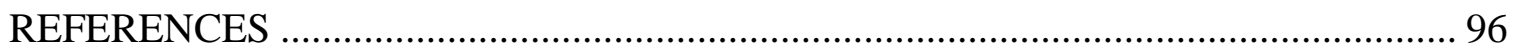

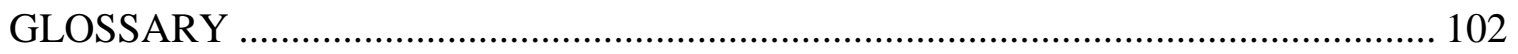




\section{UNIVERSITY OF LOUISVILLE INSTITUTIONAL REVIEW BOARD}

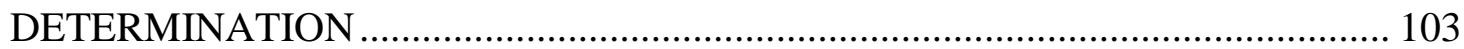

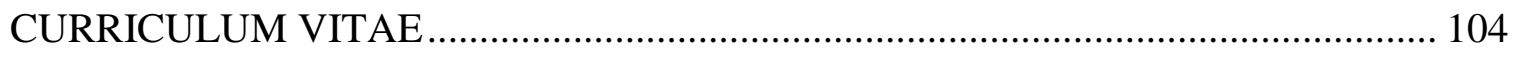




\section{LIST OF TABLES}

Table 1. State Health Insurance Market Place Types (Kaiser Family Foundation, 2016).. 5

Table 2. Medicare Risk Adjustment vs ACA Risk Adjustment ................................... 10

Table 3. Global Risk Adjustment Programs ...................................................................... 11

Table 4. Age-Sex-Metal Cofactors (Health and Human Services, 2013)....................... 14

Table 5. Payment Transfer Variables............................................................................. 16

Table 6. Induced Demand Adjustment for Each Metal Level ....................................... 17

Table 7. Metal Level Actuarial Value.......................................................................... 19

Table 8. Risk Score with Unadjusted Actuarial Value (Centers for Medicare and Medicaid Services, 2012)..................................................................... 20

Table 9. Risk Score with Unadjusted Actuarial Value (Centers for Medicare and Medicaid Services, 2012)......................................................................... 20

Table 10. Federal Age Rating Factor Curve .................................................................. 21

Table 11. 10 Essential Health Benefits .......................................................................... 34

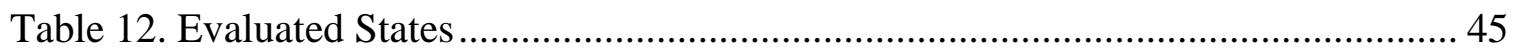

Table 13. Florida Bin Population Counts ................................................................. 47

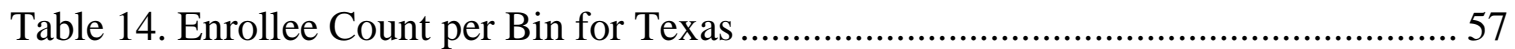

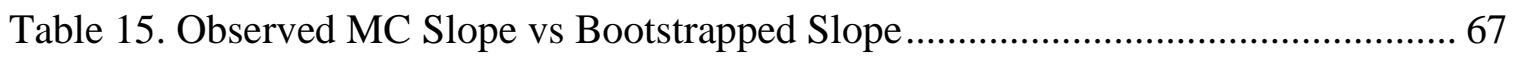

Table 16. RA Transfer as Percent of Premium by Insurer Market Share ........................ 80

Table 17. Payment Transfer as a Percent of Market Share ........................................... 82 


\section{LIST OF FIGURES}

Figure 1. Risk score calculation process .................................................................... 13

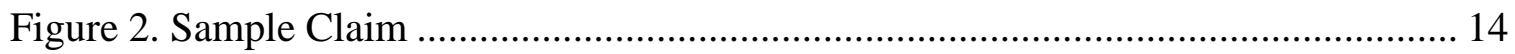

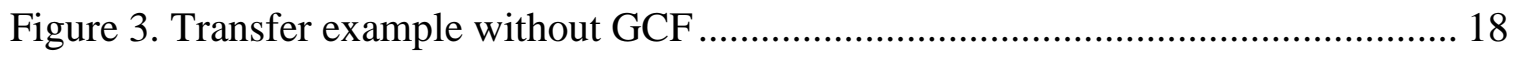

Figure 4. Transfer Example with GCF Impact …………...................................... 18

Figure 5. Transfer Payment Example Variables ............................................................ 22

Figure 6. Zero-Sum Game Theory Example - Poker...................................................... 33

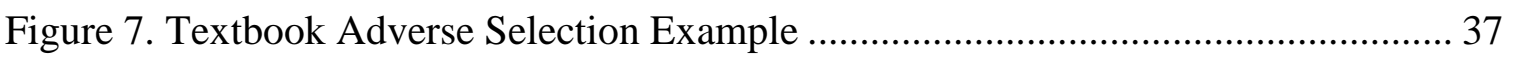

Figure 8. Einav and Finkelstein Positive Correlation Test for Selection.......................... 37

Figure 9. Graphical Framework Sample ................................................................ 38

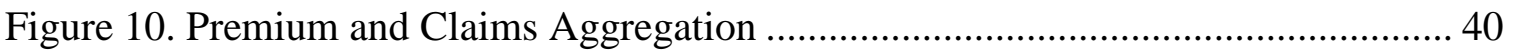

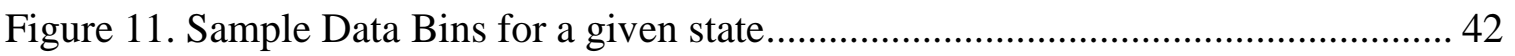

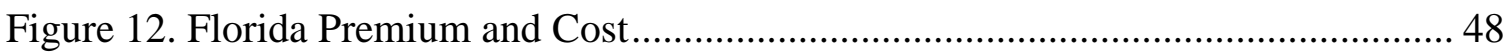

Figure 13. Florida Silver Premium and Cost ........................................................... 49

Figure 14. Florida Bronze Premium and Cost ............................................................. 50

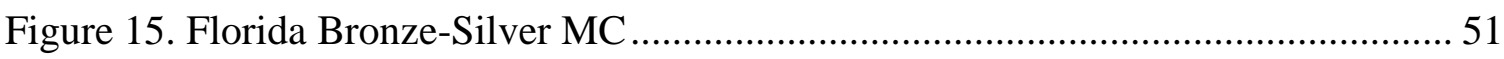

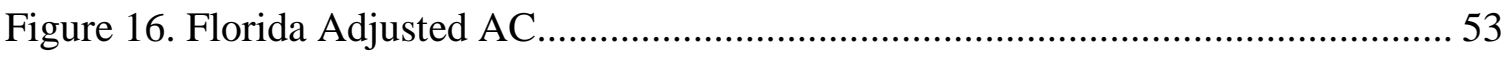

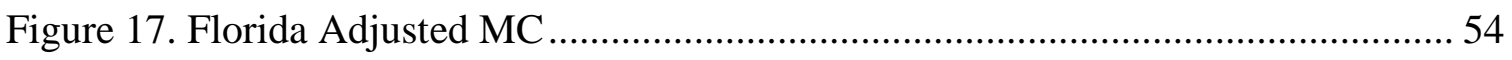

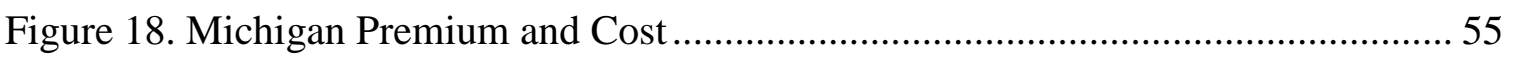

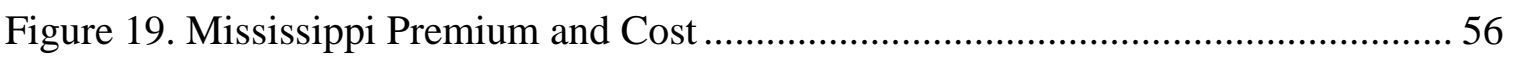

Figure 20. Texas Premium and Cost...................................................................... 58

Figure 21. Texas Platinum premium and Cost............................................................. 59

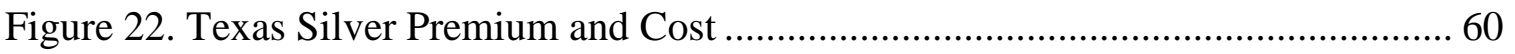

Figure 23. Texas Bronze Premium and Cost with Complete Unraveling.......................... 61

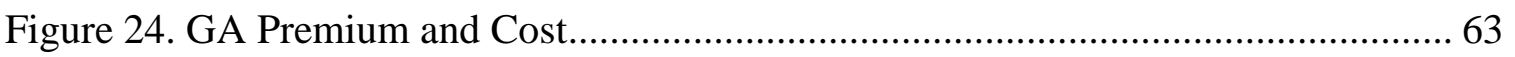

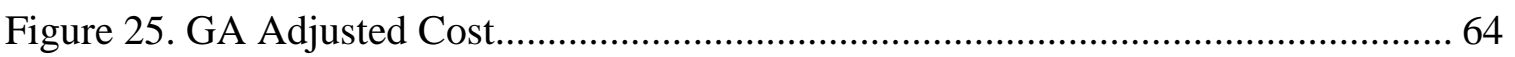

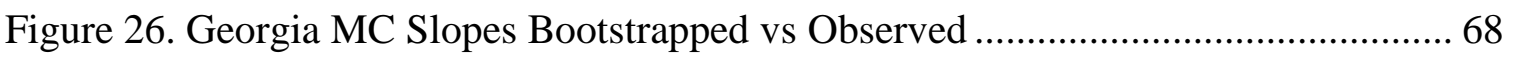

Figure 27. Georgia Platinum MC Slopes Bootstrapped vs Observed............................... 68

Figure 28. Georgia Gold MC Slopes Bootstrapped vs Observed ...................................... 69

Figure 29. Georgia Silver MC Slopes Bootstrapped vs Observed...................................... 69

Figure 30. Georgia Bronze MC Slopes Bootstrapped vs Observed.................................. 70

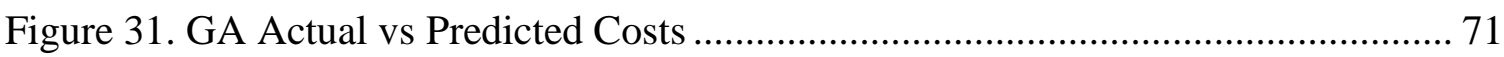

Figure 32. Actual vs Predicted Cost Differences ....................................................... 72

Figure 33. GA Platinum Actual vs Predicted Costs........................................................ 73

Figure 34. GA Gold Actual vs Predicted Costs ............................................................... 74 
Figure 35. GA Silver Actual vs Predicted Costs...................................................... 75

Figure 36. Bronze Actual vs Predicted Costs ............................................................. 76

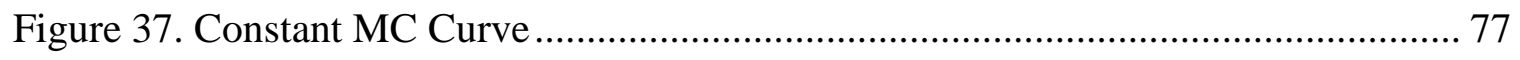

Figure 38. Risk Adjustment Receipts versus Transitional Reinsurance ......................... 85

Figure 39. Risk Adjustment Receipts by Issuer Member Months ................................ 87

Figure 40. Risk Adjustment Receipts vs Distance from State-Wide Average Claims ..... 88 


\section{CHAPTER I}

\section{INTRODUCTION}

\section{Background}

Prior to January 1, 2014 individuals (or families) who wished to obtain health insurance outside of the workplace were underwritten before they received healthcare coverage in the form of a plan from an insurance company. Essentially, the insurer would look at a person's health history, identify any risk factors (i.e., chronic disease such as diabetes) and risk behaviors (i.e., tobacco use) and create a premium (monthly payment) and cost sharing plan that would help compensate for the financial risk they assumed to provide a health plan. Cost sharing is essentially how much the insured person/family would have to pay of their own money, should they require healthcare services - these costs could include copays and deductibles. In theory, the premium amount and the cost sharing amount paid by the individual would cover their medical expenses and administrative costs incurred by the insurer for the coming year ${ }^{1}$.

One of the arguments against underwriting is that insurers could "cherry pick" members. That is to say that insurers could create plans around cost and benefits to attract healthier individuals and in turn dissuade those who have the potential to cost more in claims payouts than what they are charged in premiums or cost-sharing. Prior to healthcare reform individuals bought health insurance based on need (or perceived need).

\footnotetext{
${ }^{1}$ The term "individual" refers to the person purchasing health insurance in the individual market (not through an employer) for himself or herself and/or their family.
} 
If people did not believe they needed health insurance they would not buy it. When this happened, only those who needed insurance - usually the sick (e.g., having a chronic or known disease or condition) - were the ones buying it and thus driving up the costs. When only the sick are buying insurance and contributing to the risk pool, it is referred to as adverse selection. Insurers utilized underwriting as a way to counterbalance adverse selection.

\section{Adverse Selection}

Adverse selection has long been a concern for insurance companies when designing and pricing health benefits for consumers. Insurers are, many times, at a disadvantage when selling products to individuals. Often the individual has information about their health which the insurer does not have access to. This is a phenomenon described by George Akerlof as information asymmetry (Akerlof, 1970). For this reason, insurers are often adversely selected by those who are most at risk. A popular example demonstrating adverse selection is the restaurant that provides an all-you-can-eat buffet. These restaurants may be adversely selected by those who like to eat or know they will eat more than the "average" person. Those that know they eat more food or perceive themselves as having a larger appetite than the average person may choose the restaurant with the buffet over the al-a-carte restaurant which provides less food for the money spent. In the insurance industry, adverse selection is basically accepted as: those who purchase insurance have every intention of using it. Underwriting is the tool insurers use to help protect themselves against information asymmetry and adverse selection. In 2014 insurers had to move to a community-rated model for pricing in the individual market 
which dictates that premiums for health insurance must be the same for everyone in a particular geographic area or community and not determined on an individual basis. Moving to a community rated pricing model did not necessarily eliminate adverse selection and will be addressed further in Chapter 2.

\section{Affordable Care Act}

On March 23, 2010, President Obama signed the Patient Protection and Affordable Care Act (ACA) into law. Changes to healthcare, as a result of the ACA, have far reaching implications for the private insurance industry. The ACA's impact on commercial health plans varies depending on the size of the plan. There are different policy implications for individual health plans, small group health plans and large group health plans. Two of the most notable impacts include formation of health insurance exchanges for individuals (or exchanges) and the requirement that all individuals must purchase health insurance - also referred to as the individual mandate (Establishing Health Insurance Exchanges: An Overview of State of Affairs, 2012). Exchanges act as a retail marketplace at the state level for health insurance and were created to: help provide consumers with more choices for health benefits and options, provide competition among insurers, and drive down prices. If an individual chooses not to purchase an insurance plan they will be assessed an annual tax penalty (HHS, 2013). Prior to the ACA, insurance was seen by some as a financial hardship. The new law now includes subsidies for low income households to alleviate some of that hardship. Both the introduction of the tax penalty and subsidies are not a direct regulation aimed at health plans or insurers; however, it does affect how they choose to conduct business. Insurers must now consider 
the risk of insuring an unknown (and potentially sicker) population. Without knowing the risk mix of the population there may be resistance by insurers to participate in the exchanges. To assuage those fears, the ACA requires a group of premium stabilization programs to be implemented (Health and Human Services, 2012).

Risk adjustment, the reinsurance program, and risk corridors, commonly referred to as the 3Rs, are the stabilization components created within the ACA with the intent to diminish the financial risk of health insurers who wish to participate in the exchanges. Both the reinsurance program and the risk corridors are temporary and begin in January 2014 and will last through 2016. Risk adjustment, on the other hand, is a permanent program which also begins January $1^{\text {st }}, 2014$ (HHS, 2013). While risk adjustment is the focus of this dissertation, there will be commentary on both the reinsurance program and risk corridors throughout the various sections of this dissertation to understand their impacts.

\section{Health Insurance Exchanges}

A health insurance exchange (exchange or marketplace) is a retail-like structure at the state level created to provide competition in the health insurance marketplace. The exchanges will offer more choices for consumers with regards to health plans and options. Exchanges must meet minimum federal guidelines around options and pricing as well as provide information for each product on the exchange to help guide the consumer in choosing the best plan and benefits available for their needs and financial situation (Centers for Medicare and Medicaid Services, 2015). The exchanges started operating in January 2014 and provided a marketplace for individuals and small 
businesses of 50 or less full time employees (FTE) ${ }^{2}$. Exchanges will be run at the state level (or possibly at regional levels through interstate partnerships) and may be designed and run by the state, a state and federal partnership, or a state may defer administration of the exchange (almost wholly) to the federal government, in which case the federally developed exchange model will be implemented in those states (see Table 1) (Kaiser Family Foundation, 2016).

Table 1. State Health Insurance Market Place Types (Kaiser Family Foundation, 2016)

\begin{tabular}{|l|c|}
\hline \multicolumn{1}{|c|}{ Type of Market Place } & $\begin{array}{c}\text { Count of } \\
\text { States }\end{array}$ \\
\hline Federally-facilitated Marketplaces & 27 \\
\hline State-Partnership Marketplaces & 7 \\
\hline State-based Marketplaces & 13 \\
\hline Federally-supported Marketplaces & 4 \\
\hline
\end{tabular}

Federally-facilitated marketplaces are run and maintained by the Department of Health and Human Services (HHS). Individuals purchasing insurance through this exchange, do so through the healthcare.gov website. In state-partnership marketplaces, individuals will purchase insurance through healthcare.gov but the states provide some additional functions such as in-person assistance. The state-based exchanges are the sole responsibility of the state. The states run and administer the exchange and all associated functions. Individuals, who purchase their insurance from a state-based exchange, purchase it through the state run exchange website. Federally-supported marketplaces are

\footnotetext{
${ }^{2}$ Beginning in 2016 the small business definition will include 2-100 full time equivalent (FTE) employees. Full time equivalents include part-time employee hours who count towards Full-Time Equivalent calculation.
} 
run and administered by the state but leverage healthcare.gov as their enrollment interface.

Regardless of the type of exchange marketplace, the purpose of the exchange is to facilitate changes to the insurance market which will drive consumer engagement as well as provide plans to the medically uninsured, including individuals with little or no means of purchasing medical insurance otherwise. ACA-compliant plans are any plans that began healthcare coverage on January $1^{\text {st }}, 2014$ or later and are not considered grandfathered or transitional plans (Centers for Medicare and Medicaid Services, 2014).

\section{Underwriting}

Prior to the implementation of the exchanges and stabilization programs, insurers would determine the premium for the insurance policy and the associated benefits based on the particular individual's (and/or family members who would be included on the policy) health history. This is also known as risk rating. Gathering this information helps the insurer evaluate the potential financial risk of the individual and allows them to set the premium to help cover expected medical costs. Underwriting was utilized by insurers to protect themselves against adverse selection. With the passage of the ACA, underwriting is no longer allowed in the individual markets and insurers have had to move to a community rating model for pricing their benefits.

\section{Community Rating}

Community rating requires insurers to charge the same premium to all people in a particular geographic region. No longer can insurers consider current health or prior 
health status of an individual when charging premiums for their products ${ }^{3}$. The concept of community rating sounds advantageous for those who were previously charged much higher premiums based on their health risks. Conversely, those who are healthier or younger and with fewer health issues might see an increase in their premiums.

\section{Premium Stabilization Components Reinsurance Program}

The Reinsurance program, one of two temporary programs, was designed to stabilize premiums by partially offsetting claims for high cost members in the nongrandfathered individual market. All health insurers and self-insured plans must make contributions - meaning they must pay into the reinsurance pool. Any contributions collected for a particular state will only be used towards reinsurance payments in that state (Centers for Medicare and Medicaid Services, 2015). The HHS operated payment process is designed to ensure payments do not exceed available funds from collected contributions. Only non-grandfathered individual plans (referred to as individual ACA plans) are eligible for payments. Reinsurance is maintained at the state level and the state may run the program or defer to HHS (HHS, 2013). CMS will reimburse insurers for every member whose claims costs for a calendar year exceed $\$ 45,000$. This is sometimes referred to as the attachment point. The maximum claims costs (or cap) per member is $\$ 250,000$. Thus, the maximum eligible reinsurance reimbursement amount per member is $\$ 205,000(\$ 250,000-\$ 45,000)$.

\section{Risk Corridors}

Risk corridors were created as a direct incentive for carriers to participate in the

\footnotetext{
${ }^{3}$ Insurers can adjust premium based on age and gender as well a tobacco use.
} 
exchanges by providing protection to health plans for the first few years as they figure out how to price their products for a new and unknown risk pool. Risk corridors look at percentages and not dollar amounts. If a plan's allowable costs are less than 97 percent of its target amount, it pays HHS a percentage of the difference. If a plan's allowable costs are more than 103 percent of its targeted amount, HHS pays the insurer a percentage of the difference (HHS, 2013). If the plan's allowable costs are between $92 \%-97 \%$ then the insurer must pay HHS 50\% of their gain. If the plan's allowable costs are between $103 \%-108 \%$, HHS will share in 50\% of the costs. For those plans below $92 \%$ and above $108 \%$, HHS' respective allocation drops to $20 \%$. The formula looks something like the following (La Couture \& Booth, 2015):

$$
\begin{gathered}
\text { Allowable Costs }=\text { Medical Claims Costs }+ \text { Quality Improvement Costs } \\
\text { Target Costs }=\text { Premiums }- \text { Administrative Costs } \\
\text { Risk Corridor Ratio }=\frac{\text { Allowable Costs }}{\text { Target Costs }}
\end{gathered}
$$

To demonstrate we can fill in the values and calculate a hypothetical Risk Corridor Payment:

$$
\begin{gathered}
\text { Allowable Costs }=\$ 9,500,000+200,000 \\
\text { Target Costs }=\$ 11,000,000-1,000,000 \\
\text { Risk Corridor Ratio }=97 \%
\end{gathered}
$$

The above example would not result in any payment to or from HHS because the ratio is 97\%. The next example demonstrates payment from HHS:

$$
\begin{gathered}
\text { Allowable Costs }=\$ 9,500,000+1,000,000 \\
\text { Target Costs }=\$ 11,000,000-1,000,000 \\
\text { Risk Corridor Ratio }=105 \%
\end{gathered}
$$


We find the $103 \%$ of the target amount of $\$ 10,000,000$ which is $\$ 10,300,000$. HHS pays $50 \%$ of the allowable costs greater than this amount which equates to $\$ 100,000$ in our example.

\section{Risk Adjustment}

Risk adjustment (RA), the only permanent premium stabilizing program, transfers payment between insurers at the state level based on each insurer's risk pool ${ }^{4}$. This program is intended to reduce or eliminate premium differences between plans based solely on expectations of favorable or unfavorable risk selection or choices in the individual and small group market, purchased on the exchange (on-exchange) or outside of the exchange (off-exchange). RA scores each issuer's member based on demographic data, geographic data, and claims information (ICD-9s are mapped to conditions and each condition gets a co-factor ${ }^{5}$ ). There are some calculations to adjust for benefit differences and for allowable rating factors relative to state averages. Finally, carriers with low adjusted scores will pay into a state transfer fund and carriers with high adjusted scores will receive money from the fund. This is simply just an allocation of funds from the insurers with healthier populations to the insurers with less healthy populations. Risk adjustment was designed to eliminate adverse selection and the need for underwriting as well as encourage insurers to participate in the exchanges without out fear of great financial risk. The RA program can be operated by the state or the state may defer to the federal government (HHS) to run the program on their behalf (HHS, 2013). The federally-facilitated RA program is the most common implementation with most states

\footnotetext{
${ }^{4}$ Payment transfer is calculated independently for small group and for individual markets.

${ }^{5}$ ICD-9-CM (International Classification of Diseases, 9th edition, Clinical Modification) is a standard set of codes used by physicians and hospitals to represent diagnosis for patients (CDC).
} 
opting for this approach. As RA is the focus of this paper risk scoring (calculation of a risk score), payment transfer, and other details of this program will be discussed in greater detail later in this chapter.

\section{Risk Adjustment History}

RA, as a concept or practice, is not necessarily new in the United States. Medicare has been running a Medicare Risk Adjustment (MRA) program for over 10 years (Kautter, Pope, \& Keenan, Affordable Care Act Risk Adjustment: Overview, Context, and Challenges, 2014).

Table 2. Medicare Risk Adjustment vs ACA Risk Adjustment

\begin{tabular}{|l|l|}
\hline \multicolumn{1}{|c|}{ Medicare Risk Adjustment } & \multicolumn{1}{c|}{ ACA Risk Adjustment } \\
\hline $\begin{array}{l}\text { The carrier is paid a premium for } \\
\text { each member based on that } \\
\text { member's risk score. }\end{array}$ & $\begin{array}{l}\text { Carrier either pays in or receives a } \\
\text { payment based (heavily) on its overall } \\
\text { risk score (weighted average of all } \\
\text { members' risk scores). }\end{array}$ \\
\hline $\begin{array}{l}\text { The risk reimbursement comes } \\
\text { from CMS. }\end{array}$ & $\begin{array}{l}\text { The risk reimbursement is executed } \\
\text { between insurers via a payment } \\
\text { transfer formula. }\end{array}$ \\
\hline $\begin{array}{l}\text { Prospective determination - Prior } \\
\text { year data used for determination }\end{array}$ & $\begin{array}{l}\text { Concurrent determination - current } \\
\text { year data used for determination }\end{array}$ \\
$\begin{array}{l}\text { i.e., 2014 Risk scores use data } \\
\text { collected } \\
\text { between 7/1/2012 - 6/30/13 }\end{array}$ & $\begin{array}{l}\text { i.e., 2014 Risk scores use data } \\
\text { collected } \\
\text { between } 1 / 01 / 14-12 / 31 / 2014\end{array}$ \\
\hline
\end{tabular}

However, the Medicare model is quite different in key aspects. MRA utilizes demographic, geographic and claims data to generate a risk score at the individual level similar to the ACA version of the program. However, in MRA the insurer is reimbursed by CMS based on the health status of the individual. In CRA the premium income and 
the claims costs result in a balanced scale after payment transfers between insurers in each state. Refer to Table 2 for a summary of differences in methodology (Geyer, 2013).

\section{Existing Risk Adjustment Programs}

Globally, other countries began utilizing risk adjustment methods as early as the 1970's. Several countries have well established programs including the United Kingdom, the Netherlands, and Israel. Table 3 outlines the US version of RA compared with other established programs around the world (Susan Mateja, 2012).

Table 3. Global Risk Adjustment Programs

\begin{tabular}{|c|c|c|c|c|c|c|}
\hline & UK & Israel & Netherlands & Chile & South Africa & United States \\
\hline $\mid \begin{array}{c}\text { Health Financing } \\
\text { System }\end{array}$ & Public & Mandatory & Mandatory & Voluntary & Voluntary & Mandatory \\
\hline Health Insurers & $\begin{array}{c}\text { Primary Care } \\
\text { Trusts } \\
\text { (PCTs) }\end{array}$ & $\begin{array}{l}\text { Non - Profit } \\
\text { Sick Funds }\end{array}$ & $\begin{array}{l}\text { For - Profit } \\
\text { Sick Funds }\end{array}$ & $\begin{array}{c}\text { For - Profit } \\
\text { Isapre } \\
\text { (Instituciones de } \\
\text { Salud } \\
\text { Previsional) } \\
\end{array}$ & $\begin{array}{c}\text { Non - Profit } \\
\text { Medical Schemes }\end{array}$ & Private \\
\hline \# of Insurers & 152 & 4 & $\sim 20$ & 13 & $\sim 100$ & $758^{6}$ \\
\hline Implemented & $\begin{array}{l}\text { Started in } 1976 \\
\text { PCTs in } 2006\end{array}$ & $\begin{array}{l}\text { Sick Funds } \\
\text { 1950's } \\
\text { Risk Fund in } \\
1995\end{array}$ & $\begin{array}{c}\text { Started in } 1990 \\
\text { Mandatory in } \\
2006\end{array}$ & $\begin{array}{l}\text { Started in } 1990 \\
\text { Fund in } 2005\end{array}$ & $\begin{array}{c}\text { Schemes in } 1967 \\
\text { Task Force in } \\
2003\end{array}$ & 2014 \\
\hline Models & Budgets & Prospective & $\begin{array}{l}\text { Prospective / } \\
\text { Retrospective }\end{array}$ & Prospective & Prospective & Concurrent \\
\hline Special Features & $\begin{array}{l}\text { Person-Based } \\
\text { Resource } \\
\text { Allocation } \\
\text { (PBRA) }\end{array}$ & $\begin{array}{l}\text { 3-Tiered } \\
\text { System }\end{array}$ & $\begin{array}{c}\text { In } 2006, \text { moved to } \\
\text { mandatory } \\
\text { private } \\
\text { health care }\end{array}$ & $\begin{array}{c}\text { Explicit Health } \\
\text { Guarantees }\end{array}$ & $\begin{array}{c}\text { Risk } \\
\text { Equalization } \\
\text { Fund } \\
\text { is Transparent }\end{array}$ & $\begin{array}{c}\text { Zero Sum } \\
\text { Payment } \\
\text { Transfer }\end{array}$ \\
\hline
\end{tabular}

\footnotetext{
${ }^{6}$ Issuers are counted uniquely by state - some issuers provided plans in multiple states.
} 


\section{Affordable Care Act Risk Score Components and Calculation}

Risk adjustment is not necessarily a complex concept but implementation is not easy. This section will provide examples of scoring an individual and how that score is then used to factor into the payment between insurers. In the simplest terms, an individual receives a score based on their gender, age, geographic location, and health status at the end of the calendar year. For this dissertation and all examples the calendar year is 2014 . Getting to that member's score is a little more complicated.

To achieve an individuals' a risk score, diagnoses are mapped to condition categories (CCs) which are then moved into a Hierarchical Condition Category (HCC) and if needed moved into an HCC Group - see Figure 1. If an enrollee has multiple, unrelated diagnoses (such as prostate cancer and arthritis), both HCC values are used in calculating the individual risk score. Additionally, if an adult enrollee has certain combinations of illnesses (such as a severe illness and an opportunistic infection), a Severity Factor is added to the person's individual risk score. Finally the individual is assigned a Risk Factor that represents the relative expenditures a plan is likely to incur for an enrollee with a given category of medical diagnosis. In addition, if the enrollee is receiving subsidies to reduce their cost-sharing, they receive a cost-share adjustment to their Final Risk Score to account for potential induced demand. 
Figure 1. Risk score calculation process

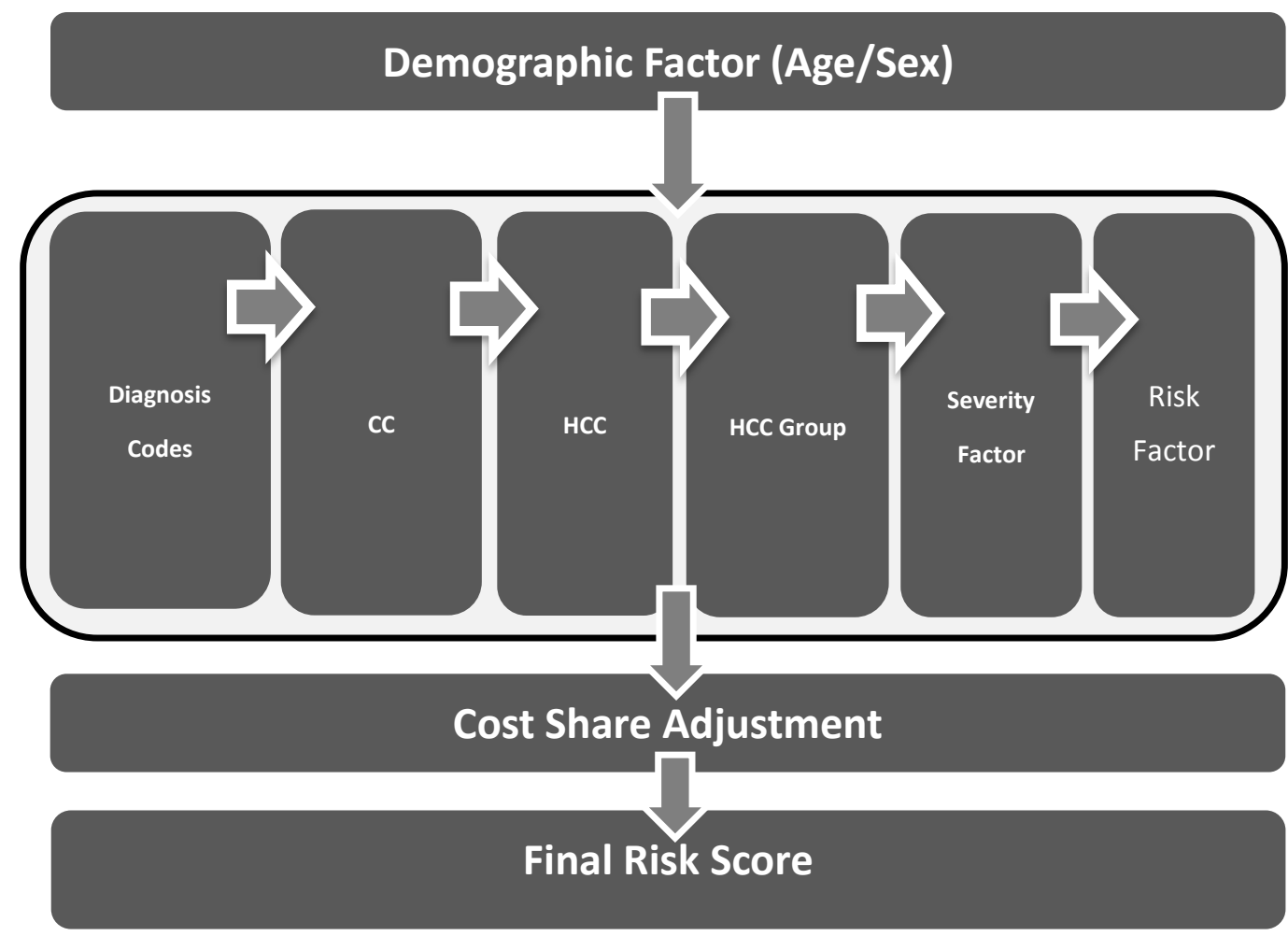

The first step in calculating a risk score is to determine the enrollee's demographic cofactor. For example, using a female of age 36 in a silver tier plan an individual would be assigned the CMS supplied cofactor of .490 (see Table 4). The next step is to convert the individual's diagnosis codes into CCs. Looking at the example claim, in Figure 2, this member has 4 diagnoses. The diagnostic codes, based on a CMS supplied table, show that diagnosis code 25000 maps to CC 21(Diabetes), diagnosis code 042 maps to CC 1 (HIV), 24900 maps to CC 21 (Diabetes) and 29000 does not map to any CC. Next the CCs go through the hierarchy process and are assigned to a Hierarchical Condition Category (HCC) are given a cofactor to be used in the scoring 
process. CMS assigns the weights for the HCC at a metal level (Health and Human Services, 2013).

Table 4. Age-Sex-Metal Cofactors (Health and Human Services, 2013)

\begin{tabular}{|c|c|c|c|c|c|c|c|c|}
\hline Model & & Variable & $\begin{array}{c}\text { Variable Used in } \\
\text { Risk Score } \\
\text { Formula? }\end{array}$ & $\begin{array}{c}\text { Platinum } \\
\text { Level }\end{array}$ & $\begin{array}{c}\text { Gold } \\
\text { Level }\end{array}$ & $\begin{array}{c}\text { Silver } \\
\text { Level }\end{array}$ & $\begin{array}{c}\text { Bronze } \\
\text { Level }\end{array}$ & $\begin{array}{c}\text { Catastrophic } \\
\text { Level }\end{array}$ \\
\hline Adult & MAGE LAST 21 & 24 & Yes & 0.258 & 0.208 & 0.141 & 0.078 & 0.062 \\
\hline Adult & MAGE LAST 25 & 29 & Yes & 0.278 & 0.223 & 0.150 & 0.081 & 0.064 \\
\hline Adult & MAGE LAST 30 & 34 & Yes & 0.338 & 0.274 & 0.187 & 0.101 & 0.079 \\
\hline Adult & MAGE LAST 35 & 39 & Yes & 0.413 & 0.339 & 0.240 & 0.140 & 0.113 \\
\hline Adult & MAGE LAST 40 & 44 & Yes & 0.487 & 0.404 & 0.293 & 0.176 & 0.145 \\
\hline Adult & MAGE LAST 45 & 49 & Yes & 0.581 & 0.487 & 0.365 & 0.231 & 0.195 \\
\hline Adult & MAGE LAST 50 & 54 & Yes & 0.737 & 0.626 & 0.484 & 0.316 & 0.269 \\
\hline Adult & MAGE LAST 55 & 59 & Yes & 0.863 & 0.736 & 0.580 & 0.393 & 0.339 \\
\hline Adult & MAGE LAST 60 & GT & Yes & 1.028 & 0.880 & 0.704 & 0.487 & 0.424 \\
\hline Adult & FAGE LAST 21 & 24 & Yes & 0.433 & 0.350 & 0.221 & 0.101 & 0.072 \\
\hline Adult & FAGE LAST 25 & 29 & Yes & 0.548 & 0.448 & 0.301 & 0.156 & 0.120 \\
\hline Adult & FAGE LAST 30 & 34 & Yes & 0.656 & 0.546 & 0.396 & 0.243 & 0.203 \\
\hline Adult & FAGE LAST 35 & 39 & Yes & 0.760 & 0.641 & 0.490 & 0.334 & 0.293 \\
\hline Adult & FAGE LAST 40 & 44 & Yes & 0.839 & 0.713 & 0.554 & 0.384 & 0.338 \\
\hline Adult & FAGE LAST 45 & 49 & Yes & 0.878 & 0.747 & 0.583 & 0.402 & 0.352 \\
\hline Adult & FAGE LAST 50 & 54 & Yes & 1.013 & 0.869 & 0.695 & 0.486 & 0.427 \\
\hline Adult & FAGE LAST 55 & 59 & Yes & 1.054 & 0.905 & 0.726 & 0.507 & 0.443 \\
\hline Adult & FAGE LAST 60 & GT & Yes & 1.156 & 0.990 & 0.798 & 0.559 & 0.489 \\
\hline
\end{tabular}

Figure 2. Sample Claim

Member ID 987654321 Claim Number 12345

\begin{tabular}{|c|c|c|c|}
\hline Primary Diagnosis & Diagnosis 2 & Diagnosis 3 & Diagnosis 4 \\
\hline 25000 & 042 & 29000 & 24900 \\
\hline
\end{tabular}

In our example CC 21 is converted to G01 and assigned a cofactor of 1.120. CC 1 is converted to a $\mathrm{HCC} 001$ with a cofactor of 4.74 . An individual can only be assigned a $\mathrm{CC}$ once in a given plan year regardless of how many times they are diagnosed with the same condition. In the above example there were two diagnoses that resulted in the same HCC. Our individual only gets the corresponding cofactor applied once. 
All scores are additive so our final calculation would look like:

$$
\begin{gathered}
\text { Demographic score }+C C 21+C C 1={\text { Final Individual Risk } \text { Score }^{7}}_{\text {or }} \\
.490+1.120+4.74=\mathbf{6 . 3 5}
\end{gathered}
$$

\section{Risk Adjustment Payment Transfer}

Insurance premiums are priced to cover the expected costs of an insurer.

However, most of the time actual costs do not equal expected costs. The difference between the two is often attributed to information asymmetry and an individual's aversion to risk. The risk adjustment transfer payment compensates insurers in those situations where premiums do not cover the actual costs.

Once individual risk scores are calculated for all enrollees in the plan, these values are averaged across the plan to arrive at the plan's average risk score. The average risk score, which is a weighted average of all enrollees' individual risk scores, represents the plan's predicted expenses (based on the demographics of enrollees). Under the HHS methodology, adjustments are made for a variety of factors, including actuarial value (i.e., the extent of patient cost-sharing in the plan), allowable rating variation, and geographic cost variation. Under risk adjustment, plans with a relatively low average risk score will make payments into the system, while plans with relatively high average risk scores will receive payments. The aggregated risk scores at the plan level are referred to as the Plan Liability Risk Score and is one of several inputs into the payment transfer formula (Pope, et al., 2014). The formula is written as (variables listed in Table 5.):

\footnotetext{
${ }^{7}$ There are severity groups and interaction cofactors that are also considered in the calculation under certain circumstances but were not used in this example to maintain simplicity for demonstration purposes.
} 


$$
T_{t}=\left[\frac{P L R S_{t} * I D F_{t} * G C F_{t}}{\sum_{t}\left(s_{t} * P L R S_{t} * I D F_{t} * G C F_{t}\right)}-\frac{A V_{t} * A R F_{t} * I D F_{t} * G C F_{t}}{\sum_{t}\left(s_{t} * A V_{t} * A R F_{t} * I D F_{t} * G C F_{t}\right.}\right] \overline{P_{s}}
$$

If we look at the formula, notice there are two parts:

left-hand side: $\frac{P L R S_{t} * I D F_{t^{*}} G C F_{t}}{\sum_{t}\left(s_{t^{*}} P L R S_{t^{*}} D F_{t^{*}} G C F_{t}\right)}$ right-hand side: $\frac{A V_{t}^{*} A R F_{t}^{*} I D F_{t^{*}} G C F_{t}}{\sum_{t}\left(s_{t^{*}} * V_{t^{*}} A R F_{t^{*}} D F_{t^{*}} G C F_{t}\right.}$.

The left-hand side of the formula, sometimes referred to as required revenue, represents premium including the plan liability risk score (PLRS) and the right-hand side, sometimes referred to as allowable revenue, represents premium without any risk variable (Pope, et al., 2014). The difference of the two signifies the transfer amount paid by the issuer into the risk pool fund if that amount is negative, meaning they incurred less risk compared with state average. If the difference is positive then this signifies the insurer amount is a receivable because more risk was incurred than the state average.

Table 5. Payment Transfer Variables

\begin{tabular}{|l|c|}
\hline \multicolumn{1}{|c|}{ Variable Name } & Variable \\
\hline Plan & $t$ \\
\hline Plan t's Transfer Amount & $T_{t}$ \\
\hline State Average Premium & $\bar{P}_{s}$ \\
\hline Plan Liability Risk Score & $P L R S_{t}$ \\
\hline Plan Allowable Rating Factor & $A R F_{t}$ \\
\hline Plan Induced Demand Factor & $I D F_{t}$ \\
\hline Area Geographic Cost Factor & $G C F_{t}$ \\
\hline Plan Metal Actuarial Value & $A V_{t}$ \\
\hline Plan share of state enrollment & $S_{t}$ \\
\hline
\end{tabular}


Evaluating the left-hand side numerator of the equation, in addition to the PLRS which not only represents the health of the plan but the Actuarial Value (AV) of the plan, there are also the Induced Demand Factor (IDF) and the Geographic Cost Factor (GCF) variables to consider. When healthcare is priced in a way that might encourage greater utilization of services (low premiums or minimal cost sharing for the enrollee) this creates induced demand. The IDF factor helps compensate for that demand at the different metal levels (Health and Human Services, 2013). Table 6 lists the IDF values for each metal level.

Table 6. Induced Demand Adjustment for Each Metal Level

\begin{tabular}{|c|c|}
\hline Metal Level & Induced Demand Adjustment \\
\hline Catastrophic & 1.00 \\
\hline Bronze & 1.00 \\
\hline Silver & 1.03 \\
\hline Gold & 1.08 \\
\hline Platinum & 1.15 \\
\hline
\end{tabular}

There are some costs associated with a plan that are inherent due to their geographic location that an insurance company cannot avoid. In order to prevent insurers from abandoning these particular locations the GCF creates an adjustment to help compensate for those related costs (Health and Human Services, 2013). Rating areas are created by the states and a GCF is created for each of those areas and is based on the state average premium of the silver plans within the state. The GCF state average value is 1.0 and any difference will represent the percent of cost difference compared to the state average. For example a GCF with a value of .95 would signify that the geographic area's costs are 5\% less than the state average. Likewise a GCF of 1.05 indicates that the geographic area's costs are $5 \%$ higher than the state average costs. Absence of the geographic cost factor 
could adversely affect payment in geographic areas with low cost for plans with low risk as well as plans with high risk in high cost areas. In Figure 3, plan B has a low risk score of .61 and the GCF has been set to 1.0 for both plans indicating that the state has a uniform geographic rating or no rating. However, in Figure 4, note that if Plan A is in a $50 \%$ more costly geographic area then that will reflect in Plan B's payment to Plan A.

Figure 3. Transfer example without GCF

\begin{tabular}{|l|l|l|l|l|l|l|r|r|r|r|r|}
\hline Plan & Metal & PLRS & ARF & AV & IDF & GCF & $\begin{array}{c}\text { Market } \\
\text { Share }\end{array}$ & $\begin{array}{c}\text { Plan } \\
\text { Liability }\end{array}$ & $\begin{array}{c}\text { Avg } \\
\text { Prem }\end{array}$ & $\begin{array}{c}\text { Transfer } \\
\text { Amt }\end{array}$ & $\begin{array}{c}\text { Mrkt Avg } \\
\text { Prem }\end{array}$ \\
\hline $\begin{array}{l}\text { Plan } \\
\text { A }\end{array}$ & Gold & 1.39 & 1.00 & 1 & 1.00 & 1.00 & 0.5 & $\mathbf{2 7 8 . 0 0}$ & $\mathbf{2 1 3 . 3 3}$ & $\mathbf{6 4 . 6 7}$ & $\$ 200.00$ \\
\hline $\begin{array}{l}\text { Plan } \\
\text { B }\end{array}$ & Silver & 0.61 & 1.00 & 1 & 1.00 & 1.00 & 0.5 & $\mathbf{1 2 2 . 0 0}$ & $\mathbf{1 8 6 . 6 7}$ & $\mathbf{- 6 4 . 6 7}$ & \\
\hline
\end{tabular}

Figure 4. Transfer Example with GCF Impact

\begin{tabular}{|l|l|r|r|r|r|r|r|r|r|r|r|}
\hline Plan & Metal & PLRS & ARF & AV & IDF & GCF & $\begin{array}{c}\text { Market } \\
\text { Share }\end{array}$ & $\begin{array}{c}\text { Plan } \\
\text { Liability }\end{array}$ & $\begin{array}{c}\text { Avg } \\
\text { Prem }\end{array}$ & $\begin{array}{c}\text { Transfer } \\
\text { Amt }\end{array}$ & $\begin{array}{c}\text { Mrkt Avg } \\
\text { Prem }\end{array}$ \\
\hline $\begin{array}{l}\text { Plan } \\
\text { A }\end{array}$ & Gold & 1.39 & 1.00 & 1 & 1.00 & 1.50 & 0.5 & $\mathbf{3 0 9 . 4 6}$ & $\mathbf{2 5 2 . 6 3}$ & $\mathbf{5 6 . 8 3}$ & $\$ 200.00$ \\
\hline $\begin{array}{l}\text { Plan } \\
\text { B }\end{array}$ & Silver & 0.61 & 1.00 & 1 & 1.00 & 1.00 & 0.5 & $\mathbf{9 0 . 5 4}$ & $\mathbf{1 4 7 . 3 7}$ & $\mathbf{- 5 6 . 8 3}$ & \\
\hline
\end{tabular}

The right hand side numerator of the equation (which does not include the risk variable) includes the AV factor, the ARF, IDF and GCF. The IDF and GCF are the same for both sides of the formula. Actuarial value measures the relative generosity of benefits covered by a health insurance plan. Under the ACA, a health insurance plan's actuarial value indicates the average share of medical spending that is paid by the plan, as opposed to being paid out of pocket by the consumer. The calculation takes into account a plan's various cost-sharing features, such as deductibles, coinsurance, copayments, and out-of-pocket limits. Aside from cost-sharing features, however, the calculation does not 
reflect other plan features that may be important for consumers who are choosing plans. The actuarial value is mapped to what CMS calls "metal" levels or tiers shown Table 7.

Table 7. Metal Level Actuarial Value

\begin{tabular}{|c|c|}
\hline Metal Level & Actuarial Value \\
\hline Platinum & .90 \\
\hline Gold & .80 \\
\hline Silver & .70 \\
\hline Bronze & .60 \\
\hline Catastrophic & .57 \\
\hline
\end{tabular}

Insurers, based on Table 7, will pay approximately $70 \%$ of all medical expenses for any individual in a silver level plan and the individual would be responsible for about the other $30 \%$ of their medical costs during the plan period. (Centers for Medicare and Medicaid Services) ${ }^{8}$. AV is necessary to guarantee each insurer is paying their fair share into the transfer funds pool. Low risk plans with a low AV would actually pay more money into the transfer pool if AV was not factored into the formula. In this situation claims expenses are considered but not adjusted to compensate for their relative value (Pope, et al., 2014). Conversely, plans with high risk scores and higher AV would receive less money from the transfer process. Below is an example showing the impact of AV on the transfer payment. The actuarial value of a plan has direct impact on the PLRS. Table 8 below shows the plan liability risk score without any AV adjustment

\footnotetext{
${ }^{8}$ The $70 \%$ actuarial value in practice refers to the total value of out-of-pocket costs across all enrollees in particular plan - not for each individual in a plan. However for the purposes of this paper we apply the AV to the individual.
} 
given by the predicted liability divided by the state average. Only using the predicted liability, Plan A has an understated risk score and Plan B has an overstated risk score.

Table 9 shows the plan's liability risk score with the AV adjustment.

Table 8. Risk Score with Unadjusted Actuarial Value (Centers for Medicare and Medicaid Services, 2012)

\begin{tabular}{|l|c|c|c|}
\hline & Plan A & Plan B & State Average \\
\hline Actuarial value & $.6($ Bronze) & $.8(\mathrm{Gold})$ & .7 \\
\hline $\begin{array}{l}\text { Predicted total } \\
\text { Expenditures }\end{array}$ & $\$ 1,000$ & $\$ 1,000$ & $\$ 1,000$ \\
\hline Predicted liability & $\$ 600$ & $\$ 800$ & $\$ 700$ \\
\hline $\begin{array}{l}\text { Liability risk } \\
\text { score }\end{array}$ & $\begin{array}{c}.86 \\
(\$ 600 / \$ 700)\end{array}$ & $\begin{array}{c}1.14 \\
(\$ 800 / \$ 700)\end{array}$ & 1.0 \\
\hline
\end{tabular}

Table 9. Risk Score with Unadjusted Actuarial Value (Centers for Medicare and Medicaid Services, 2012)

\begin{tabular}{|c|c|c|c|}
\hline & Plan A & Plan B & Average/Total \\
\hline Actuarial value & .6 & .8 & .7 \\
\hline $\begin{array}{l}\text { Predicted total } \\
\text { expenditures }\end{array}$ & $\$ 1,000$ & $\$ 1,000$ & $\$ 1,000$ \\
\hline Predicted liability & $\$ 600$ & $\$ 800$ & $\$ 700$ \\
\hline $\begin{array}{l}\text { Unadjusted liability } \\
\text { risk score }\end{array}$ & $\begin{array}{l}.86 \\
(\$ 600 / \$ 700)\end{array}$ & $\begin{array}{l}1.14 \\
(\$ 800 / \$ 700)\end{array}$ & 1.0 \\
\hline AV adjustment & $\begin{array}{l}.86 \\
(.6 / .7)\end{array}$ & $\begin{array}{l}1.14 \\
(.8 / .7)\end{array}$ & \\
\hline Adjusted risk score & $\begin{array}{l}1.0 \\
(.86-.86+1)\end{array}$ & $\begin{array}{l}1.0 \\
(1.14-1.14+1)\end{array}$ & \\
\hline
\end{tabular}

The allowable rating factor is only used to adjust for age. As required by the ACA, states had to develop age ranges (sometimes referred to as age bands) and corresponding age factors to be used by insurers. States had the option to default to the federal rating bands (shown in Table 10) if they chose not to develop their own (Pope, et al., 2014). 
These age-relating factors help fill the gap due to any age incongruities between plans and associated costs based on age ${ }^{9}$. The ACA requires that the age rating ratio be no more than 3:1, however states may modify the ratio as long as it conforms to the requirement. For example a 2.5:1 ratio may be used. This allowable rating factor permits an insurer to charge a premium more consistent with covering costs for someone of a particular age. Based on the federal rating factors in Table 10, a 46 year old individual would receive an ARF of 1.5 and would be allowed to be charged a premium $50 \%$ greater than a 22 year old with a ARF of 1.0 (1.5:1 Ratio).

Table 10. Federal Age Rating Factor Curve

\begin{tabular}{|l|c|r|r|r|r|}
\hline Age & $\begin{array}{c}\text { Premium } \\
\text { Ratio }\end{array}$ & \multicolumn{1}{c|}{ Age } & $\begin{array}{c}\text { Premium } \\
\text { Ratio }\end{array}$ & \multicolumn{1}{c|}{ Age } & \multicolumn{1}{c|}{$\begin{array}{c}\text { Premium } \\
\text { Ratio }\end{array}$} \\
\hline 21 & 1.000 & 36 & 1.230 & 51 & 1.865 \\
\hline 22 & 1.000 & 37 & 1.238 & 52 & 1.952 \\
\hline 23 & 1.000 & 38 & 1.246 & 53 & 2.040 \\
\hline 24 & 1.000 & 39 & 1.262 & 54 & 2.135 \\
\hline 25 & 1.004 & 40 & 1.278 & 55 & 2.230 \\
\hline 26 & 1.024 & 41 & 1.302 & 56 & 2.333 \\
\hline 27 & 1.048 & 42 & 1.325 & 57 & 2.437 \\
\hline 28 & 1.087 & 43 & 1.357 & 58 & 2.548 \\
\hline 29 & 1.119 & 44 & 1.397 & 59 & 2.603 \\
\hline 30 & 1.135 & 45 & 1.444 & 60 & 2.714 \\
\hline 31 & 1.159 & 46 & 1.500 & 61 & 2.810 \\
\hline 32 & 1.183 & 47 & 1.563 & 62 & 2.873 \\
\hline 33 & 1.198 & 48 & 1.635 & 63 & 2.952 \\
\hline 34 & 1.214 & 49 & 1.706 & $64+$ & 3.000 \\
\hline 35 & 1.222 & 50 & 1.786 & - & - \\
\hline
\end{tabular}

While the numerator represents an individual plan's revenue (required and allowed), the denominators present the state averages for required revenue and allowable revenue ${ }^{10}$. Finally the factors are multiplied by the state average premium.

\footnotetext{
${ }^{9}$ The ARF is only applied to adults age 21 or over. Infants age 0 to 1 have a set value and Children ages 2 20 have a set value

${ }^{10}$ The denominator as well as the premium uses weighted averages as denoted by "s" in the formula.
} 
Using example data provided by Pope et al in Figure 5, one can step through the payment transfer formula.

Figure 5. Transfer Payment Example Variables

\begin{tabular}{|c|c|c|c|c|c|c|c|c|c|c|c|}
\hline Plan & $\begin{array}{l}\text { Metal } \\
\text { Level } \\
\end{array}$ & PLRS & ARF & AV & IDF & $\begin{array}{c}\mathrm{G} \\
\mathrm{CF} \\
\end{array}$ & $\begin{array}{c}\text { Plan } \\
\text { Market- } \\
\text { Share } \\
\end{array}$ & $\begin{array}{c}\text { Plan } \\
\text { Liability }\end{array}$ & $\begin{array}{l}\text { Plan Avg } \\
\text { Premium }\end{array}$ & $\begin{array}{l}\text { Transfer } \\
\text { Amount }\end{array}$ & $\begin{array}{c}\text { State } \\
\text { Average } \\
\text { Premium } \\
\end{array}$ \\
\hline $\begin{array}{l}\text { Plan } \\
\text { A }\end{array}$ & Gold & 1.39 & 1.0 & 1.0 & 1.0 & 1.0 & 0.5 & 532.83 & 408.89 & 123.94 & $\$ 383.33$ \\
\hline Plan B & Silver & 0.61 & 1.0 & 1.0 & 1.0 & 1.0 & 0.5 & 233.83 & 357.77 & -123.94 & \\
\hline
\end{tabular}

Each plan will have access to the values that are inputs to the numerators on both halves of the equation. What is unknown, are all the inputs to the denominator. As of 2015, CMS did not publish state average risk scores or premiums, so calculating the payment transfer was, at best, difficult for an individual insurer to perform. In our example, the state average premium represents the value calculated by CMS. We first start with Plan A's left had side of the equation:

$$
\begin{gathered}
\frac{P L R S_{t} * I D F_{t} * G C F_{t}}{\sum_{t}\left(\boldsymbol{s}_{t} * \boldsymbol{P L R S}_{\boldsymbol{t}} * I D \boldsymbol{F}_{\boldsymbol{t}} * \boldsymbol{G C F} \boldsymbol{F}_{t}\right)} \\
\text { or } \\
\mathbf{T}_{\text {Plan A }}=\underset{(.50 * 1.39 * 1 * 1)+(.50 * .61 * 1 * 1)}{\underline{1.39 * 1 * 1}}
\end{gathered}
$$

Solving the left hand side we get 1.39 which must then be multiplied by the state average premium of $\$ 383.33$ to give us $\$ 523.83^{11}$. This tells us that based on the health risk of Plan A's enrollees, that this is Plan A's required revenue needed to compensate for

\footnotetext{
${ }^{11}$ Depending on rounding precision, this example may result in minor differences in calculated values when trying to reproduce this example.
} 
providing cost of care to their population. Next we determine Plan A's allowable revenue by calculating the right hand side of the transfer formula:

$$
\begin{aligned}
& \frac{A V_{t} * A R F_{t} * I D F_{t} * G C F_{t}}{\sum_{t}\left(s_{t} * A V_{t} * A R F_{t} * I D F_{t} * G C F_{t}\right.} \\
& \text { or } \\
& \frac{.8 * 1 * 1 * 1}{(.5 * .8 * 1 * 1 * 1)+(.5 * .7 * 1 * 1 *)}
\end{aligned}
$$

Solving the right side for Plan A we get 1.066 which we must multiply by the state average premium of $\$ 383.33$ to get $\$ 408.89$. To determine the transfer amount we subtract the right side form the left side to get $\$ 123.94$. A positive amount indicates the amount to be received through a transfer payment. Knowing that Plan A is receiving money and that ACA Risk Adjustment is a zero-sum program, we should see, after calculating Plan B's transfer, that Plan B should have to pay $\$ 123.94$. We can check this by stepping through the formula for Plan B and starting with the left hand side of the equation:

$$
\mathbf{T}_{\text {Plan B }}=\frac{.61 * 1 * 1}{(.50 * 1.39 * 1 * 1)+(.50 * .61 * 1 * 1)}
$$

This translates into .61 and multiplied by the state average premium of $\$ 383.33$ to give Plan B the required revenue of $\$ 233.83$. The next step is to calculate the right side:

$$
(.5 * .8 * 1 * 1 * 1)+(.5 * .7 * 1 * 1 *)
$$


The result is .933 and is multiplied by the state average premium to give allowable revenue of $\$ 357.77$. After subtracting the allowable revenue from $\$ 233.83$, Plan B's calculated difference is $\$-123.94^{12}$. The negative difference indicates a payment into the transfer pool to be distributed among the carriers in the state with less healthy populations, which in this example is only Plan A.

\section{Risk Adjustment's Role in Public Health}

According to the Organisation for Economic Co-operation and Development (OECD) health data from 2012, the United States spends nearly $18 \%$ of its GDP on health care (OECD, 2014). The OECD average GDP for all countries is under $10 \%$. The country with closest health care expenditures as a percent of GDP is the Netherlands at 12\%. The United States cannot continue to keep growing its current increasing rate of health care expenditures. Health care costs are exorbitant in almost all facets from hospital care, insurance, dental services, and nursing homes. Risk Adjustment's intended goal is to lower costs and to help make insurance affordable for everyone regardless of socioeconomic status. Affordable insurance creates more opportunity for access to care and preventive services in turn lowering costs in the long run. Previous risk adjustment models have not taken into consideration socioeconomic status or other public health related variables such as behavior and environment. The current ACA RA model does consider income and provides subsidies for low-income families. The current model is based on community rating (premiums based on a population not an individual) and is usually limited to a large geographic area - the county level or larger (HHS, 2013). There

\footnotetext{
${ }^{12}$ This is a simple example where market share is even across two plans. As more insurers participate and market share is distributed across numerous insurers and rating areas you can expect the transfer amounts received and paid by each insurer to change accordingly.
} 
are, many times, large health disparities within a given county especially between urban and suburban areas. It can be argued that the current ACA risk adjustment model should be revised to rate members at a more granular level such as the neighborhood similar to UK's model for Risk Adjustment (Susan Mateja, 2012)

\section{The Unknown}

In order for Risk Adjustment to be effective, healthy people must participate in the exchanges to help offset the costs of the less healthy. The ACA attempts to accomplish this task through the "individual mandate". The ACA required all persons to purchase insurance or pay a tax penalty. In theory, this penalty would entice people to purchase insurance who may normally opt out (usually these are younger, healthier people). This increases the amount of premiums paid into the risk pool which would help cover the costs of providing services to the less healthy people in the risk population.

Prior to the ACA there were approximately 40 million uninsured Americans. In 2014, the first year of the exchanges and the individual mandate, approximately 7 million Americans enrolled in ACA insurance plans through the exchanges. However, of those 7 million enrollees, it was reported that only $26 \%$ of those were previously uninsured (Roy). In addition, The Kaiser Family Foundation reports that $83 \%$ of enrollees qualified for premium subsidies (Levitt, Claxton, \& Damico, 2014). Since the new enrollees are unknown, there is uncertainty about the financial impact they will have on insurers (claims costs) and the government (subsidies). An influx of primarily unhealthy enrollees could cause more destabilization of the market and premiums. 
Over and above the concern with new and unknown enrollees, insurers have new regulations by which they must adhere. They must renew any policy as long as the premium is paid in full. Health plans may not refuse renewal because of illness which occurs after the initial policy is issued. Some numbers indicate that as many as 10,000 people a year were dropped from their current plan due to illness or injury prior to the ACA (Editorial Board, 2013). In addition insurers may not drop or water down (eliminate) the benefits of the plan for those who become sick. Insurers may not increase premiums by ten percent without providing justification of the increase to state or federal officials. In 2010, 75 percent of the rate increases were for ten percent or higher. The same report indicated that in 2012, after the policy was implemented, that number fell to 34 percent; which resulted in an average premium increase of 30 percent less than in 2010.

The mandate was designed to increase the demand for health insurance products and foster competition. Unfortunately, the penalties are not severe enough to overcome the hurdle to purchasing a plan that is often more expensive than the penalty itself (Keckley, Coughlin, Korenda, \& Rice, 2011). The Congressional Budget Office(CBO) estimates four million people will choose to pay the penalty - most of whom will be young, healthy Americans who estimate they can afford to go without insurance (Moeller, 2012). In addition, there are no enforcement provisions for the penalties and no criminal actions or liens can be imposed on those who do not pay.

\section{Statement of the Problem}

The premium stabilization rule is a new program under healthcare reform and there is much uncertainty about the program's ability to reduce costs for individuals, insurers, and the government. Although there has been much discussion around premium 
stabilization, and risk adjustment in particular, impacts and outcomes of the program have only been simulated and modeled recently (Zhu, Layton, Sinaiko, \& McGuire, 2013). The 3R's were implemented in calendar year 2014 and insurers did not know how they fared until June $30^{\text {th }}$ of 2015 when CMS provided each carrier a payment transfer notice. Until now there has been little or no empirical evidence or historical context from which to assess a commercial federal risk adjustment program in the United States. A case study of the first year of the program will provide quantifiable impacts not previously realized through simulations or modeling.

\section{Purpose of the Study}

The goal of this study is to determine if a public health policy, specifically ACA risk adjustment, produced the desired results by offsetting adverse selection in the individual marketplace.

\section{Significance}

This study is unique because the Premium Stabilization rule is a new program with little history within the United States. This will be one of the first such case studies to examine the ACA program and measure the effectiveness of eliminating adverse selection and creating premium and cost equilibrium within a subpopulation in the United States.

\section{Research Question}

Did the ACA Risk Adjustment program effectively eliminate adverse selection during 2014, the first year of implementation? 


\section{Hypothesis}

The ACA risk adjustment will neutralize adverse selection.

\section{Alternative Hypothesis}

Adverse selection will continue to exist despite the intervention of risk adjustment.

\section{Summary}

Although the Patient Protection and Affordable Care Act (ACA), also referred to as healthcare reform, was signed into effect in March of 2010 many of the components that directly attempt to lower the costs of insurance for individuals did not take effect until January 1, 2014. One crucial piece of reform legislation prohibits insurers from rejecting enrollees based on prior or current health status or from charging "sick" enrollees higher premiums (this means no more underwriting). The risk population now is referred to as community rated which means that insurance policies offered within a given geographical area must be offered at the at the same price to all individuals regardless of prior or current health status. Thus the community must have a large, yet diverse (healthy and sick) risk pool so that costs are spread across all members. In order for this to work there needs to be a mechanism in place to preclude insurers from not participating in the individual exchange market space. That mechanism is the premium stabilization programs created through the ACA.

The premium stabilization rule, through the payment transfer process, eliminates underwriting and adverse selection. Risk adjustment will fill the gap when an issuer assumes more financial risk of its enrollees than is covered by premium payments and other cost-sharing methods. This program is intended to reduce or eliminate premium 
differences between plans based solely on expectations of favorable or adverse risk selection or choices in the individual market, in and out of the exchange. The RA methodology, at high level, scores each issuer's member based on demographic data, geographic data, and diagnosis codes from claims and those scores are then aggregated at the state level. Finally, carriers with lower adjusted scores will pay money into an RA pool in each state and carriers with higher adjusted scores will receive money from that pool. This equates to a transfer of funds from the insurers with healthier populations (lower risk scores) to insurers with less healthy or populations (higher risk scores). This zero-sum strategy was developed to entice insurers to participate in providing healthcare insurance without fear of losing money due to high claims costs. This dissertation will measure the ACA Risk Adjustment program's ability to eliminate adverse selection. 


\section{CHAPTER 2}

\section{LITERATURE REVIEW}

Asymmetric information is a concept familiar in economics and has been proven to lead to adverse selection in many markets where goods or services are bought and sold. (Greenwald \& Stiglitz, 1986). The health insurance market is not exception and there has been much written on the topic of adverse selection in the health insurance markets. Ronald Andersen outlines a behavioral model for health services which identifies the sources that influence an individual's perceived health needs which may lead to asymmetric information between the individual and the insurer (Andersen, 1995). His original model creates three categories that drive the information asymmetry: Predisposing characteristics, enabling resources, and need for care.

Predisposing characteristics include the individual's demographic information, social structure and health beliefs. Demographic information might include age, gender and health history. Social structure includes family, education, occupation, and physical environment. Health beliefs include diet and exercise. Enabling resources stem from family and community. Need for care is the individual's perceived need for a service or treatment.

To eliminate or reduce adverse selection would require a method to neutralize information asymmetry. The question until now is how best to solve for adverse selection in the health insurance. The most common discussion around solving for adverse selection in healthcare is risk adjustment, though there appear to be different thoughts on 
the optimal approach or model (Glazer \& McGuire, Optimal Risk Adjustment in Markets with Adverse Selection: An Application to Managed Care, 2000).

Although risk adjustment does seem to be the preferred solution there are notable problems that may exist with this approach. Michael Geruso and Timothy Layton introduce a model that identifies the effect of inaccurate medical record coding. They developed this model to identify medical record coding anomalies which could be the result of insurers incentivizing physicians and other health care providers to "upcode" diagnoses (Geruso \& Layton). Upcoding is a term used to describe a method in which physicians indicate a more severe version of a diagnosis in the medical record or possibly even falsely add diagnoses to the record. Since insurers are reimbursed (through the risk score process) by diagnosis codes they could potentially improve their transfer payment amount through the upcoding process. For ACA risk adjustment, improving the payment transfer could include either lowering the amount you pay out or increasing the amount you receive.

Another concern for the risk adjusted approach is favorable selection (Newhouse, Price, Willaims, Hsu, \& McGuire, 2015). Tiag Sawhney refers to this as indirect selection and it occurs when insurers attempt to influence the consumers to choose a plan or benefit that will minimize the financial risk for the insurer (Sawhney, 2012). This could be accomplished through health benefit design by raising the premiums or lowering the number or types of services covered that may not appeal to those who require considerable medical treatment. One note of interest regarding selection may be that insurers believe sicker enrollees equate to more money in the way of risk adjustment transfer payments. This situation may cause unintended consequences based on the 
approach to selection given that insurers must still pay claims for these high-risk enrollees. Risk adjustment's aim is to alleviate favorable selection by insurers' but both Sawhney and Newhouse, et al. offer reasons why risk adjustment may fall short in that regard. One theory is that there may be attainable "sweet spot" for some insurers; meaning they have those enrollees that are diagnosed with high risk factors but either do not utilize all the services available to them to address the diagnoses or, more likely, certain enrollees with high risk factors find alternative forms of care or care for themselves. One example would be someone who is diagnosed as a diabetic but performs the necessary actions, such as following a prescribed diet and exercise routine and thereby avoids unneeded physician and hospital visits.

\section{Theoretical Perspectives}

This dissertation will focus on three theoretical perspectives: Utility theory, game theory, information asymmetry. Utility theory is based on the premise that people will choose the option most preferable to them based on the value or worth of the good or service (Fishburn, 1968). Utility theory In the case of Risk Adjustment posits that certain individuals may opt to pay the tax penalty rather than purchase insurance as the penalty is perceived as a considerably less financial hardship.

The transfer payment and the resulting zero-sum gain for insurers falls under game theory as introduced by John Von Neumann and Oskar Morgenstern (Von Nuemann \& Morgenstern, 1953). More expressly, we can say that any player's loss or gain is exactly balanced by the loss or gain of another player or players in the game. We can use poker as an example. If 10 people are invited to play poker and the buy-in (or the 
amount required to sit at the table and participate) is $\$ 100$ then the total amount of money will sum to $\$ 1000$. Consider a winner take-all poker match. In this case the winner gains $\$ 900$ and all other players would have lost $\$ 100$ each for a total of $-\$ 900$ between all of them. The same would hold true for a timed game where each player leaves after one hour with the money in their pot. Assuming again, that each player started with $\$ 100$ we can show the results of the game after one hour in Figure 6.

Figure 6. Zero-Sum Game Theory Example - Poker

\begin{tabular}{|l|r|r|r|}
\hline & Buy-in & Amount Won/Lost & Take Home Amount \\
\hline Player 1 & $\$ 100$ & $\$ 150$ & $\$ 250$ \\
\hline Player 2 & $\$ 100$ & $\mathbf{\$ 2 5 )}$ & $\$ 75$ \\
\hline Player 3 & $\$ 100$ & $\mathbf{\$ 1 5 0}$ & $\$ 250$ \\
\hline Player 4 & $\$ 100$ & $\mathbf{\$ 7 5 )}$ & $\$ 25$ \\
\hline Player 5 & $\$ 100$ & $\mathbf{\$ 7 5}$ & $\$ 175$ \\
\hline Player 6 & $\$ 100$ & $(\$ 100)$ & $\$ 0$ \\
\hline Player 7 & $\$ 100$ & $(\$ 100)$ & $\$ 0$ \\
\hline Player 8 & $\$ 100$ & $(\$ 100)$ & $\$ 0$ \\
\hline Player 9 & $\$ 100$ & $(\$ 100)$ & $\$ 225$ \\
\hline Player 10 & $\$ 100$ & $\mathbf{\$ 1 2 5}$ & $\mathbf{\$ 1 , 0 0 0}$ \\
\hline Sum & $\mathbf{\$ 1 , 0 0 0}$ & $\mathbf{\$ 0}$ & \\
\hline
\end{tabular}

Prior to the ACA, the model for purchasing insurance is closely related to Akerlof's concept that there is competition among suppliers of goods or service based on price but not necessarily based on the features or the quality of the goods or services (Akerlof, 1970). To demonstrate his concept, Akerlof uses the example of selling used cars. Someone purchasing a car cannot know whether the car is a good car or a bad car. Akerlof refers to these bad cars as "lemons". He posits that "lemons" and good cars can be bought or sold for the same price because information asymmetry. The seller of the "lemons" holds information about the car that the buyer does not have. For example the windshield wipers may not work when it is raining. If the seller knows this information 
but the buyer does not then this results in information asymmetry. This information asymmetry, in the health insurance industry, often led to adverse selection prior to the ACA. Often times, those who knew they required medical services were the ones who purchased insurance.

In the Pre-ACA days, insurance companies may have been competing to supply various services and plans were underwritten or based on what the insurance company knew about their enrollees. This approach tried to eliminate some of the information asymmetry and services and costs were more tailored to the expected needs of the individual. Today however, Akerlof's concept, with regard to health insurance, may be even more valid because the ACA requires all insurers to provide 10 essential health benefits (EHB), as listed in Table 11 and insurers now must focus more on competing based on price but also allows for larger gaps of information asymmetry (Centers for Medicare and Medicaid Services, 2013).

For example, a person with diabetes may understand that they will require several physician and hospital visits and may choose the insurance policy that has a platinum level actuarial value versus a policy with a bronze level. In this scenario the fact that the consumer has diabetes may be unknown to the insurer. Another example may be the person who has decided that since they must now purchase an insurance plan (as a result of the mandate) they will now maximize their utility based on their, now required, investment. This means an individual may feel obligated to utilize or obtain services simply because she is paying for them rather than having a need for them.

Table 11. 10 Essential Health Benefits

1. Outpatient care - the kind you get without being admitted to a hospital 


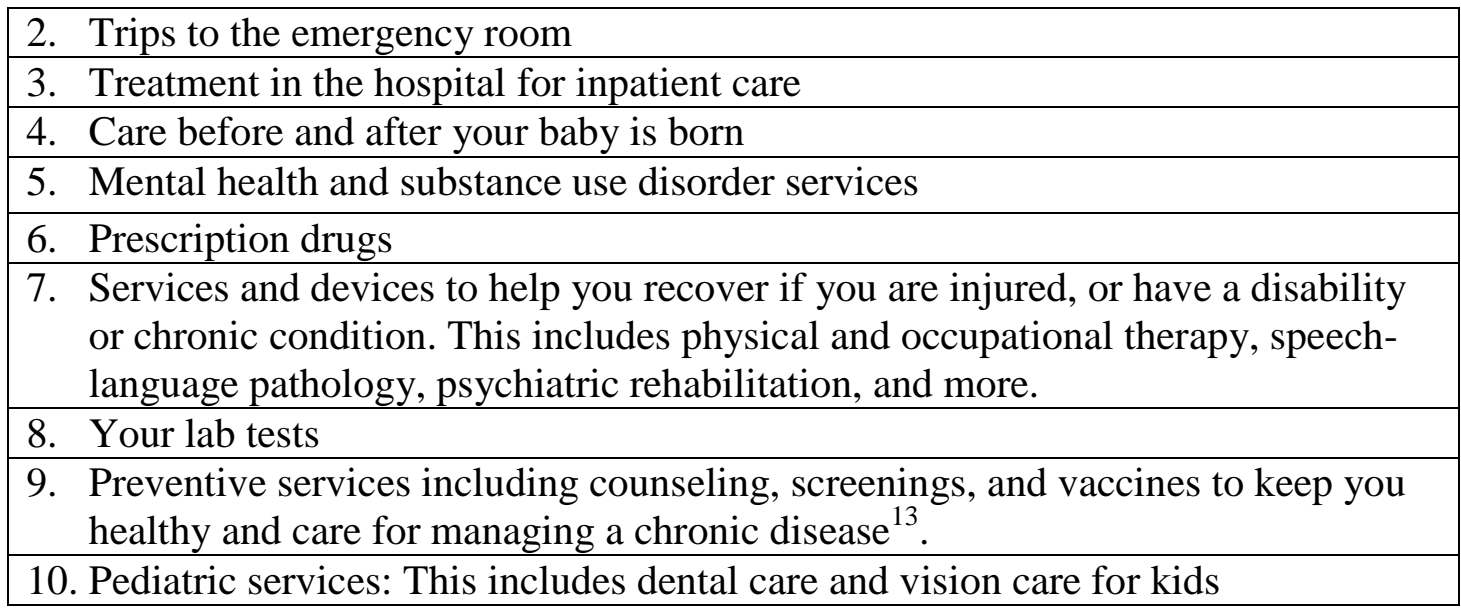

\section{Theoretical Framework}

To examine adverse selection this study will utilize the graphical framework established by Liran Einav and Amy Finkelstein (Einav \& Finkelstein, 2011). This framework provides the ability to empirically test for adverse selection under different scenarios. Specifically for this dissertation, the Einav and Finkelstein model for "positive correlation" will be used and will be referred to as the EF model. This test will compare one insurer's costs (paid claims) and premium across a given state. A similar graphical framework will be constructed for risk adjustment to determine the ACA risk adjustment's ability to effectively stabilize premiums during the first year of the program.

Einav and Finkelstein refer to the representation in Figure 7 as the textbook model. The textbook example illustrates an insurance market based on price where consumers have the option to purchase insurance or not purchase insurance and all maintain the same aversion to risk. Price and cost are represented by the vertical axis and the horizontal axis represents the quantity of individuals who purchased insurance, also referred to as demand. The Demand Curve is represented by line $B E$ where $B$ is the most

\footnotetext{
${ }^{13}$ Preventive Services exist for three categories: all adults, women and children.
} 
expensive plan and $E$ is the least expensive plan. This line indicates an individual's willingness to pay for a plan. The marginal cost (MC) is indicated by the MC curve represented by line $A F$. Marginal costs in most markets, outside of health insurance, are usually attributed to the cost of producing one extra unit of a product or service. In creating widgets we know the cost of creating $\mathrm{x}$ number of widgets. We can then determine the cost of creating $x+1$ number of widgets. However, in the health insurance market, marginal cost is difficult to measure. Following the utility theory, it reasons that those that have the highest expected utility (or costs) are those willing to pay the most for insurance (those closer to point $B$ on the demand curve) which is demonstrated in this version of the EF model. The model shows that the demand/cost relationship that creates adverse selection can be graphically represented by a downward slopping $\mathrm{MC}$ curve seen in Figure 7. The $\mathrm{AC}$ curve (line $A G)$ denotes the average cost, $\mathrm{P}_{\text {eqm }}$ (line $P_{\text {eqm }} J$ ) represents equilibrium price, $\mathrm{Q}_{\text {eqm }}$ (line $Q_{\text {eqm }} C$ ) is the quantity equilibrium and $\mathrm{Q}_{\max }$ is maximum number of insured individuals. Point $\mathrm{C}$ is the competitive equilibrium price and quantity. The area between points DCEF is referred to as deadweight loss which indicates that supply and demand are not in equilibrium. This dissertation will focus on the MC curve. In Einav and Finkelstein's model test for positive correlation for selection shown in Figure 8, they build upon the first graphical framework by considering two populations and their average costs: insured (ACinsured) and uninsured ( $\mathrm{ACuninsured)}$. They also add price efficiency $\left(\mathrm{P}_{\text {eff }}\right)$ and quantity efficiency $\left(\mathrm{Q}_{\text {eff }}\right)$. 
Figure 7. Textbook Adverse Selection Example

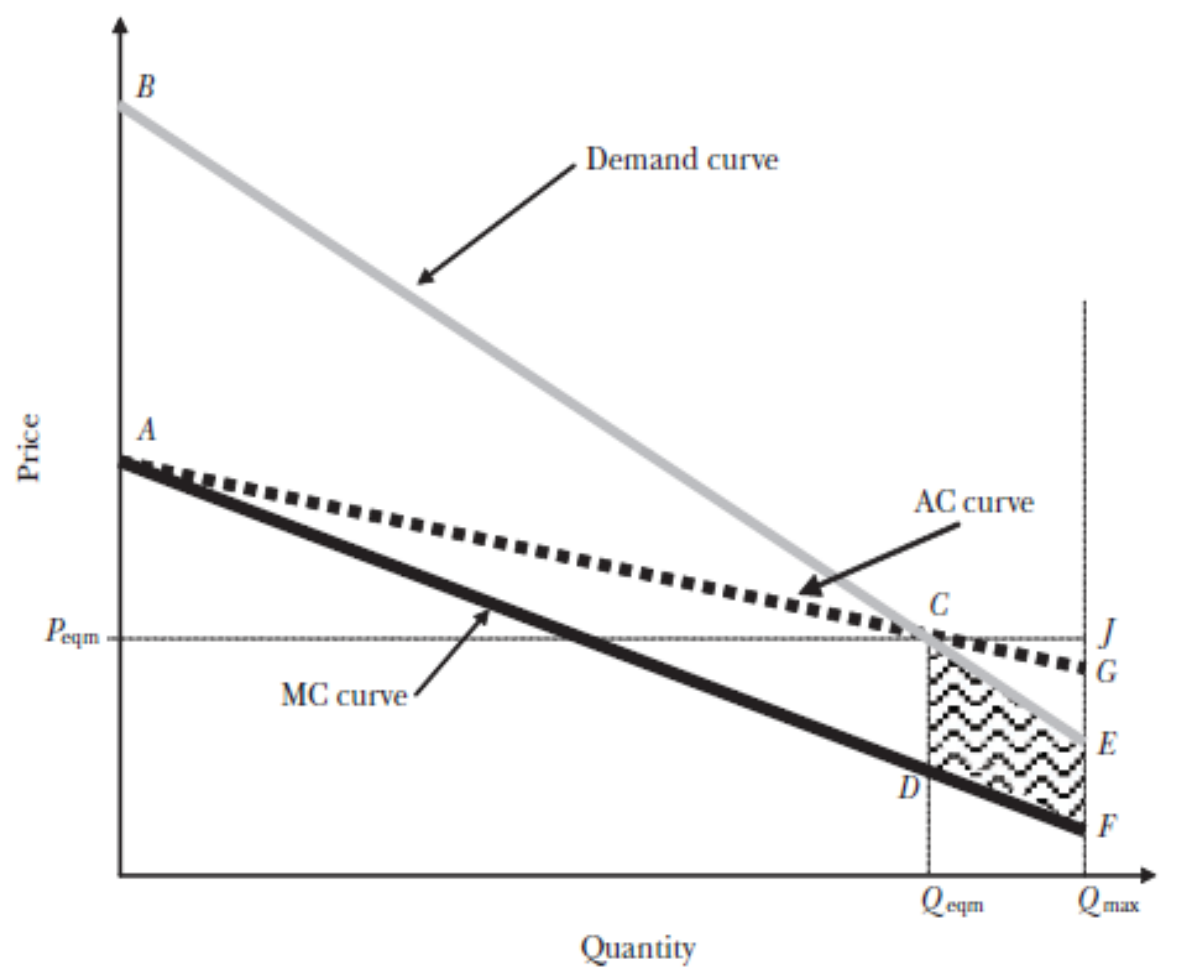

Figure 8. Einav and Finkelstein Positive Correlation Test for Selection

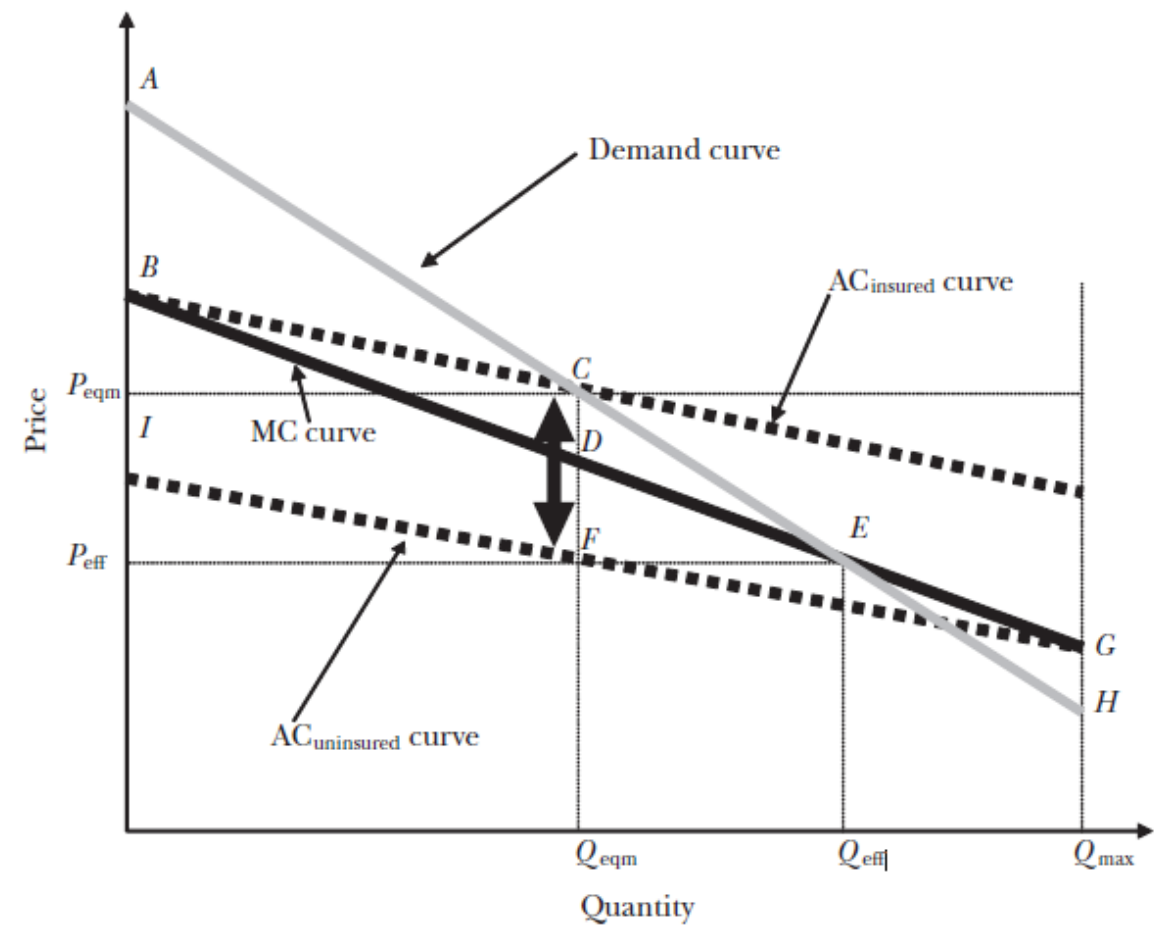


The graphical models in this study will simplify the EF model. The study will focus mostly on the MC Curve and will remove any consideration given to equilibrium, efficiency and welfare loss. The analysis will follow closely to Figure 9 below.

Figure 9. Graphical Framework Sample

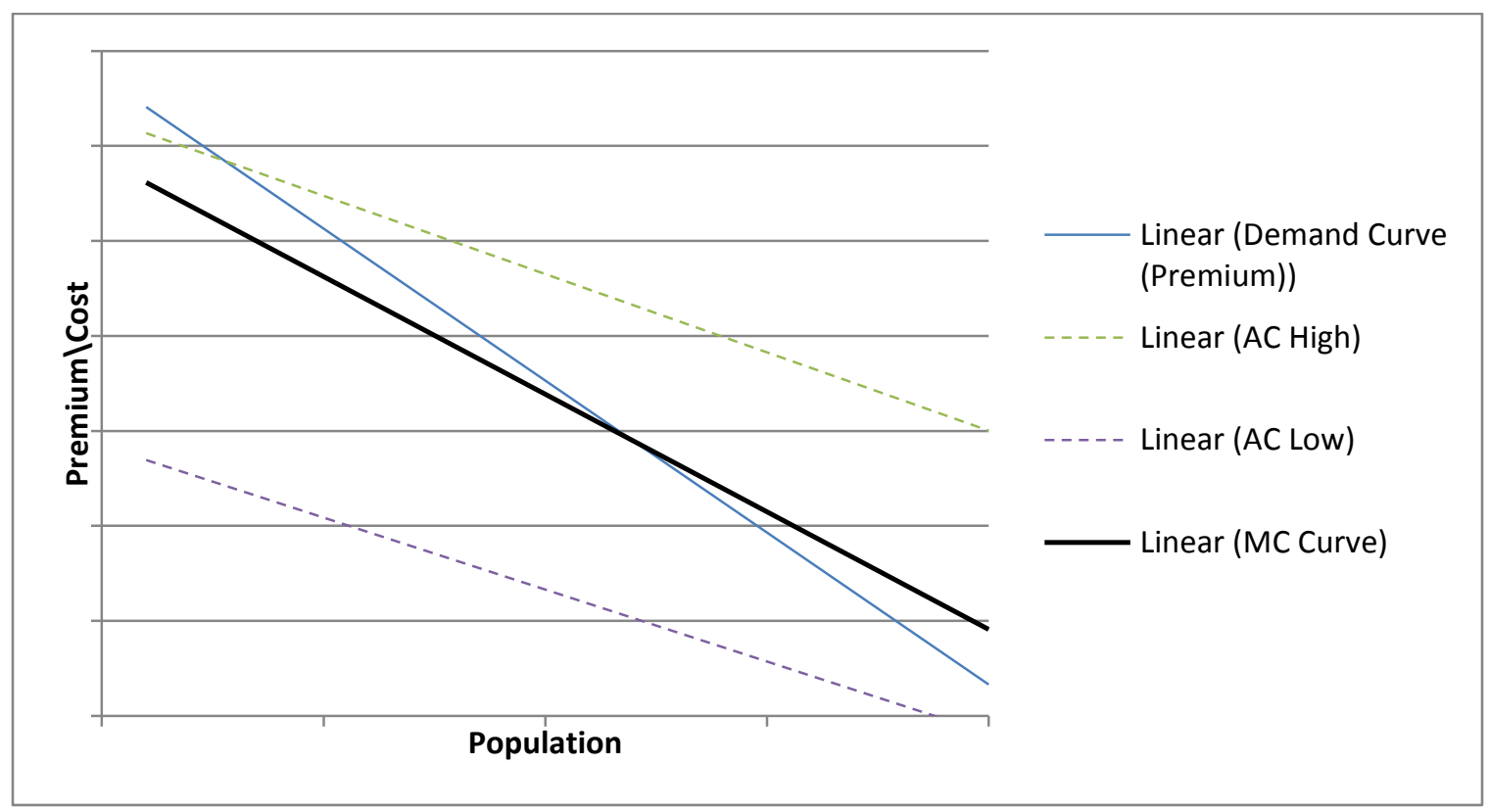

The EF model, Positive Correlation Test for Selection, attempts to show the theoretical impact of adverse selection on welfare loss. Others, such as Glazer, McGuire and Shi modified the model to analyze various aspects of premium and cost relationships to equilibrium. The Glazer et al model used Medical Expenditure Panel Survey data and which was a true empirical test. However, it did not test for adverse selection utilizing ACA Risk Adjustment enrollees or data. This dissertation will focus solely on applying empirical data to the model of the EF framework variations to test for adverse selection. 


\section{CHAPTER 3}

\section{METHODS}

\section{Study Design}

The study is a retrospective case study utilizing quantitative data for one insurer who participated in 5 states, providing ACA-complaint insurance to approximately 500,000 individuals. The study will examine the insurer's state and metal aggregated enrollee premiums, claims costs and relative health compared with the rest of the state's total insured risk pool population to determine: 1) if adverse selection existed and 2) if the payment transfer formula results in amelioration of any adverse selection ${ }^{14}$. The study will use descriptive and graphical analysis based on the framework of Liran Einav and Amy Finkelstein.

\section{Population}

The population of this study includes five states and will examine each state independently. The five states chosen represent the insurer's top five states based on population of individual membership and consisted of members who purchased health insurance and were enrolled in a plan for any period of time during the 2014 calendar year. The population for this study was also limited those members who purchased a metal-level plan (Platinum, Gold, Silver, Bronze) and did not include those who purchased a catastrophic plan. In addition, individuals must have had made at least one

\footnotetext{
${ }^{14}$ Relative health is measured by the ACA Risk Adjustment risk scoring methodology
} 
premium payment. Since premiums are charged to a subscriber (person purchasing the insurance), all costs directly associated with a subscriber and/or their dependent(s) were aggregated at the subscriber level. The definition of subscriber is provided to help provide context around the process for allocating premium and claims costs. However, for this study, the term enrollee will be utilized instead of subscriber. We limited the study to states where the evaluated insurer had at least 10,000 enrollees through the course of the 2014 year $^{15}$. Monthly premiums were aggregated into a yearly total premium for each enrollee based on the number months the he or she was enrolled in a plan (billable enrollee months) - see Figure 10 for an example.

Figure 10. Premium and Claims Aggregation

\begin{tabular}{|l|l|l|c|c|l|l|l|l|}
\hline Enrollee & $\begin{array}{l}\text { Enrollee } \\
\text { ID }\end{array}$ & $\begin{array}{l}\text { ID } \\
\text { Suffix }\end{array}$ & Subscriber & Premium & $\begin{array}{l}\text { Billable } \\
\text { Enrollee } \\
\text { Months }\end{array}$ & $\begin{array}{l}\text { Total 2014 } \\
\text { Premium }\end{array}$ & $\begin{array}{l}\text { Total } \\
\text { Claims } \\
\text { Cost }\end{array}$ & $\begin{array}{l}\text { Aggregated } \\
\text { Claims } \\
\text { Costs }\end{array}$ \\
\hline $\begin{array}{l}\text { John } \\
\text { Doe }\end{array}$ & 1111 & $\mathrm{~A}$ & $\mathrm{Y}$ & $\$ 100$ & 6 & $\$ 600$ & $\$ 100$ & \multirow{2}{*}{$\$ 350$} \\
\hline $\begin{array}{l}\text { Jane } \\
\text { Doe }\end{array}$ & 1111 & $\mathrm{~B}$ & $\mathrm{~N}$ & $\$ 0$ & 0 & $\$ 0$ & $\$ 200$ & \\
\cline { 1 - 6 } Joe Doe & 1111 & $\mathrm{C}$ & $\mathrm{N}$ & $\$ 0$ & 0 & $\$ 0$ & $\$ 50$ & \\
\hline
\end{tabular}

\section{Description of Study Variables}

\section{Independent Variables}

The independent variables for this study are: insurer's aggregated claims costs and insurer's state average premium which represents demand. The insurer's claims costs acts as the de facto representation of the overall health status of the insurer's population for the given state. Finally, premiums reflect the insurer's revenue and are the

\footnotetext{
${ }^{15}$ This number was chosen so that the binning of members in the next chapter is at least 2000 enrollees per bin at the state level - 2000 enrollees is a commonly accepted actuarial credibility standard for cost estimates (American Academy of Actuaries' Life Valuation Subcommitte, 2008).
} 
actual premium rates charged or billed for insurance. That is to say that the premium amount is the enrollee's share of premium plus, if applicable, any financial assistance provided through an APTC. Based on past studies that indicate premium drives purchase decisions, this dissertation will use the premium to create the independent variable demand and the resulting demand curve (Buchmueller, 2006). The premium is also used as an input in the payment transfer formula described in Chapter 1.

\section{Dependent variable}

In the graphical framework utilized in this study, the marginal cost curve represents a dependent variable of interest with a downward sloping curve indicating adverse selection as explained in Chapter 2. The payment transfer amount (either paid or received) is the other dependent variable under observation and will indicate if the final results of risk adjustment in 2014 accurately compensated insurers based on the health of their population when compared with premium.

\section{Data Analysis}

For the purposes of plotting the data utilizing the EF Model, data bins were created. Each state bin consisted of at least 2000 enrollees and the number of bins per state was dependent on the insurer's total enrollee population of the state. The total premium and costs for each bin were aggregated and divided by the number of enrollees

per bin to give an average premium per enrollee per bin and an average cost per enrollee per bin. Figure 11 shows an example of the binning product. 
The data was aggregated in relational database tables in a Microsoft SQL server and then imported and graphed in Microsoft Excel. The linear regression $\left(\mathrm{R}^{2}\right)$ of each line was calculated using Excel to study the fit and slope of each of the data curves. Each state was graphed prior to applying the payment transfer amount and then again after applying the payment transfer. The payment transfer amount was distributed across the data bins to achieve an adjusted cost per member and the adjusted average cost was applied to the graph to demonstrate the financial adjustment to that curve.

Figure 11. Sample Data Bins for a given state

\begin{tabular}{|c|c|c|c|c|c|c|c|c|c|}
\hline 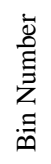 & 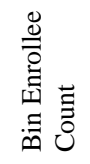 & 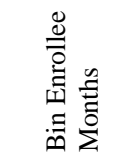 & 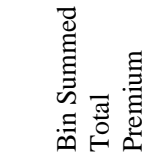 & 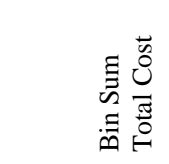 & 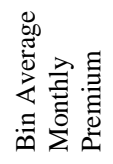 & 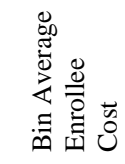 & 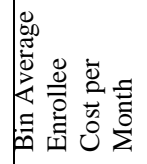 & 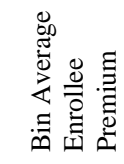 & 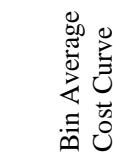 \\
\hline 10 & 6613 & 54299 & 3457840.75 & 31338767.16 & 522.89 & 4738.96 & 577.15 & 4293.38 & 6589.28 \\
\hline 9 & 6613 & 54233 & 3617899.66 & 34681758.34 & 547.09 & 5244.48 & 639.50 & 4486.66 & 6794.87 \\
\hline 8 & 6613 & 54695 & 3783336.26 & 34850760.65 & 572.11 & 5270.04 & 637.18 & 4731.79 & 6988.66 \\
\hline 7 & 6613 & 53646 & 3993661.15 & 36870723.49 & 603.91 & 5575.49 & 687.30 & 4899.05 & 7234.18 \\
\hline 6 & 6613 & 54685 & 4317954.41 & 36982739.86 & 652.95 & 5592.43 & 676.29 & 5399.45 & 7510.63 \\
\hline 5 & 6613 & 54980 & 4717672.70 & 46979961.69 & 713.39 & 7104.18 & 854.49 & 5931.10 & 7894.27 \\
\hline 4 & 6613 & 53291 & 5232189.10 & 43023425.21 & 791.20 & 6505.89 & 807.33 & 6375.88 & 8091.79 \\
\hline 3 & 6613 & 54444 & 5953611.77 & 48816759.14 & 900.29 & 7381.94 & 896.64 & 7411.97 & 8620.43 \\
\hline 2 & 6613 & 56443 & 6843417.84 & 54402907.89 & 1034.84 & 8226.66 & 963.86 & 8832.55 & 9239.67 \\
\hline 1 & 6613 & 56854 & 8466588.51 & 67800988.44 & 1280.29 & 10252.68 & 1192.55 & 11007.09 & 10252.68 \\
\hline
\end{tabular}

The bin numbers are created and ordered based on premium so that bin number 1 contains the highest average enrollee premium. These are the individuals that are willing to spend the most money for insurance. Bin 10 contains the lowest average enrollee premium. The bins also contain the average cost per enrollee for that respective bin. 


\section{Confidentiality}

The University of Louisville Institutional Review Board (IRB) evaluated and granted approval for this study after an expedited review. A copy of the approval letter is included in Appendix A.

\section{Summary}

This study examines the membership and cost relationship of one insurer participating in the first year of the ACA Risk Adjustment program. The study encompasses 5 states and approximately 500,000 individuals whose claims costs were evaluated at the state level as well as the metal tier level within each state (Platinum, Gold, Silver, and Bronze). The population included all subscribers in an ACA compliant, individual plan for the evaluated states. The case study utilized graphical analysis and descriptive statistics to measure adverse selection based on claims costs prior to the CMS payment transfer and then again after the transfer of funds. The model used in this paper was based on the established framework of Liran Einav and Amy Finkelstein and the results from the study are offered in Chapter 4.

\section{Limitations of the Study}

This is a case study utilizing data from one insurer (with the exception of the CMS published state data) and may or may not be generalizable to other health plans. An initial year study is likely to look different from insurer to insurer. It is also likely that a study will result in different outcomes conducted in subsequent years of the RA program 
as health plans learn more about the potential population and gain a better understanding of how to price and design benefits for these populations.

\section{Conclusion}

In the pre-reform era of healthcare, individuals self-reported medical history to health insurance carriers who in turn used this information to underwrite an insurance policy for that particular individual. This allowed the policy to be written in such a way that the insured burdened some of the risk. Someone with more self-reported illness would pay a higher deductible or possibly be denied for a plan altogether. This arrangement sometimes led to adverse selection where only the sick were buying insurance. The ACA's Premium Stabilization rule looks to address both of these issues and create level playing field for insurers. 


\section{CHAPTER 4}

\section{RESULTS}

This chapter will provide the results of the study utilizing graphical and descriptive analysis. The initial results tested, graphically, for adverse selection of a given state and where possible, between metal tiers. A subsequent graphical analysis applies the payment transfer funds to the graph in the form of an adjusted cost curve for comparison. An R-squared regression is used to determine fit for all curves on the graph. See Table 12 for the list of states for this study.

Table 12. Evaluated States

\begin{tabular}{|l|l|l|l|}
\hline State & Enrollee Count & $\begin{array}{l}\text { State Average } \\
\text { Risk Score }\end{array}$ & $\begin{array}{l}\text { Insurer Average } \\
\text { Risk Score }\end{array}$ \\
\hline Florida (FL) & 174,506 & 1.639 & 1.408 \\
\hline Georgia (GA) & 198,387 & 1.594 & 1.614 \\
\hline Michigan (MI) & 28,197 & 1.813 & 1.312 \\
\hline Mississippi (MS) & 32,239 & 1.621 & 1.696 \\
\hline Texas (TX) & 88,022 & 1.682 & 1.494 \\
\hline
\end{tabular}

In Table 12, enrollee count represents the number of subscribers; the State Average Risk Score is the CMS calculated risk score indicating the relative health of the entire individual market population for the state. Insurer Average Risk score represents the relative health of the examined insurer's population within the state. Where the 
insurer Average Risk Score is lower than the State Average Risk Score the Insurer paid into the transfer pool of funds. Also, the cost curve moves to the right. Conversely, where the Insurer risk score is lower than the state average, the insurer receives transfer funds and in this case, the cost curve moves to the left.

Below are the results for each of the previously listed states. Each state created a bin of enrollees. The bins are sorted by premium (or demand). Each bin aggregates the premium (price of the plan) and claims and calculates the average Premium per member, average costs across all enrollees, and average claims costs per member per bin. The number of enrollees per bin is provided in each state section.

\section{Florida}

The first state of interest is Florida and, shown in Figure 12, illustrates the premium per member (Prem/Mbr), this could also be noted as Demand, and the average cost (AC) of the population distributed across all bins. The cost per member (for each bin) is the Marginal Cost (MC) and will be the focus of most graphs (recall that a downward sloping MC curve indicates adverse selection). See Table 13 for enrollee Florida population per bin. As is with all states in this study, the Silver metal tier had the highest number of enrollees, and in Florida, the Bronze tier had the second highest number of enrollees, followed by Gold and then Platinum. The second Florida graph, Figure 13, will show the Premium and Cost for the Platinum tier and Figure 14 will express the same information for the Bronze tier. The Gold and Platinum tiers account for about only $12 \%$ of the Insurer's Florida population and neither were large enough to 
graph separately. Finally, Figure 15 includes both the Silver and Bronze metal tiers and the relationship of the MC curve between the two populations.

Relying on the EF textbook model for adverse selection, Figure 12 indicates that the Insurer was adversely selected in the state of Florida. The same holds true for the Bronze and Silver Metal tiers. In Figure 14 the purpose is to determine if one metal tier (one with more coverage) was adversely selected over another metal tier (one with lese coverage) for the insurer. The Silver plan is the higher priced plan but also covers more of the costs than the Bronze plan. This analysis is equivalent to the EF Positive Correlation Test for Selection described in the Chapter 2 and shown in Figure 8.

Table 13. Florida Bin Population Counts

\begin{tabular}{|c|c|c|}
\hline State & Metal Tier & $\begin{array}{c}\text { Number of } \\
\text { Enrollees per Bin }\end{array}$ \\
\hline FL & All & 6980 \\
\hline FL & Platinum & 787 \\
\hline FL & Gold & 917 \\
\hline FL & Silver & 6951 \\
\hline FL & Bronze & 1451 \\
\hline
\end{tabular}




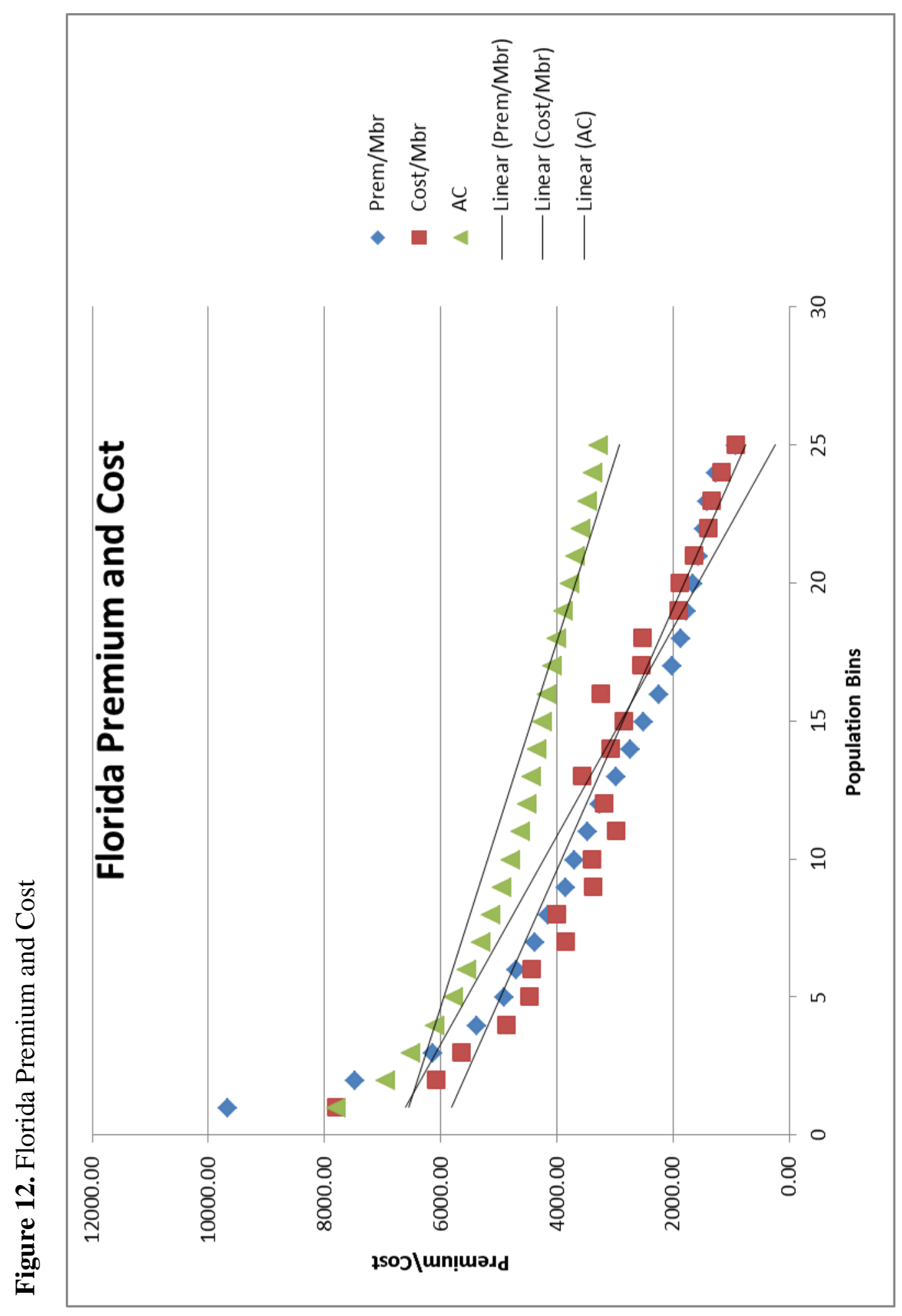




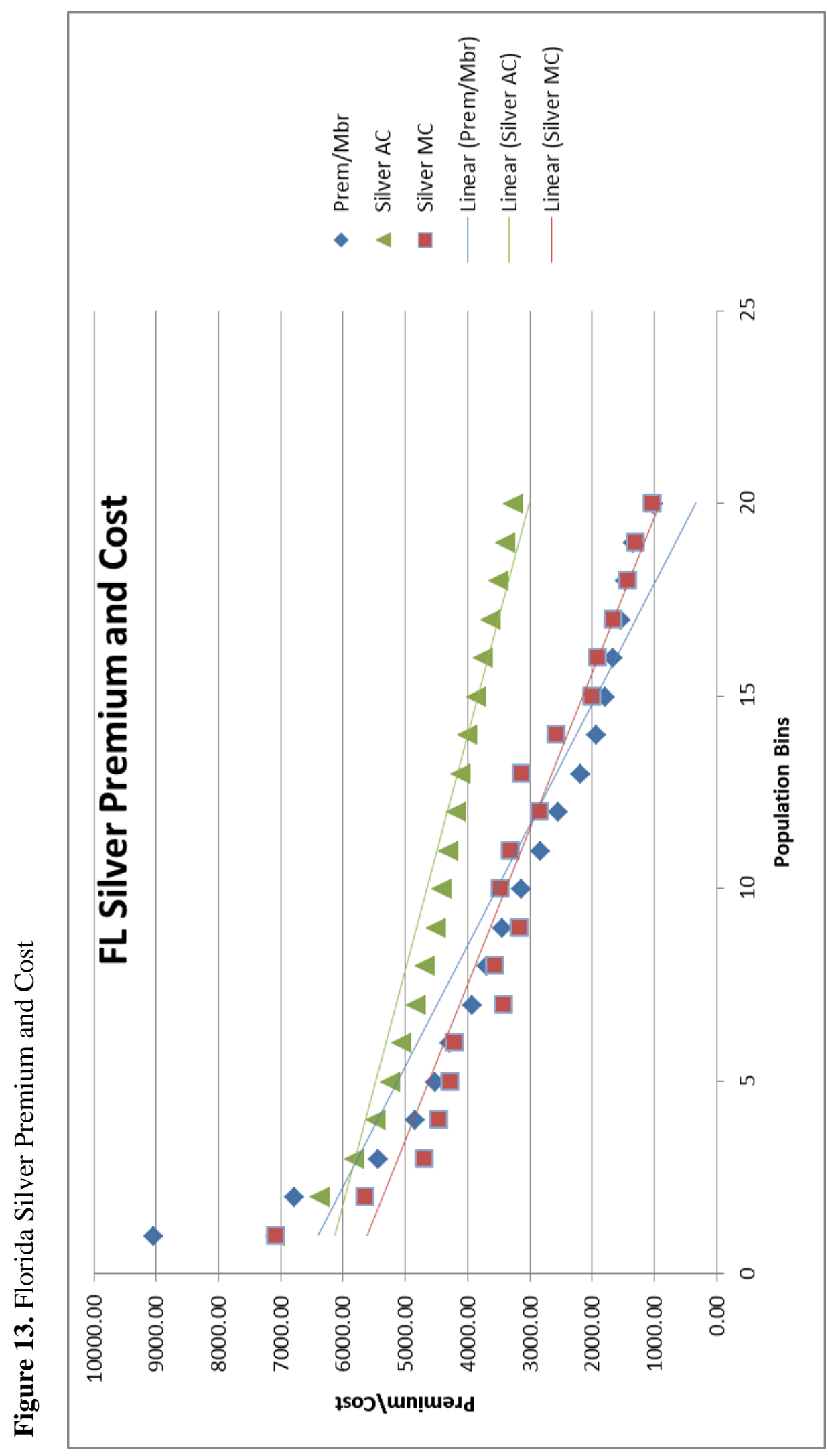




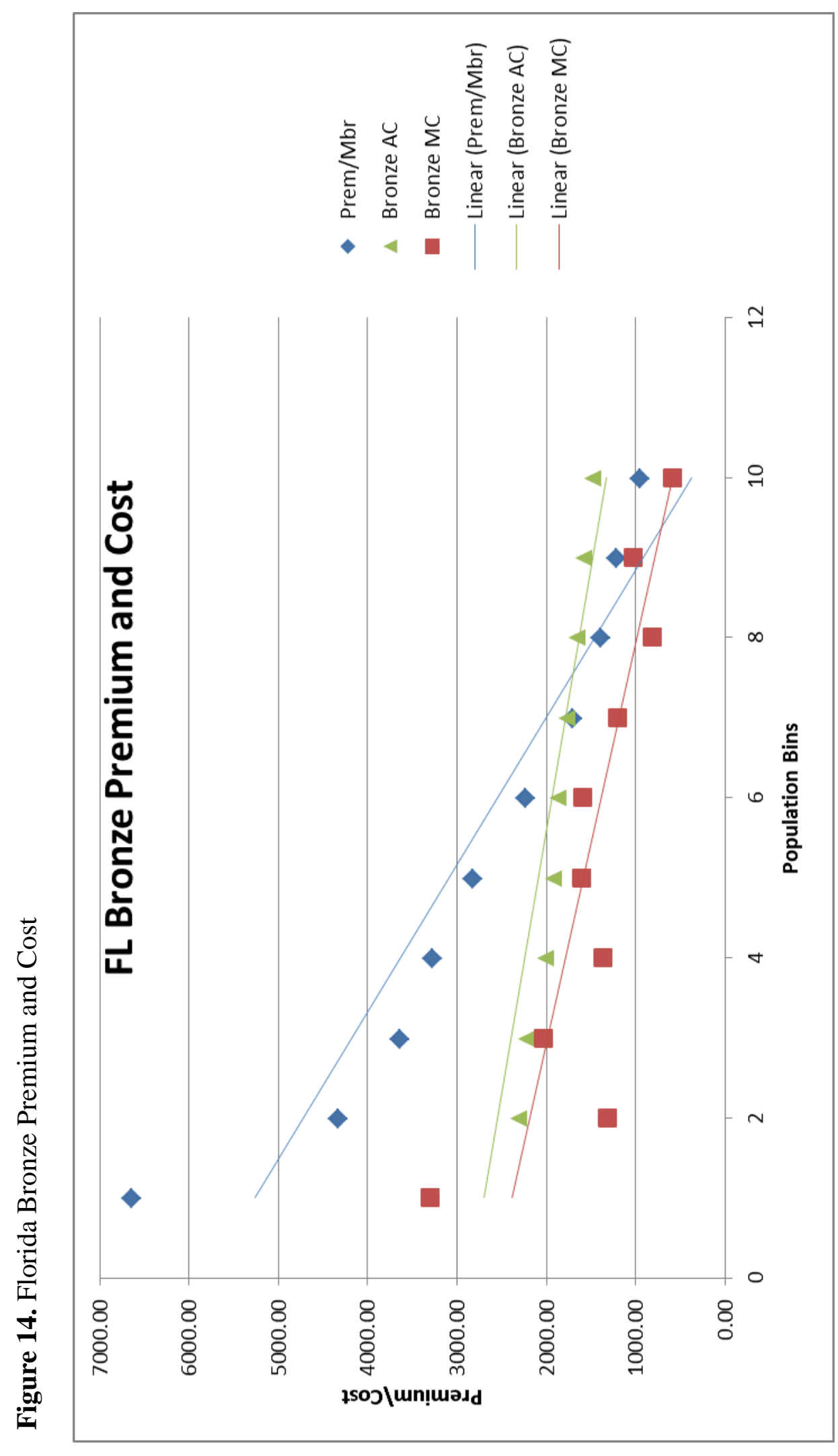




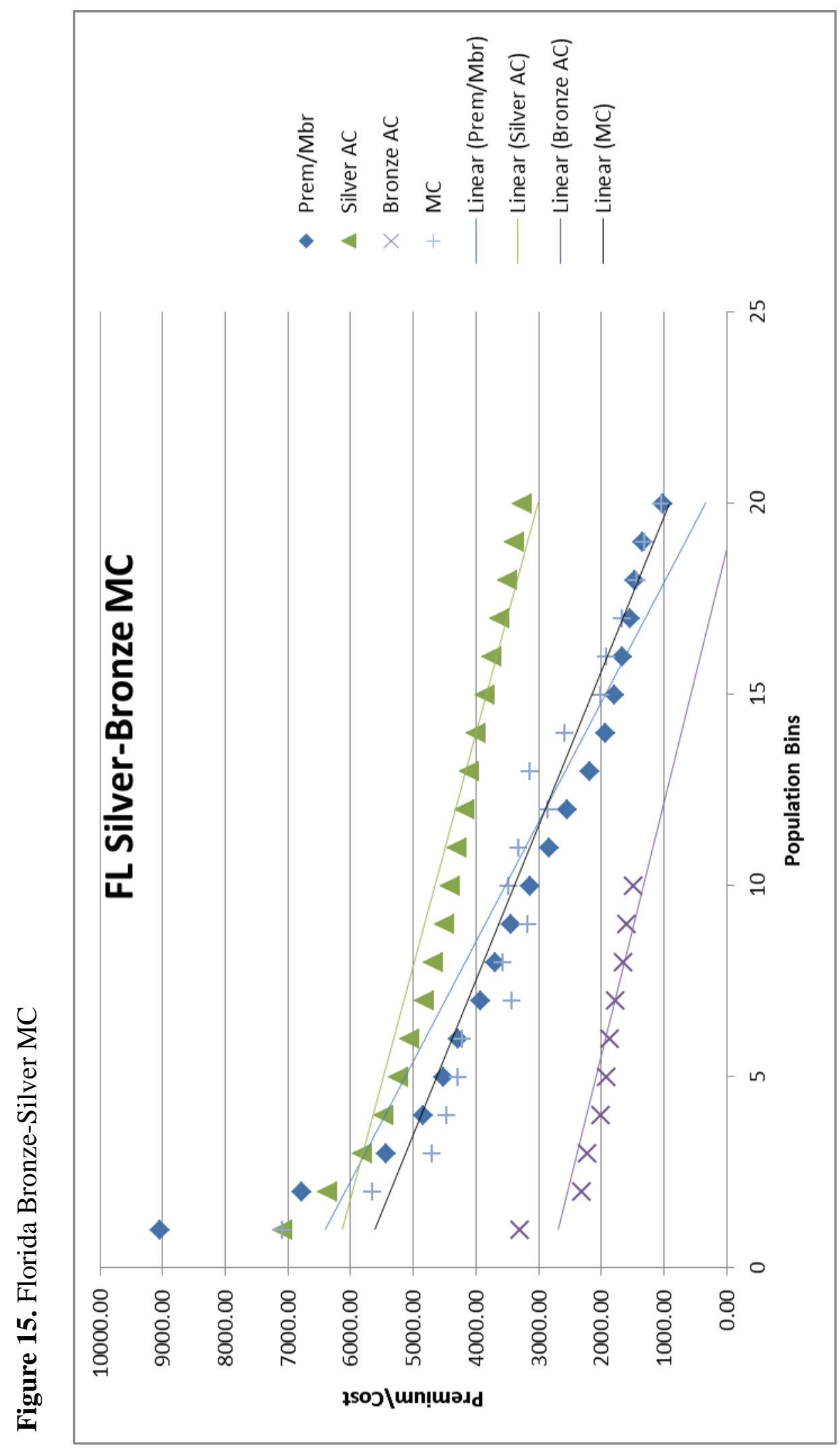


Figure 15 demonstrates that the Silver plan has a downward sloping MC and was adversely selected over the Bronze Plan. The next step after determining adverse selection was to apply the adjusted cost per member (marginal cost minus the payment transfer amount) to the graph and observe the impact of that cost (adjusted marginal cost) in relationship to the premium. First we graph the State Average Premium. The CMS reported Risk Score for the state of Florida is 1.639 and the CMS calculated risk score for the insurer was 1.408 . The state average risk score was $16 \%$ higher than the insurer's risk score indicating the insurer had a relatively healthier population than the state as whole. The insurer had to pay transfer funds to the state of Florida in the amount of $\$ 77,885,835$ which translates into 446.32 per member ${ }^{16}$. This amount is added to the insurer's member cost and is noted as the adjusted cost in the graph. This took the average cost per member for 2014 from $\$ 3,285$ to $\$ 3,823$. This adjusted amount is $16 \%$ higher than prior to the transfer payment. Figure 16 plots the Adjusted AC next to the pre-transfer AC to show how the adjusted cost aligns with the premium (or demand). Notice as the insurer pays out in transfer funds, the adjusted AC curve moves further away from the premium. In Figure 17 the adjustment is applied to the MC to give an adjusted MC. The actual value of the slope of the curve in Figure 17 is not as relevant as to whether the slope is downward sloping (negative value) or upward sloping (positive value). In all cases for the state of Florida the slopes are negative, indicating adverse selection.

\footnotetext{
${ }^{16}$ The payment transfer amount indicated does not reflect catastrophic members. This CMS published payment report includes catastrophic members and will show a slight variance when compared with the membership in this dissertation.
} 


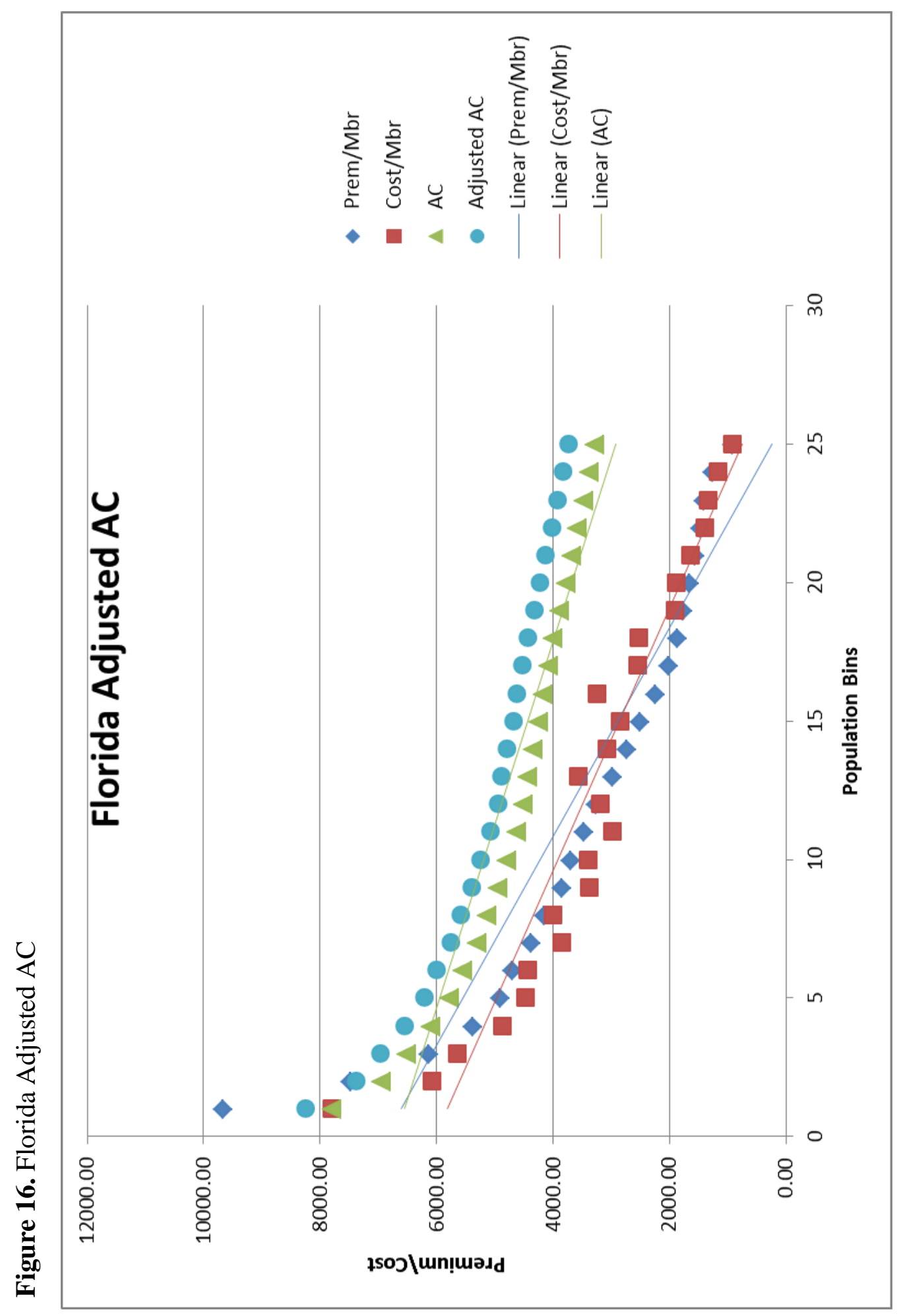




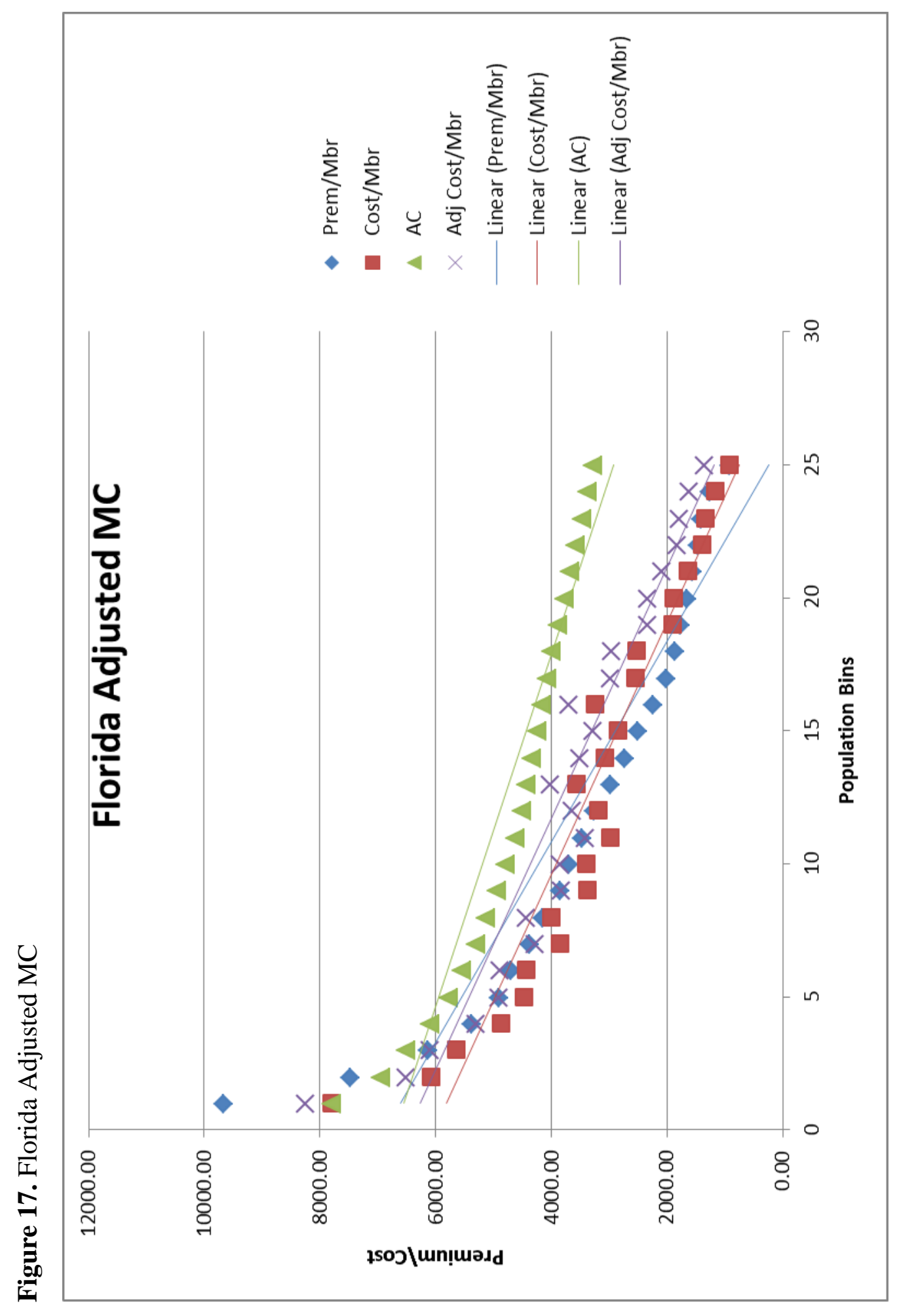




\section{Michigan}

Michigan follows the same downward slope for the MC curve as shown in Figure 18. The population bins for Michigan each contain 1,410 enrollees.

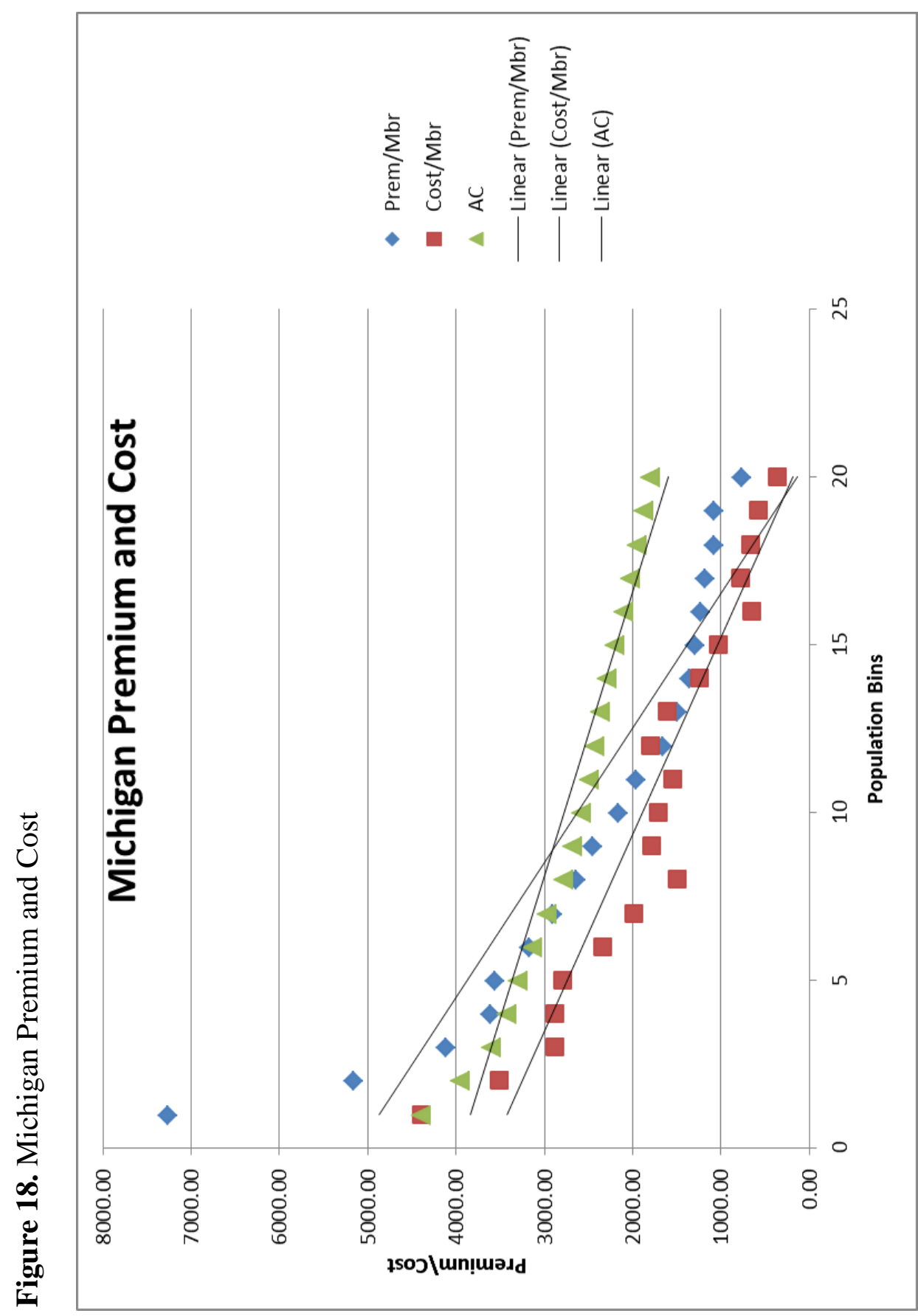




\section{Mississippi}

Mississippi follows the same downward slope for the MC curve as noticed in

Figure 19. The population bins for Mississippi each contain 1,410 enrollees.

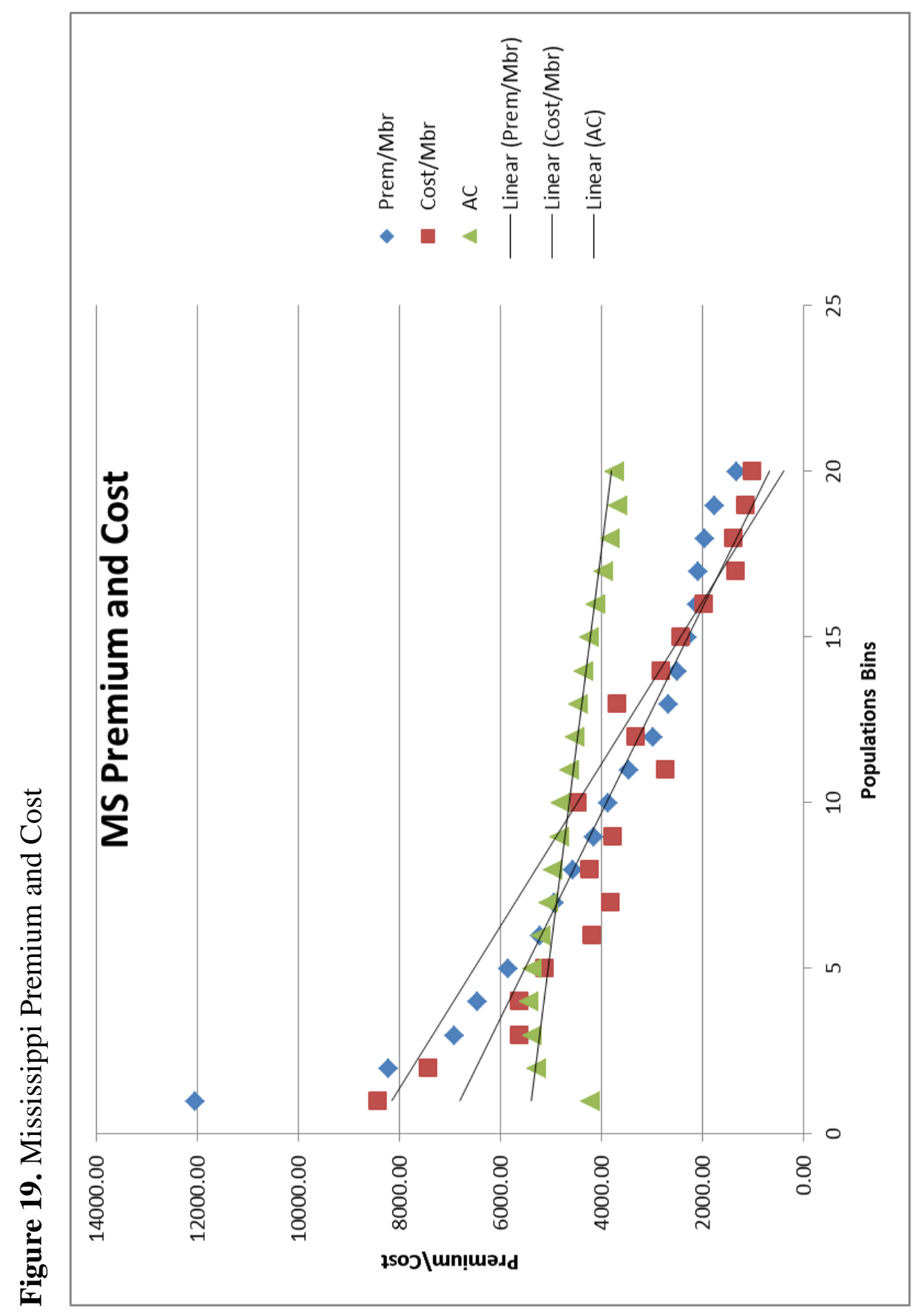




\section{Texas}

In the state of Texas, the insurer had a lower state average risk score which resulted in a payment in to the transfer find pool. What's interesting to note in Figure 20 is that the cost per member was greater than the premium even before adjusting for the transfer payment. This indicates that the insurer had high claims costs and did not receive a payment transfer but rather paid into the transfer pool. Most of this is caused by the Platinum and Silver plans having lower premiums than incurred costs as seen in Figures 21 and 22 respectively. Finally, in Figure 23, the Texas Bronze population demonstrates what the EF model refers to as complete unraveling. This happens when the AC curve is always above the premium (or demand curve) and the MC curve is always below the premium. According to Einav and Finkelstein an event known as the death spiral can lead to this situation. The death spiral is caused when insurers try to increase their costs based on the average cost $(\mathrm{AC})$ of the prior coverage period. As this cycle continues from one period to the next, the insurer eventually prices themselves out the market. In this particular case the insurer could choose not to sell a Bronze plan but remain in the market selling other plans. The enrollee counts per bin for Texas are in Table 14 below.

Table 14. Enrollee Count per Bin for Texas

\begin{tabular}{|c|c|c|}
\hline State & Metal Tier & $\begin{array}{c}\text { Number of } \\
\text { Enrollees per Bin }\end{array}$ \\
\hline TX & All & 3521 \\
\hline TX & Platinum & 1239 \\
\hline TX & Gold & 855 \\
\hline TX & Silver & 2791 \\
\hline TX & Bronze & 510 \\
\hline
\end{tabular}




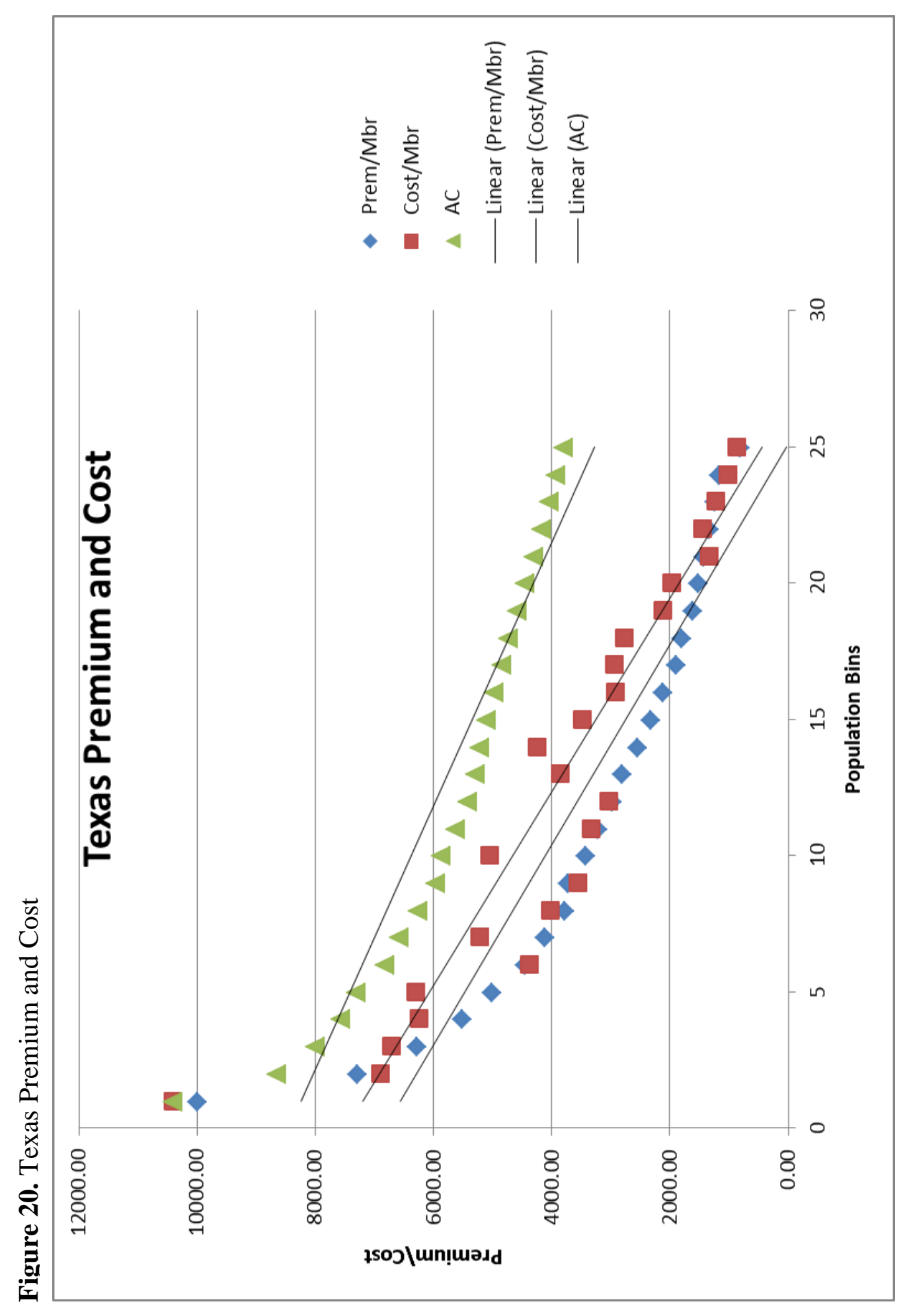




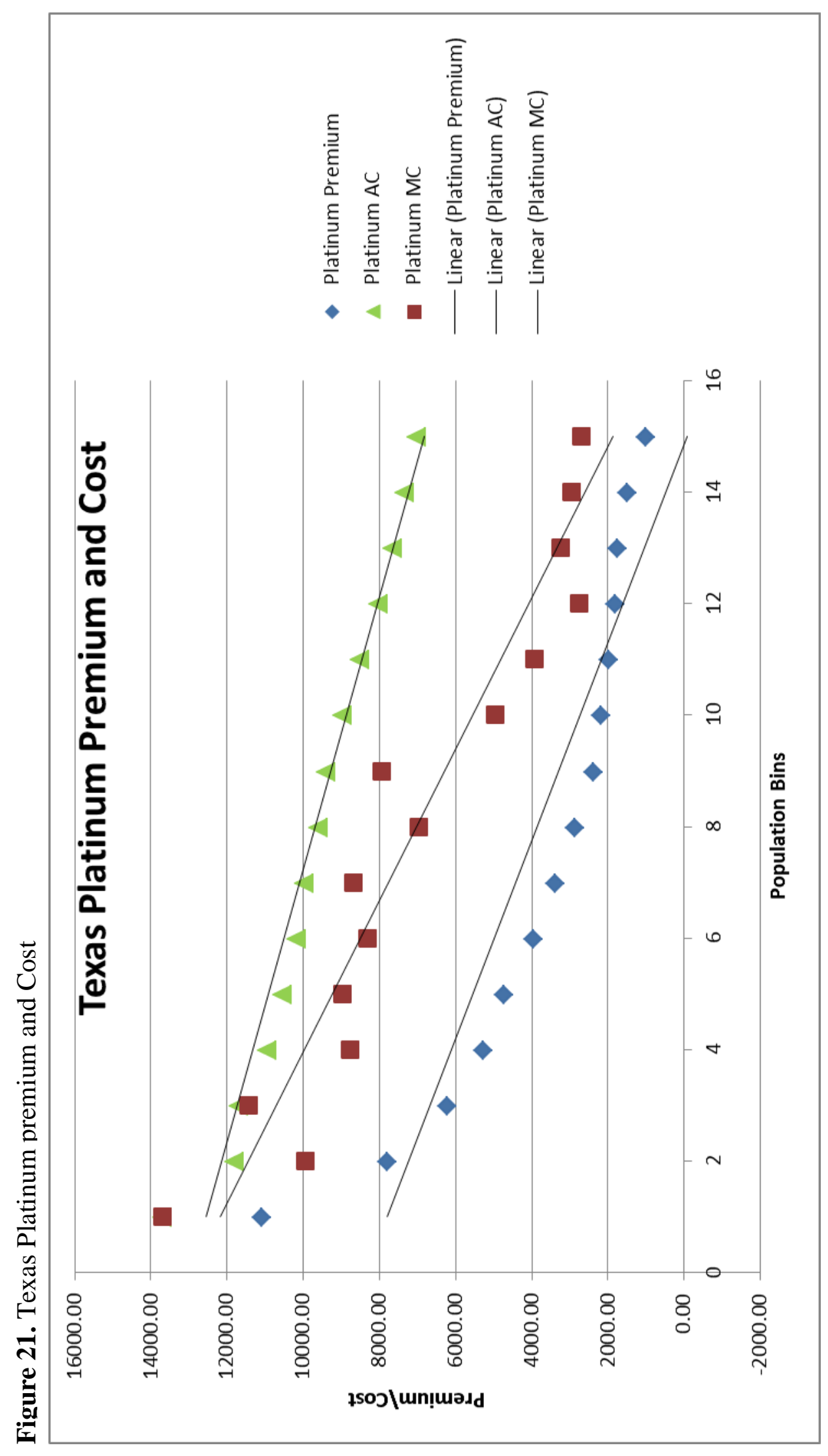




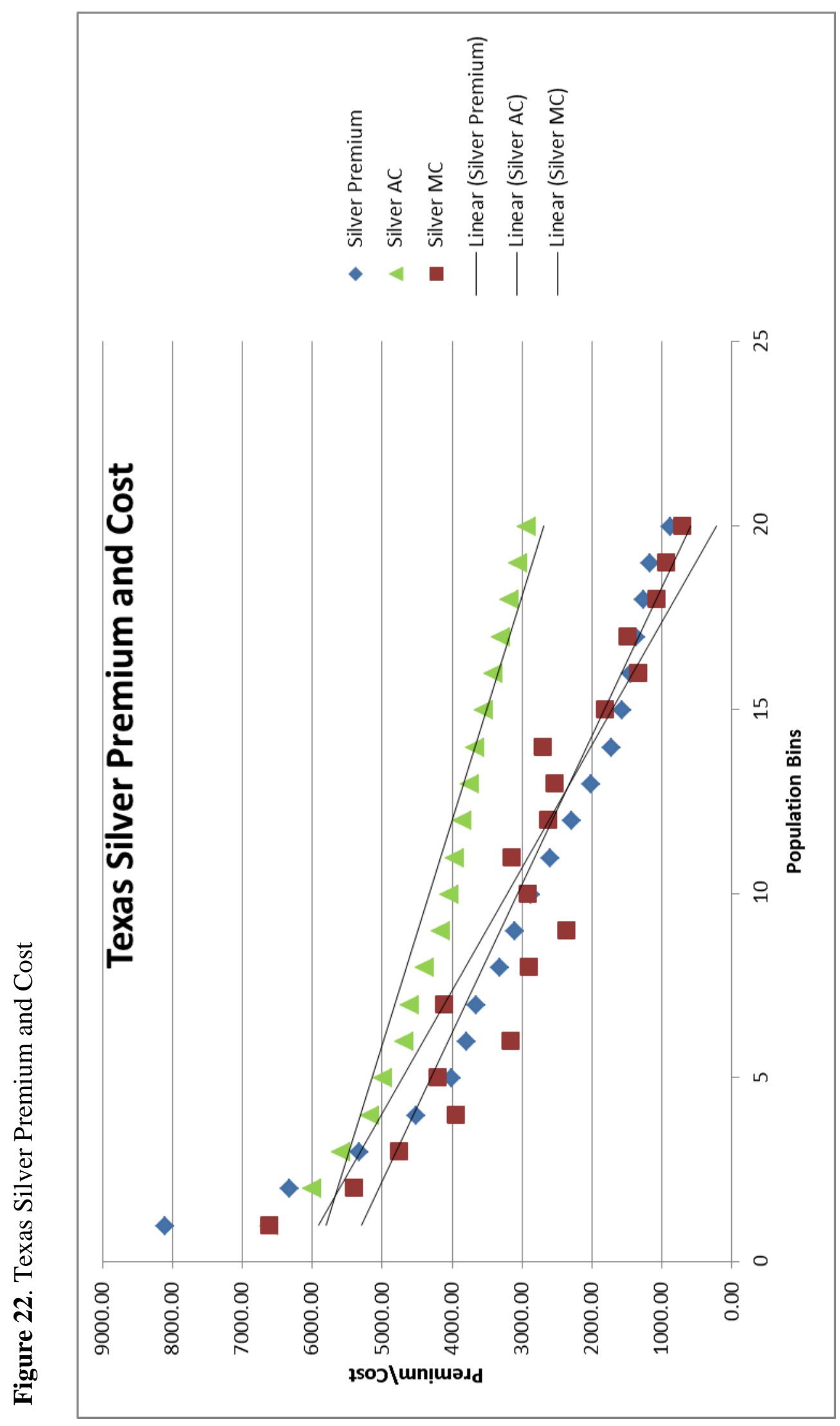




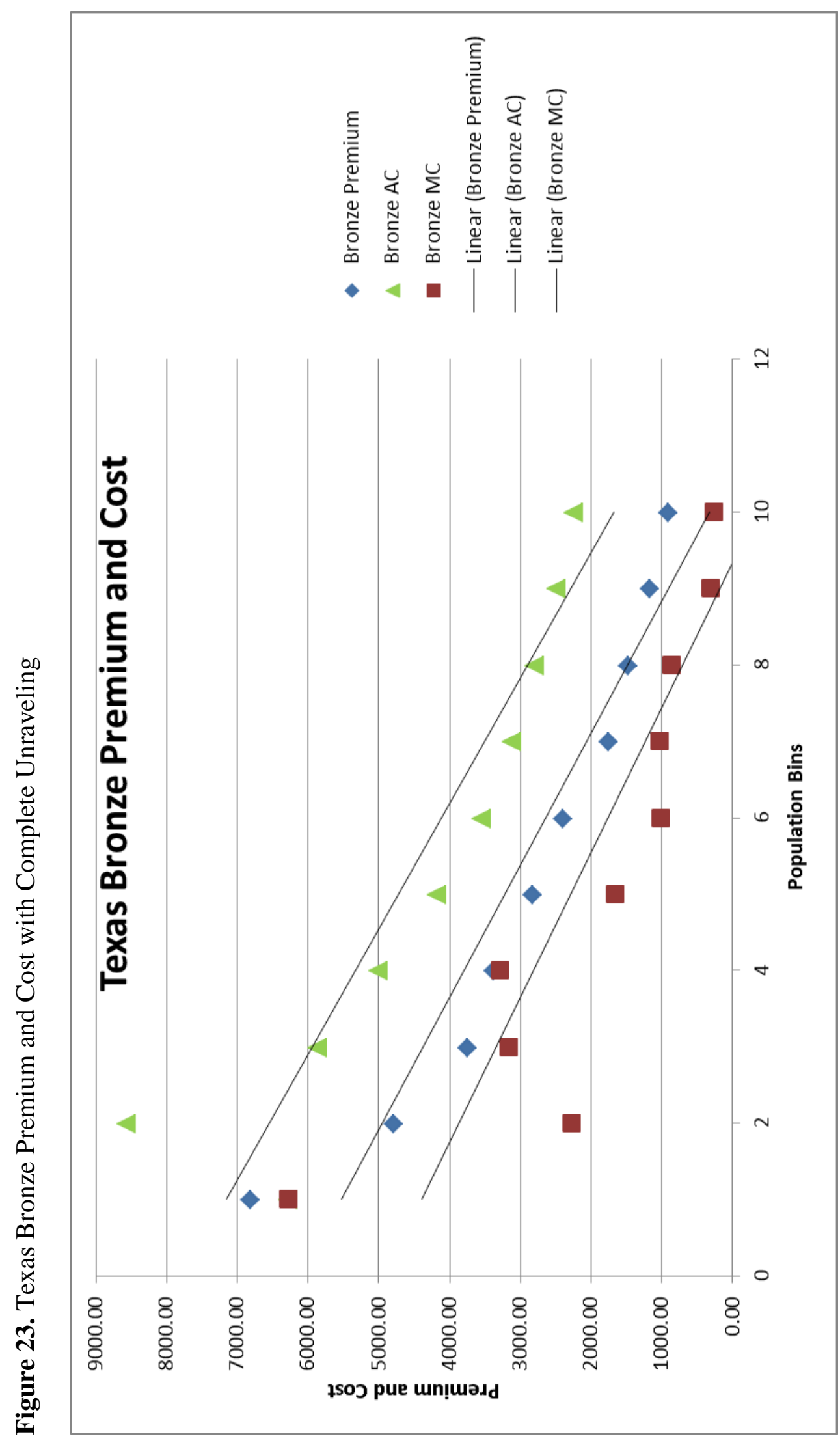




\section{Georgia}

The state of Georgia is unique in that the studied insurer provided coverage to approximately $70 \%$ of the enrolled Georgia individual population. The first graph, Figure 24, illustrates the insurer's total Georgia population premium and cost. Reviewing the risk score in Table 12, it can be inferred that the insurer had a relatively sicker population and thus would expect a payment to offset the costs of providing for that population. The insurer did receive a payment but that payment resulted in $\$ 11.02$ per member which moved the cost line to the left but, as noticed in Figure 125 did not compensate entirely for the incurred costs. Consequently, the adjusted costs remain greater than the premium. Even with the distribution of the transfer payment, the slope of the marginal cost curve is still unchanged. This will be the case in all instances. The payment transfer will not change the direction of the slope (from positive to negative) but it will demonstrate the new relationship between marginal cost and premium. 


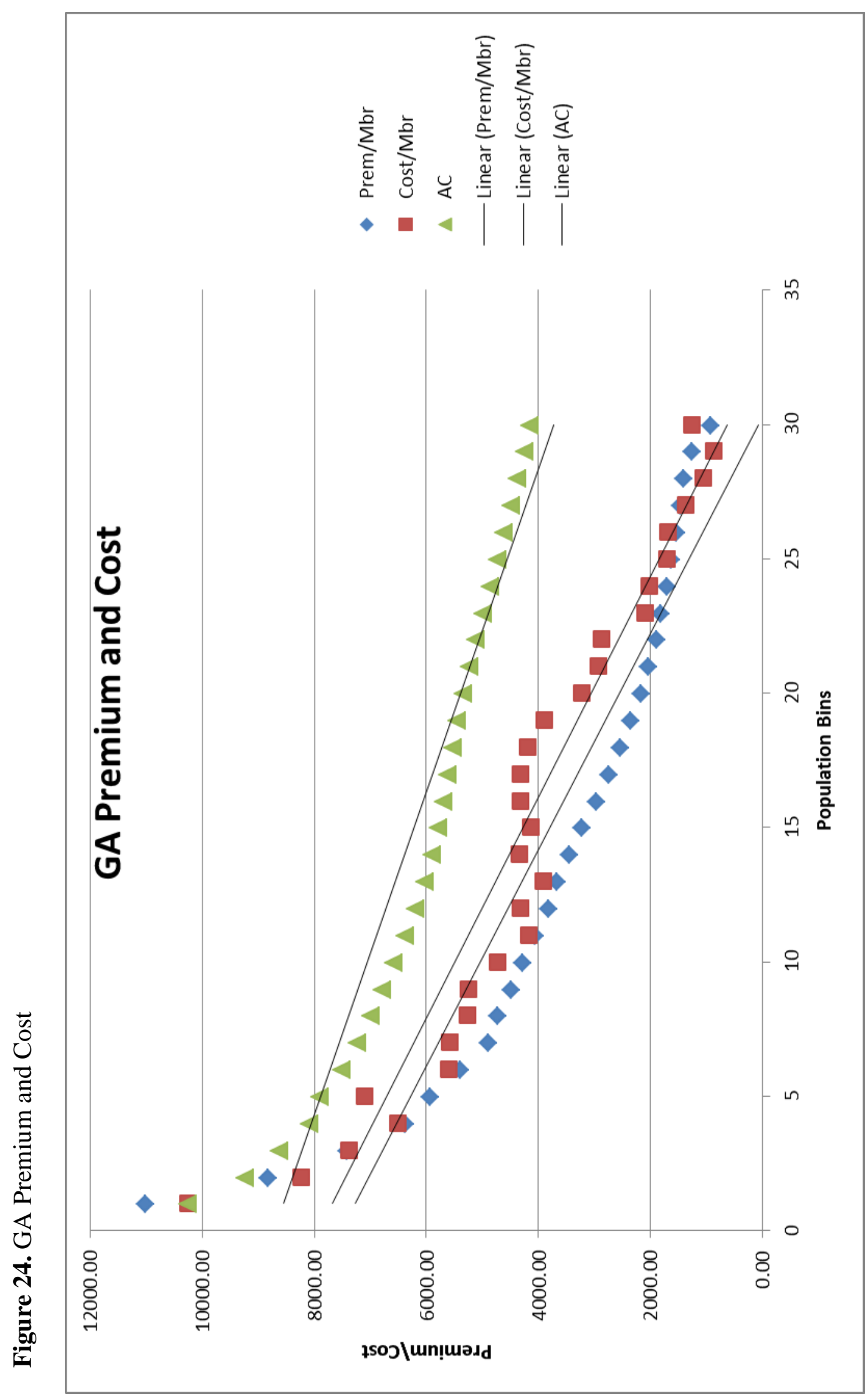




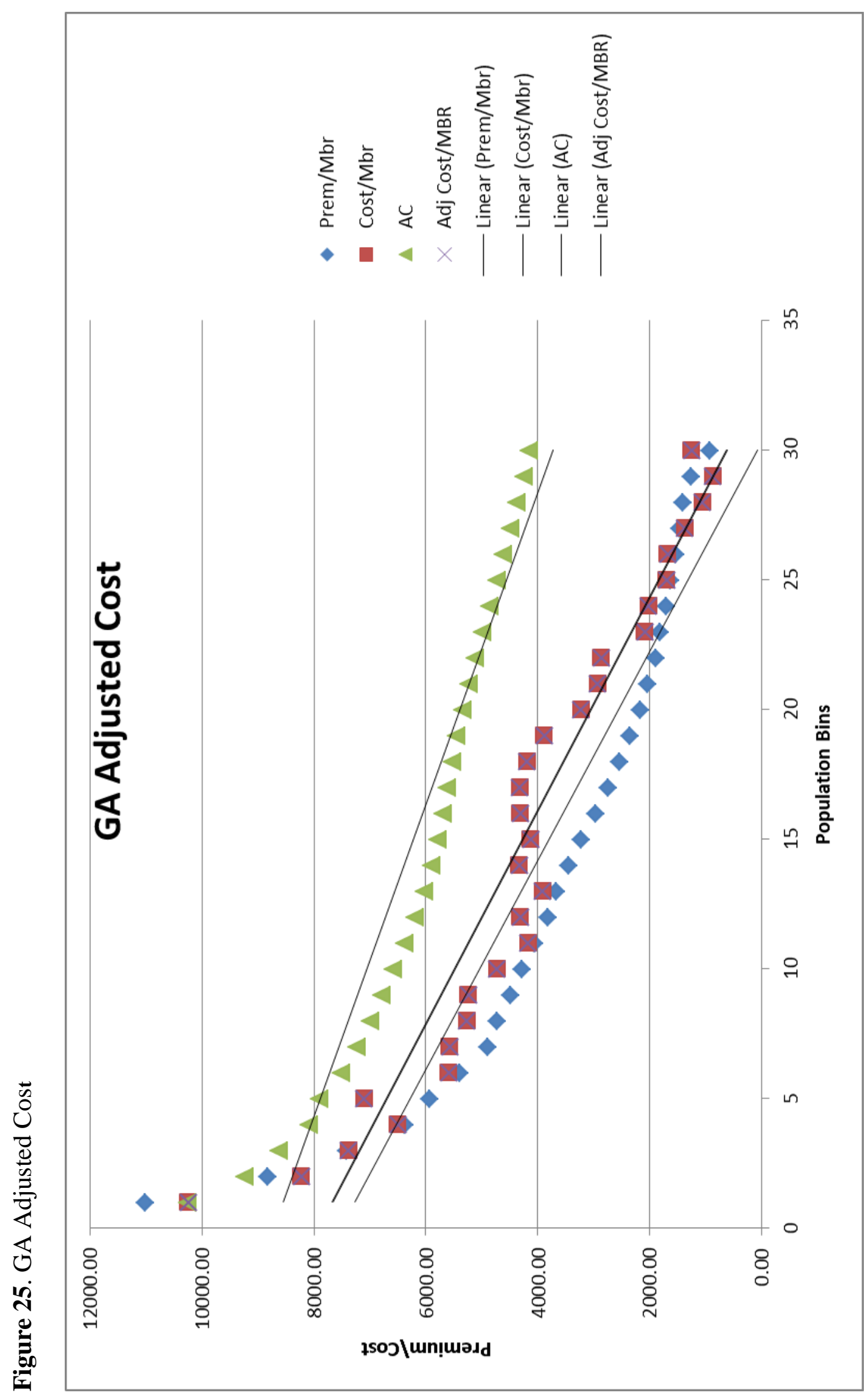




\section{CHAPTER 5}

\section{DISCUSSION}

This chapter begins with a more thorough analysis of the state of Georgia. Secondly, an examination of the potential drivers of adverse selection will be discussed. Also, 2014 risk adjustment conclusions provided by other analyses will be reviewed and discussed in comparison to the findings in this dissertation. Next, the strengths and limitations of the study will be addressed. Finally, recommendations for future research are presented.

\section{Georgia}

Given the market share of the Insurer in Georgia (which is one of the inputs to the payment transfer formula); a bootstrap analysis (resampling with replacement) was conducted to determine if there was any opportunity for the insurer to avoid being adversely selected. Bootstrapping is used to validate the original data's variances especially in extreme cases. More specifically, bootstrapping provides a more normalized set of central tendencies around averages for aggregated data such as claims costs and premium which might be skewed after binning. Additionally, resampling the observed data provides the "least prejudiced estimate possible (Shalizi, 2010)."

The bootstrapping analysis used in this study generated 10,000 samples of the insurer's total Georgia population and then again for each metal tier. Each sample included the same number of individuals as the observed population. Each sample 
calculated the slope of the marginal cost curve to determine if a slope greater than or equal to zero could be realized. A downward sloping curve is negative and indicates adverse selection. Table 15 contains the observed slopes compared to the bootstrapped slopes.

Figures 26 - 30 display the histograms for the insurer's entire population of the state of Georgia and for each of the metal tier populations in the state.

To ensure an effective comparison between the observed and sampled data, a calculation was used to generate 10,000 random rows of the observed data utilizing the mean and standard deviation. The bootstrapping method reduced the sampling errors found in the observed data. This is evident in the narrower dispersion of slopes as indicated in the histograms.

The bootstrapping method does have some limitations. It does not accurately estimate minimum or maximum values of distribution. The accuracy of the results that occurs with bootstrapping is dependent on the number samples taken. As the number of samples increases the sampling errors generated by bootstrapping decreases. For this reason the study used a bootstrapping count of 10,000. After validating the results with bootstrapping, the predicted costs were plotted against the observed costs to identify the outliers. The standard error (SE) of the bootstrapped results was applied the predicted MC Slopes in each histogram. Figures $31-36$ illustrate the predicted marginal costs of the Georgia population with SE bars. Any observed point outside the reach of the SE bar is considered an outlier. Figure 31 shows the actual versus the predicted values for the entire state. 


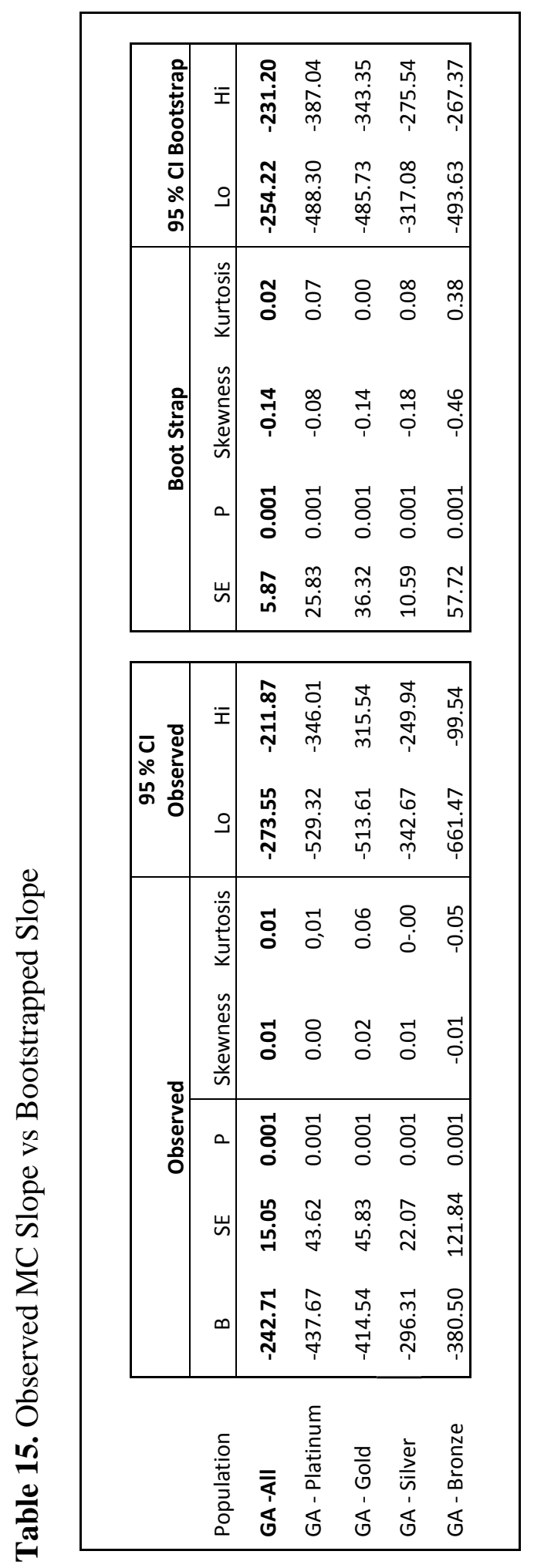


Figure 26. Georgia MC Slopes Bootstrapped vs Observed

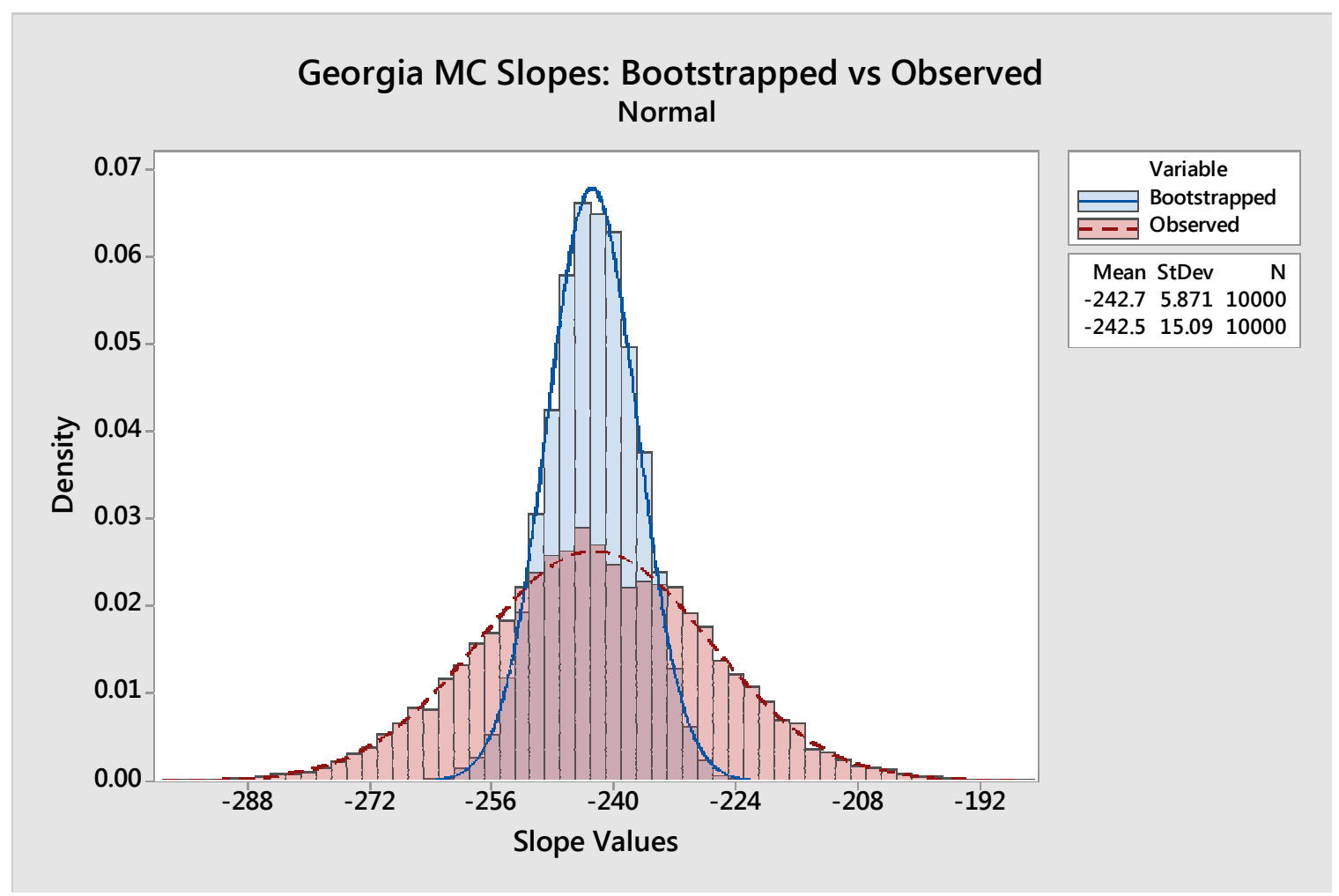

Figure 27.Georgia Platinum MC Slopes Bootstrapped vs Observed

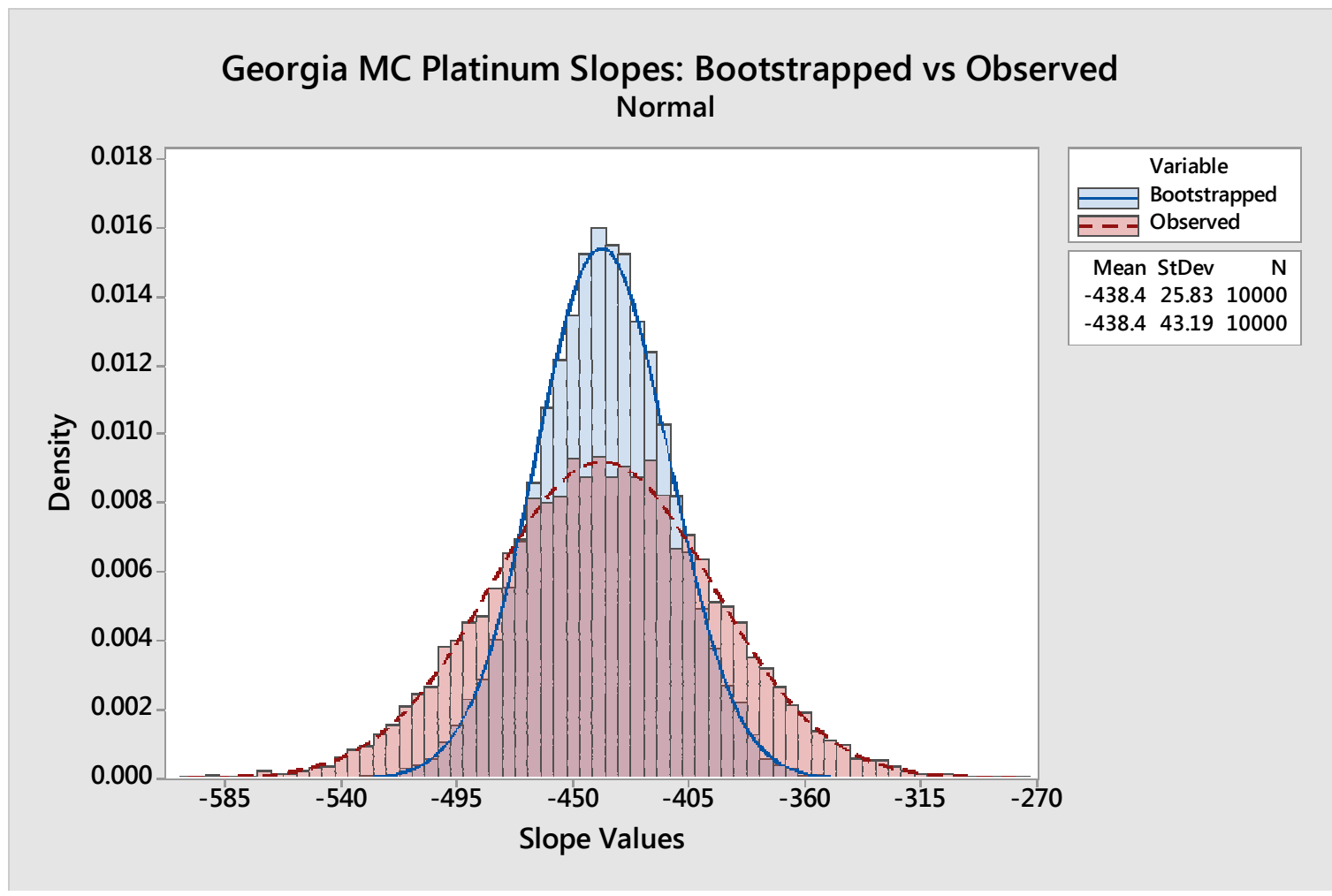


Figure 28. Georgia Gold MC Slopes Bootstrapped vs Observed

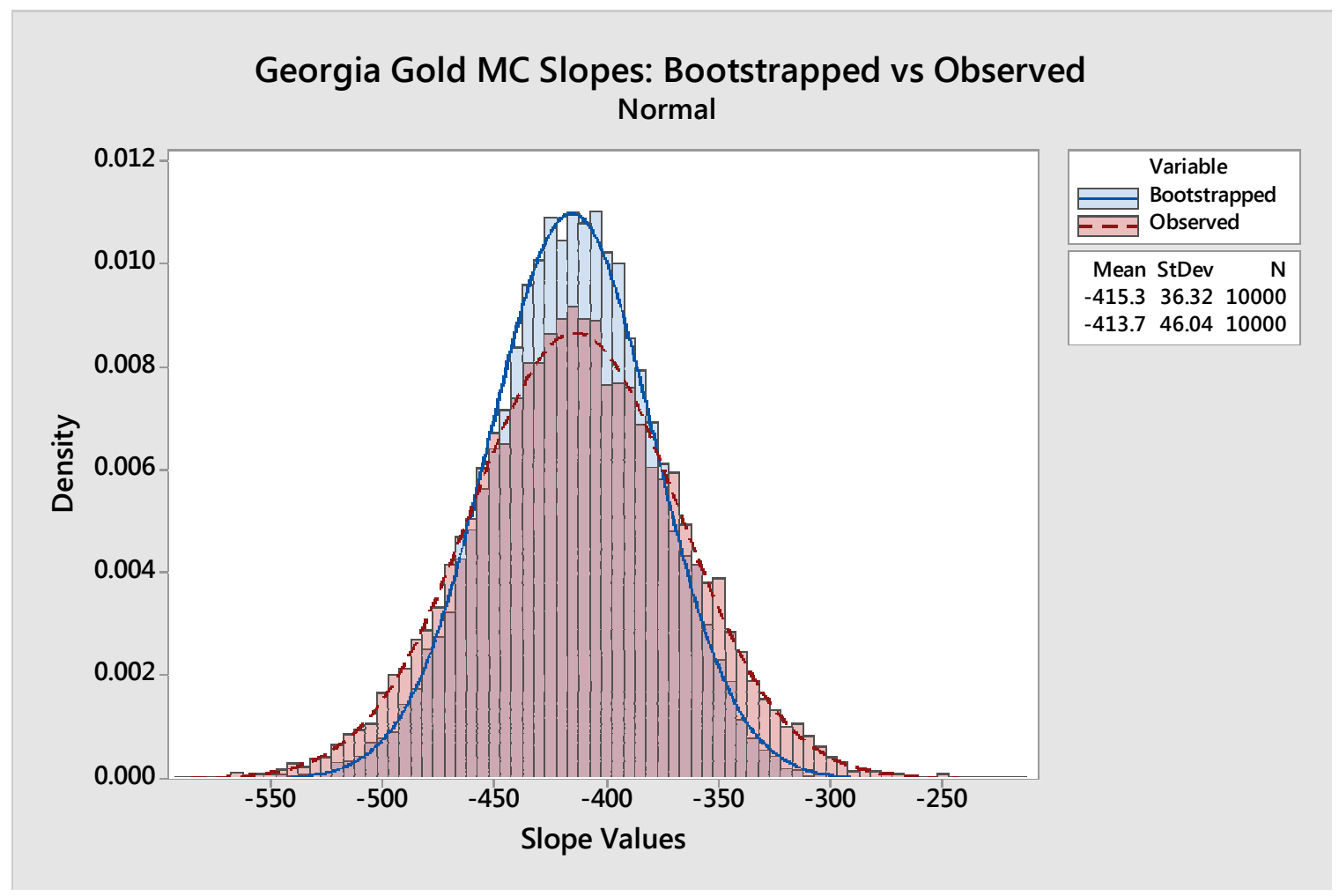

Figure 29. Georgia Silver MC Slopes Bootstrapped vs Observed

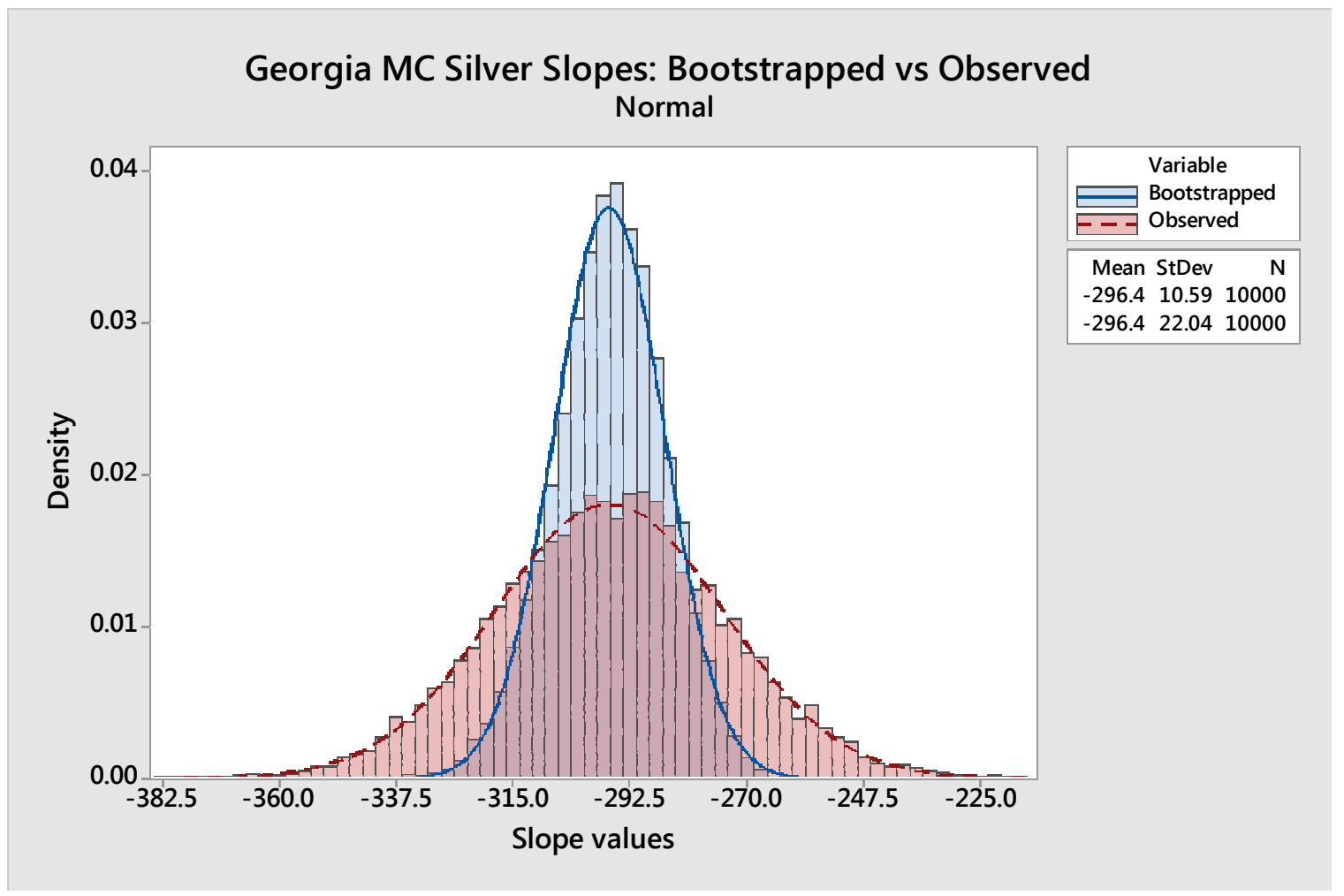


Figure 30. Georgia Bronze MC Slopes Bootstrapped vs Observed

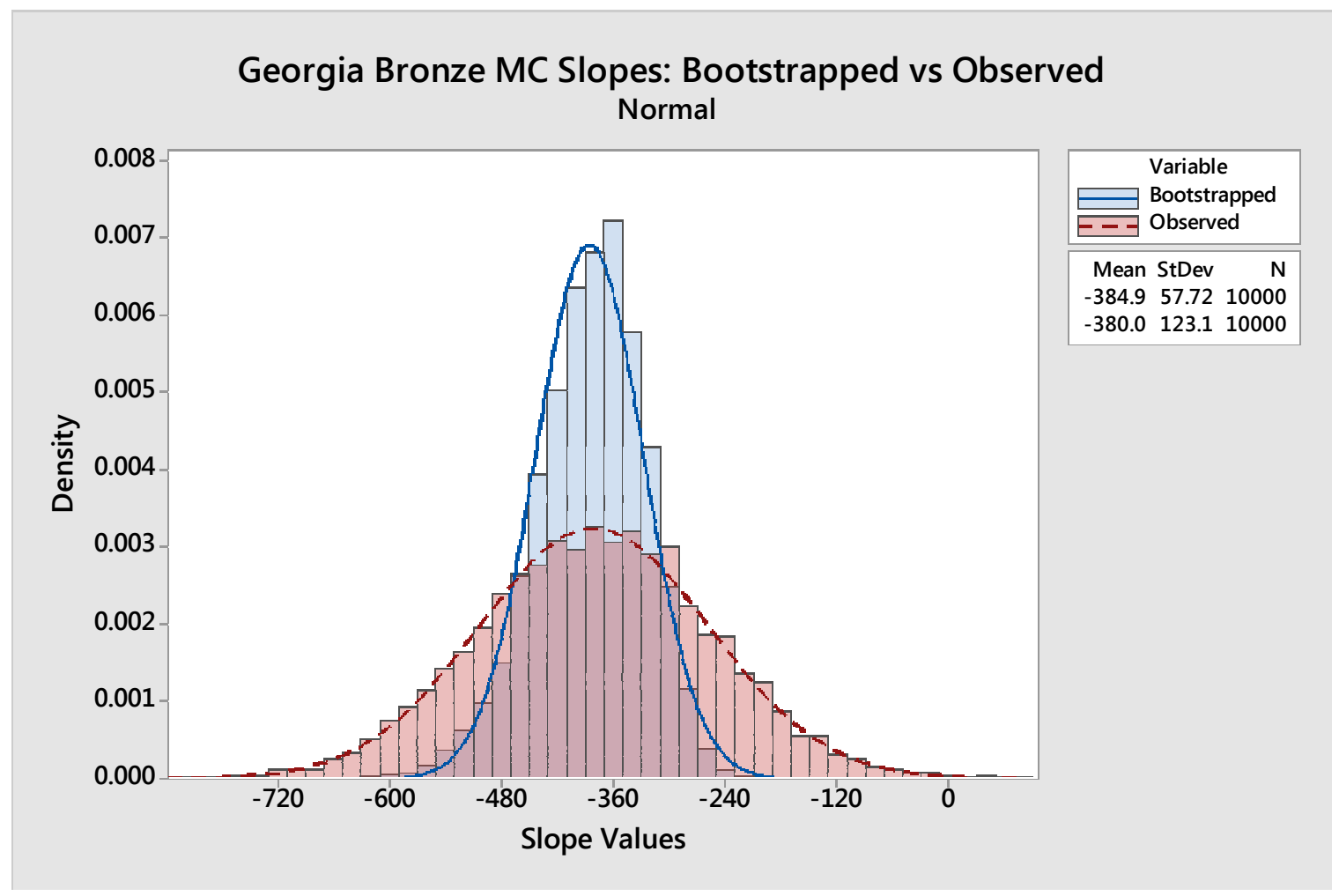

Figure 32 illustrates the financial impact of the claims costs outliers. The first population bin (the far left of the graph) shows that incorrectly predicting the costs (outside the standard error) resulted in a $\$ 17$ million difference. The second population bin resulted in $\$ 2$ million of unexpected costs. The payment transfer amount received through risk adjustment did not cover these unexpected financial losses. 


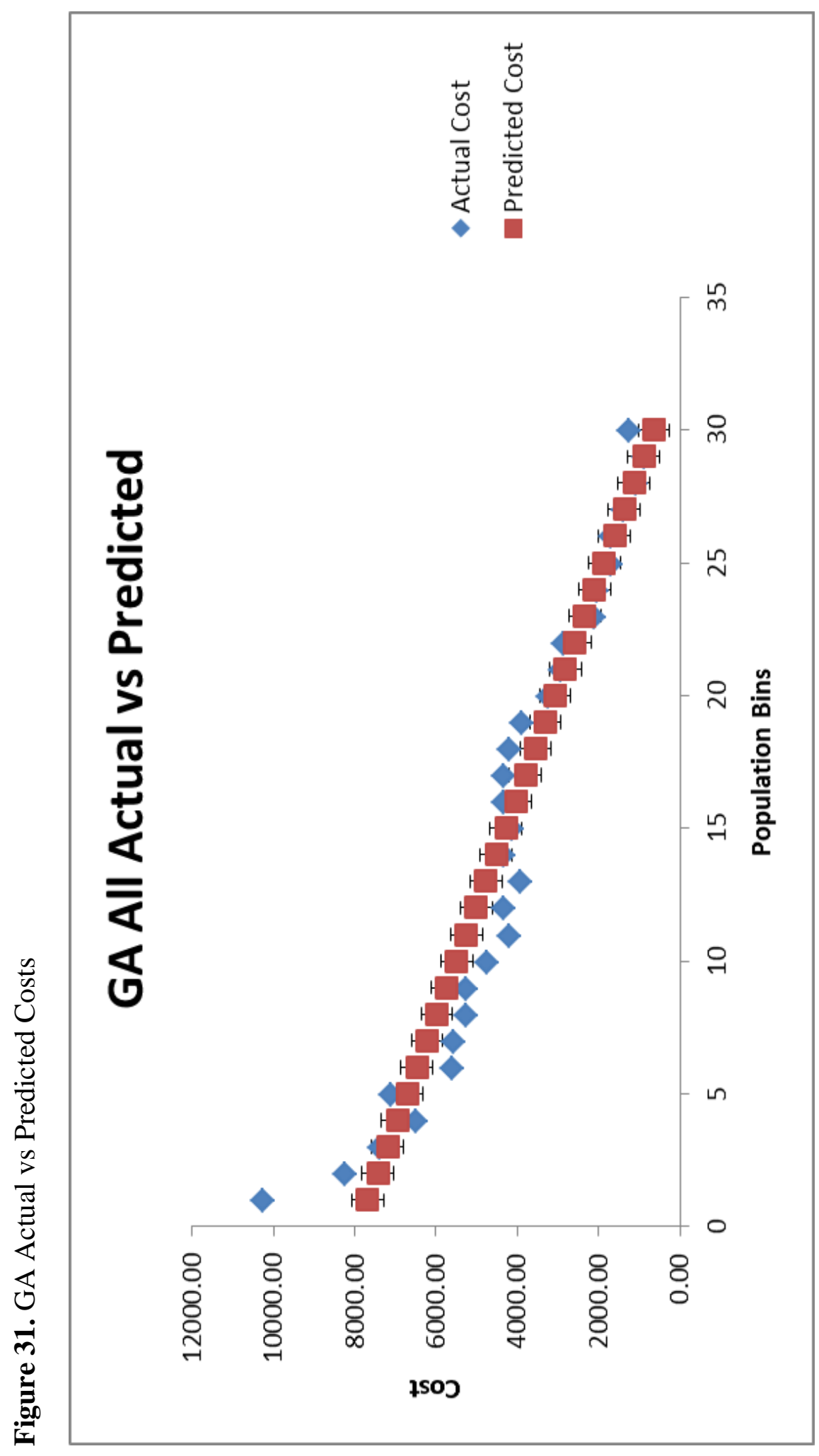




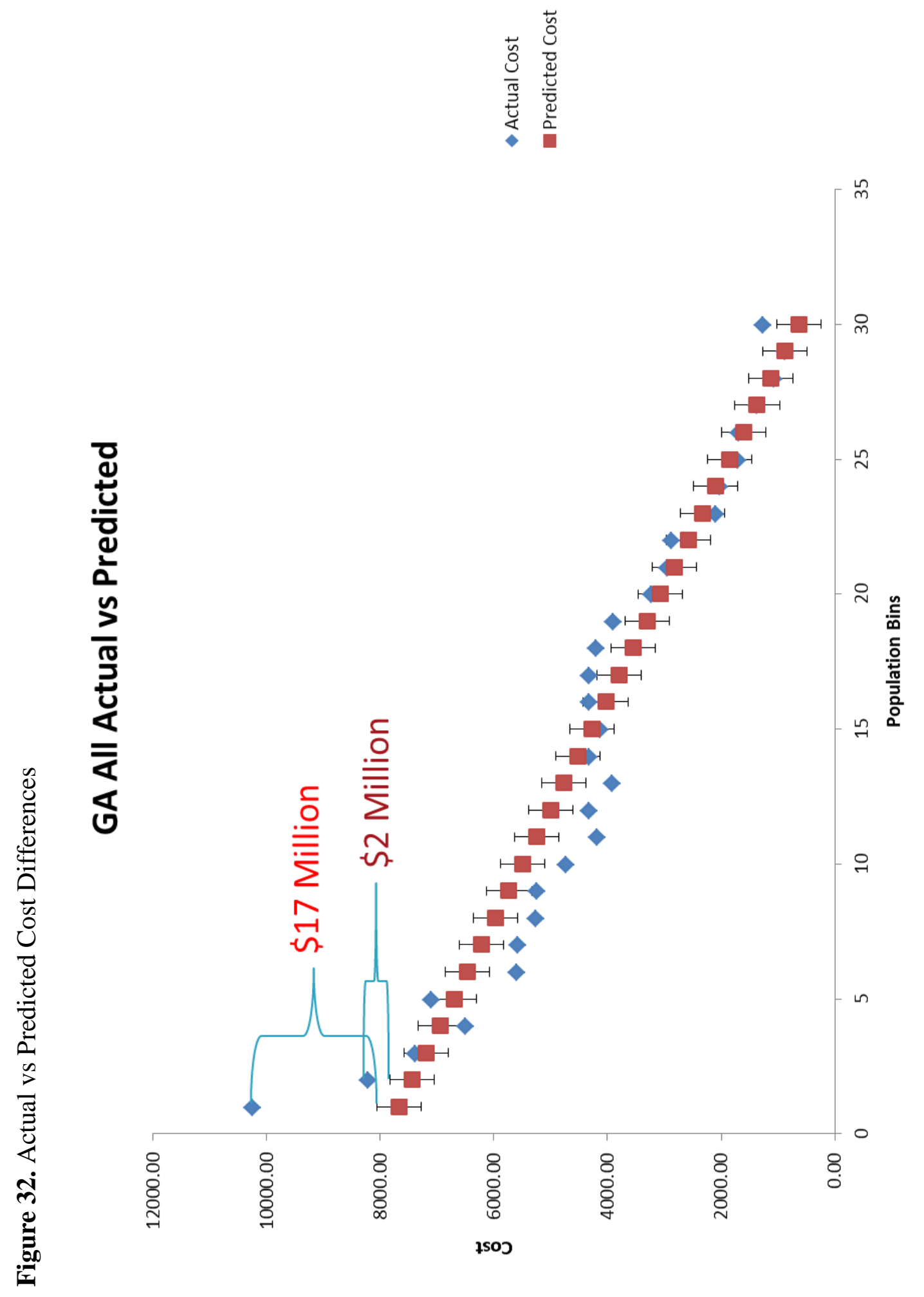




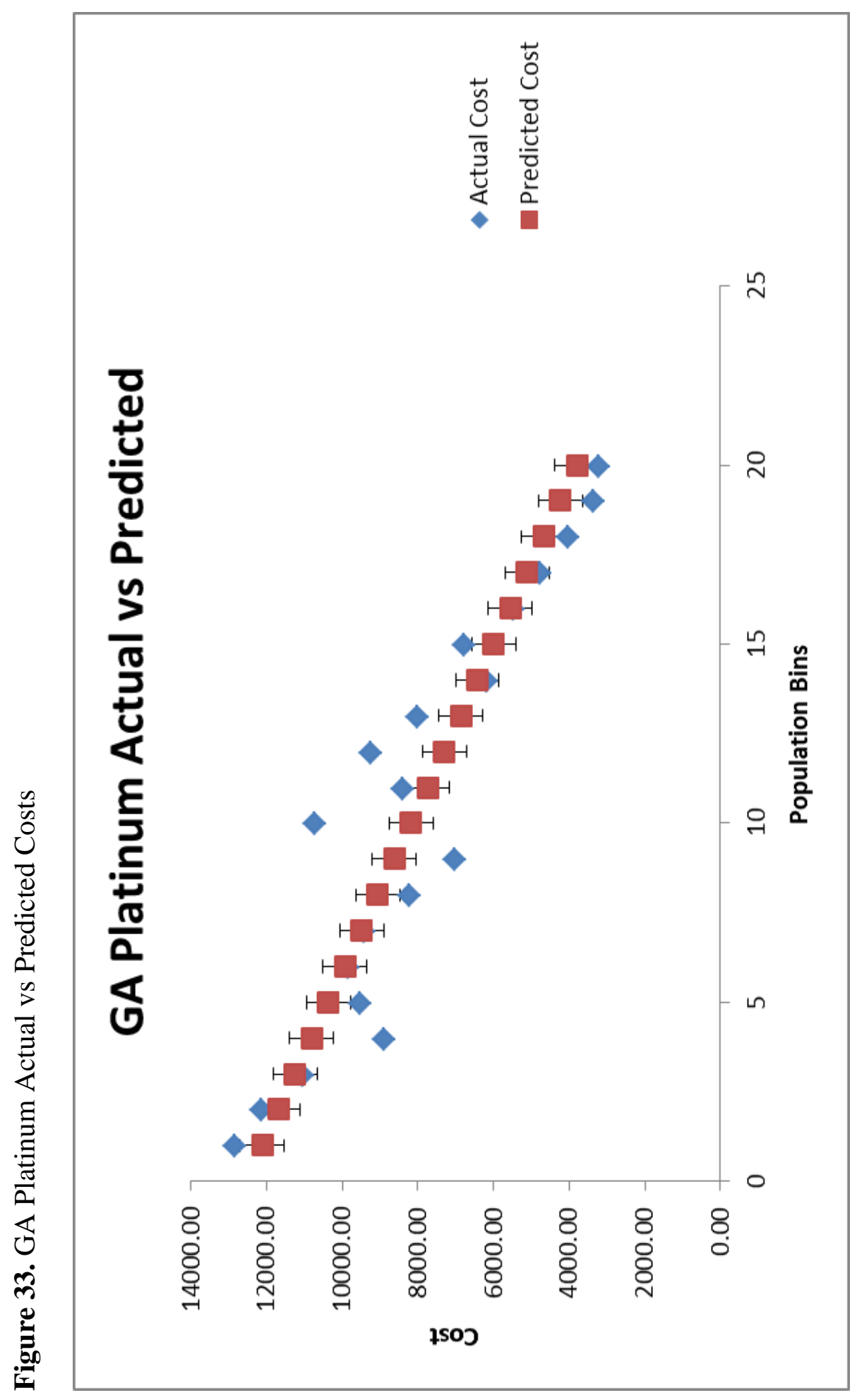




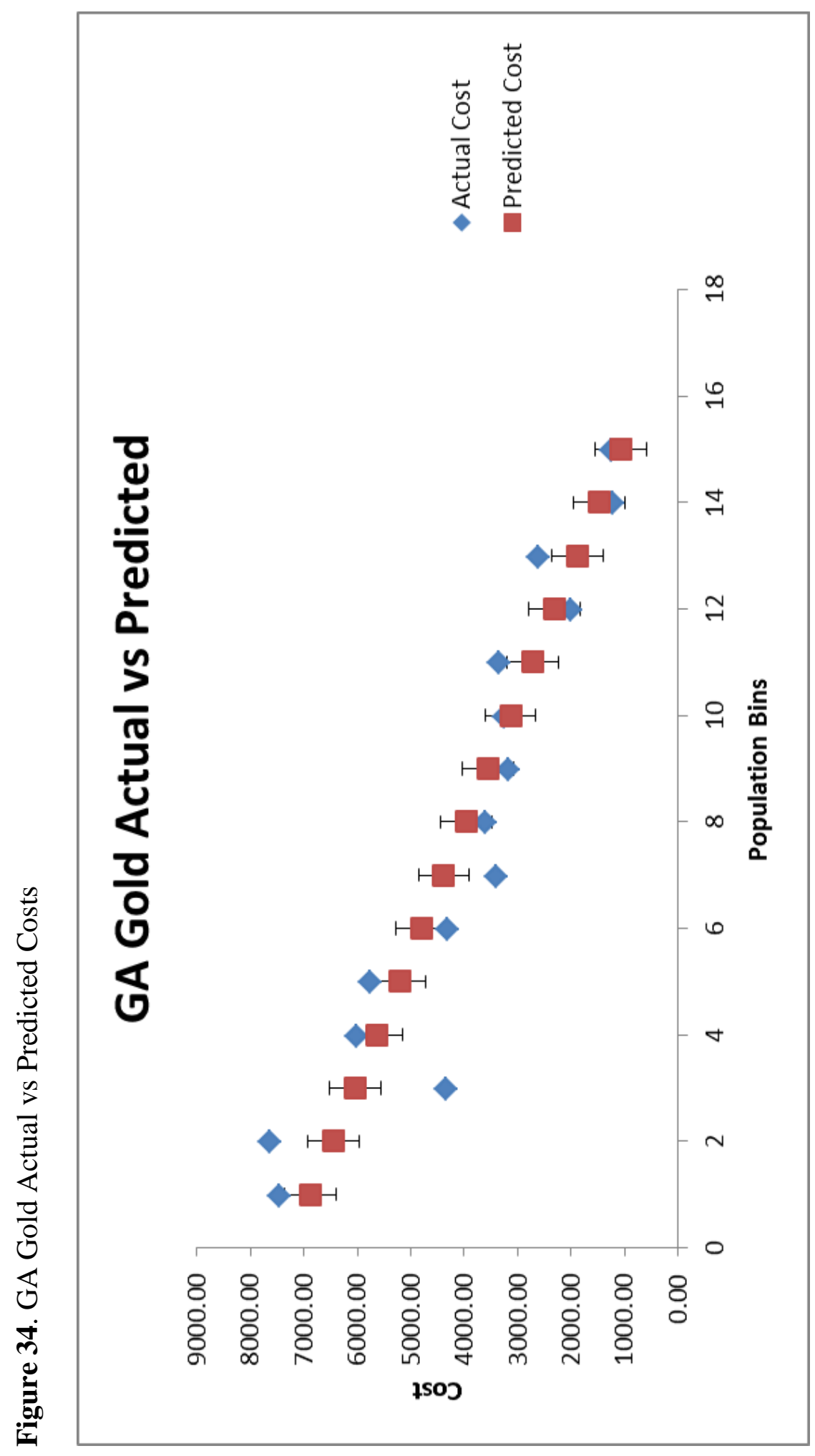




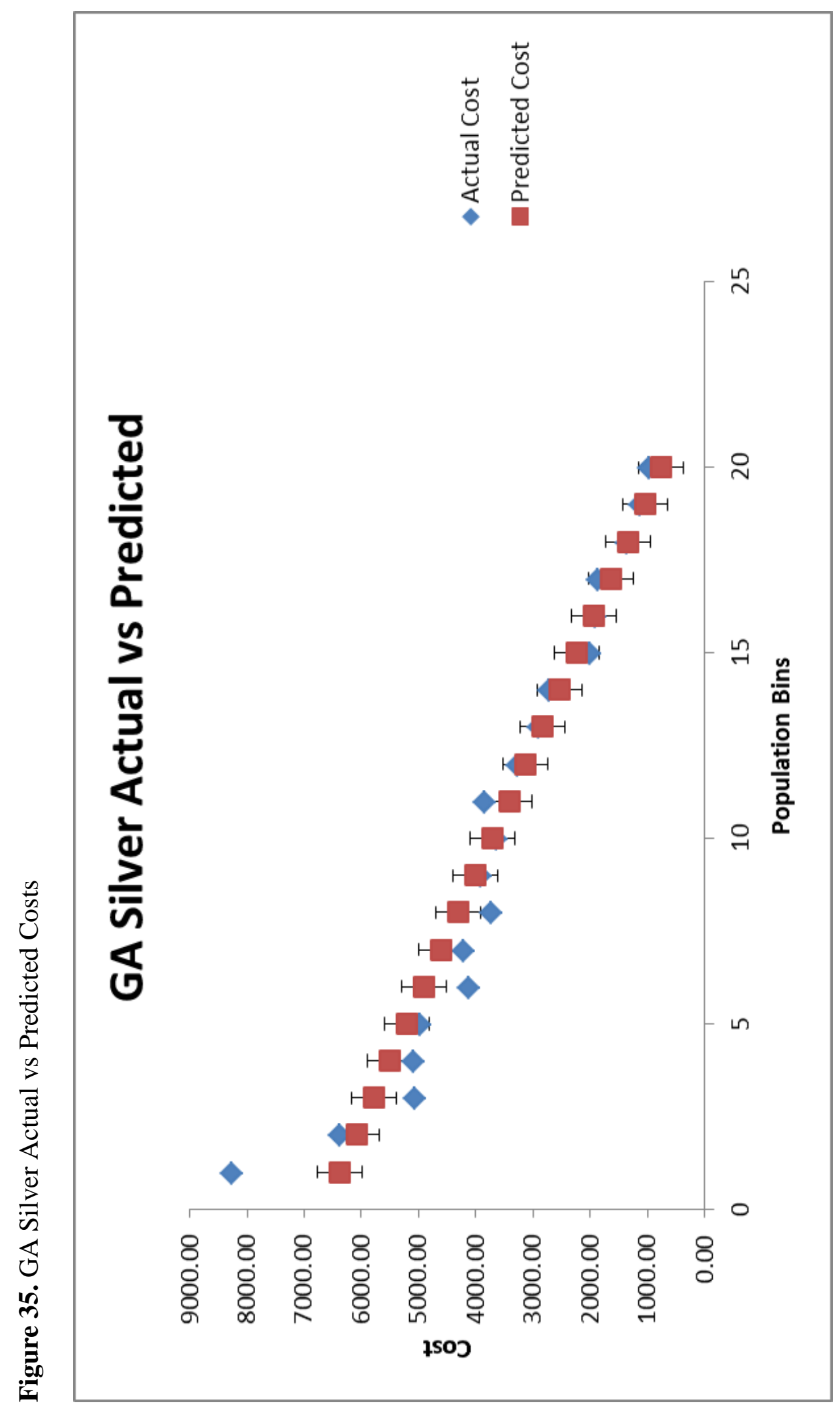




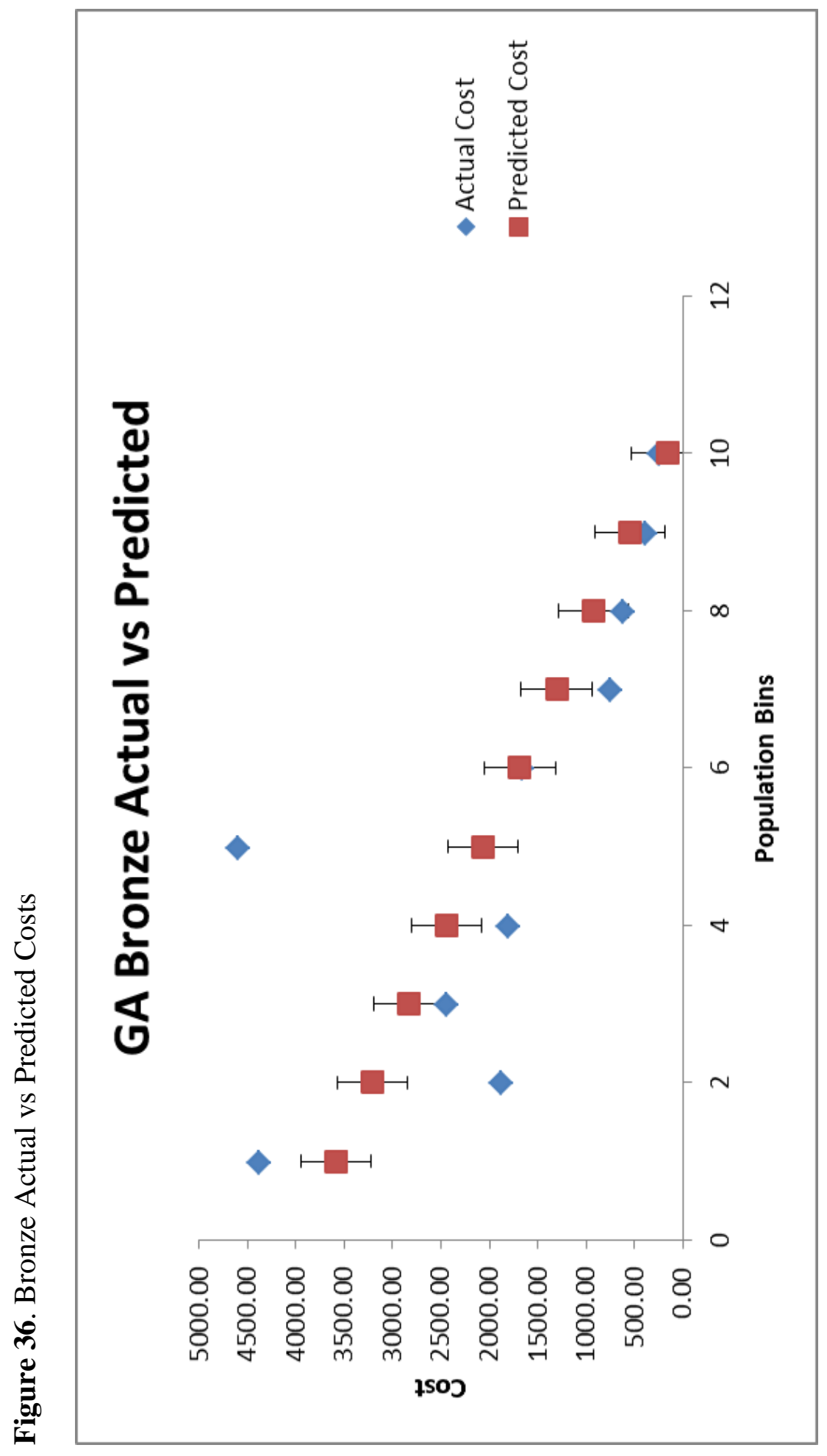


To overcome adverse selection, insurers want to strive for a constant marginal cost. Since costs are estimated for a community, insurers expect an average cost for that community. The constant marginal cost can be represented by a flat MC curve see in Figure 37. This flat MC curve would indicate that individuals are purchasing health insurance plans more consistent with their true health costs.

Figure 37. Constant MC Curve

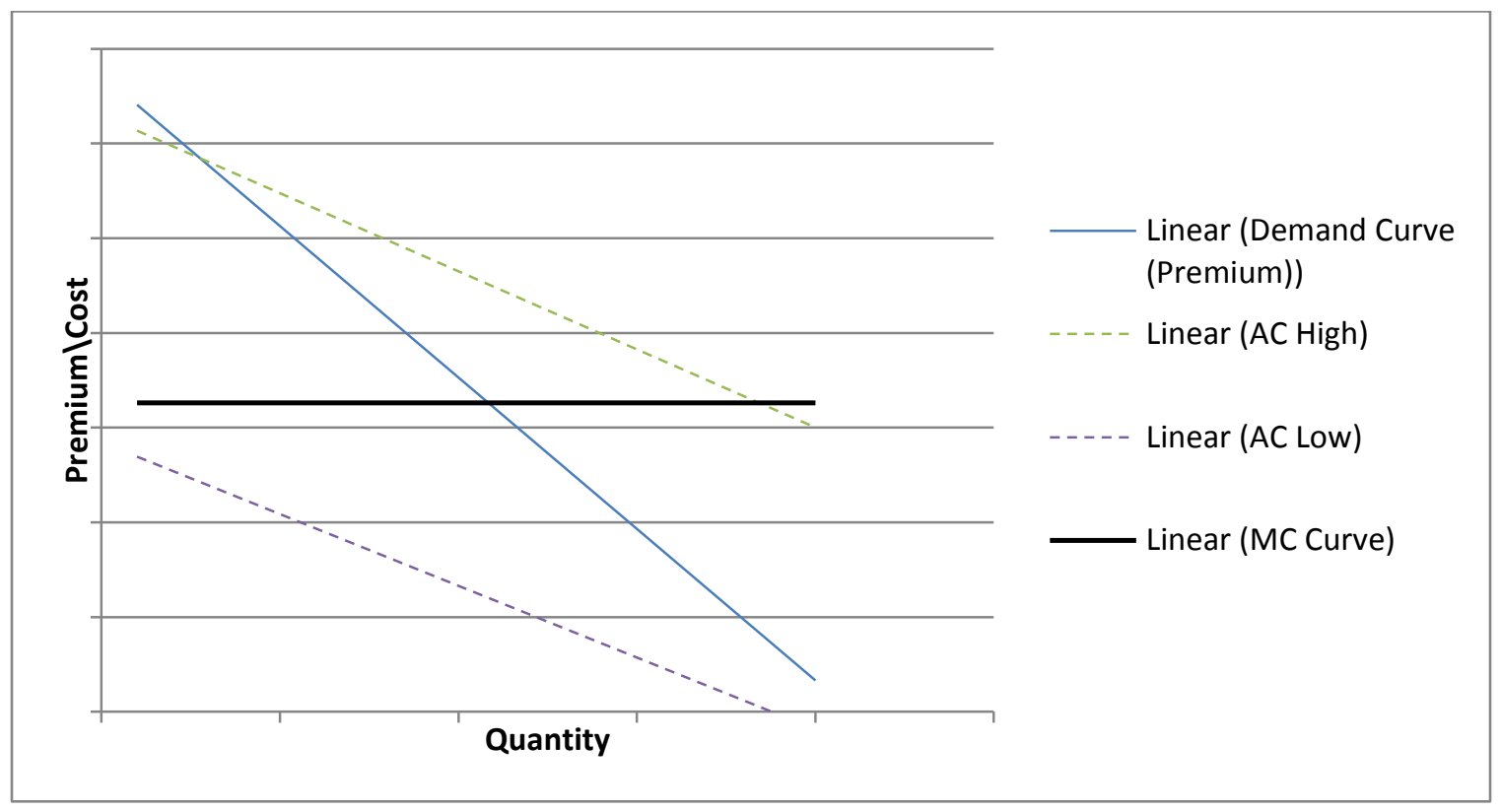

\section{Drivers of Adverse Selection}

As stated in previous chapters, the prevailing catalyst of adverse selection is information asymmetry. However, it is possible that there are those individual that do not fully understand their risk behavior or their expected health costs and may not purchase the plan that coincides with those risks. If a person who constantly refuses to go to the doctor for what they believe to be a nagging ailment but eventually requires inpatient 
surgery, that person has overvalued their health risks and undervalued their health costs and thus purchases the wrong plan (possibly purchases a bronze plan instead of a silver plan or silver instead of gold). This dissertation labels this circumstance as uninformed asymmetry since the individual is truly uninformed about their health risks or health needs. Essentially, uninformed asymmetry is an individual's inability to accurately estimate their expected health costs.

While individuals ultimately purchase insurance based on their perceived needs, other factors contribute to insurers being adversely selected. One of the possible drivers of adverse selection realized in the study, at least for some states, is the number of insurers that participated, or sold insurance (especially on the exchanges) within each state. According to healthinsurance.org, the state of Mississippi had only two insurers participating on the state exchanges (Norris, Mississippi Health Insurance Marketplace, 2016). To compound matters, the participating insurers, initially, combined to only participate in about $44 \%$ of the state's counties. Eventually, one of the participating insurers offered plans state wide. However, $95 \%$ of the counties in Mississippi had only one insurer participating in anyone location, leaving many residents without a choice. It would stand to reason that if you are the only insurance option available then that insurer would expect to be adversely selected by default. In addition, The Kaiser Family Foundation reports that only about one-third of those eligible to purchase insurance on the exchanges in Mississippi actually purchased insurance on the exchange. This places Mississippi in the bottom-third of states based on eligible individuals participating in the exchanges. This would lend itself to the conclusion that those who perceived a need for insurance are the ones who actually purchased insurance (The Henry J. Kaiser Family 
Foundation, 2015). Two-thirds of those that purchased a plan on the Mississippi exchange belonged to the studied insurer. This is one possible reason for the demonstrated adverse selection in Mississippi.

Georgia also suffered a similar pitfall as Mississippi as only one insurer offered plans that provided coverage in all counties within the state thus limiting the options of the potential enrollees (Norris, Georgia Health Insurance Exchange/Marketplace, 2016). Another similarity to Mississippi was that only about $30 \%$ of eligible exchange enrollees actually purchased insurance through the exchange.

The state of Texas had twelve insurers selling plans in 2014 and the state had over 700,000 enrollees on the exchanges alone. The number of enrollees on the exchange in Texas was second only to Florida for those states operating a federally-facilitated marketplace (Norris, Texas Health Insurance Exchange/Marketplace, 2016). Even with a large number of enrollees, and numerous options for those enrollees, the insurer researched for this study still experienced adverse selection

In those places where there were multiple insurers, the advantage could go to the insurers with the larger shares of the market. This is due to the fact that larger insurers should theoretically align closer to the market average premium. The insurers with small market shares, comparatively, are likely to enroll either the above-average risk population or the below-average risk population. The American Academy of Actuaries stresses this point in a published report in April 2016 (American Academy of Actuaries, 2016). Table 16 , from the report, illustrates the payment transfer as percent of premium by insurer market share. 


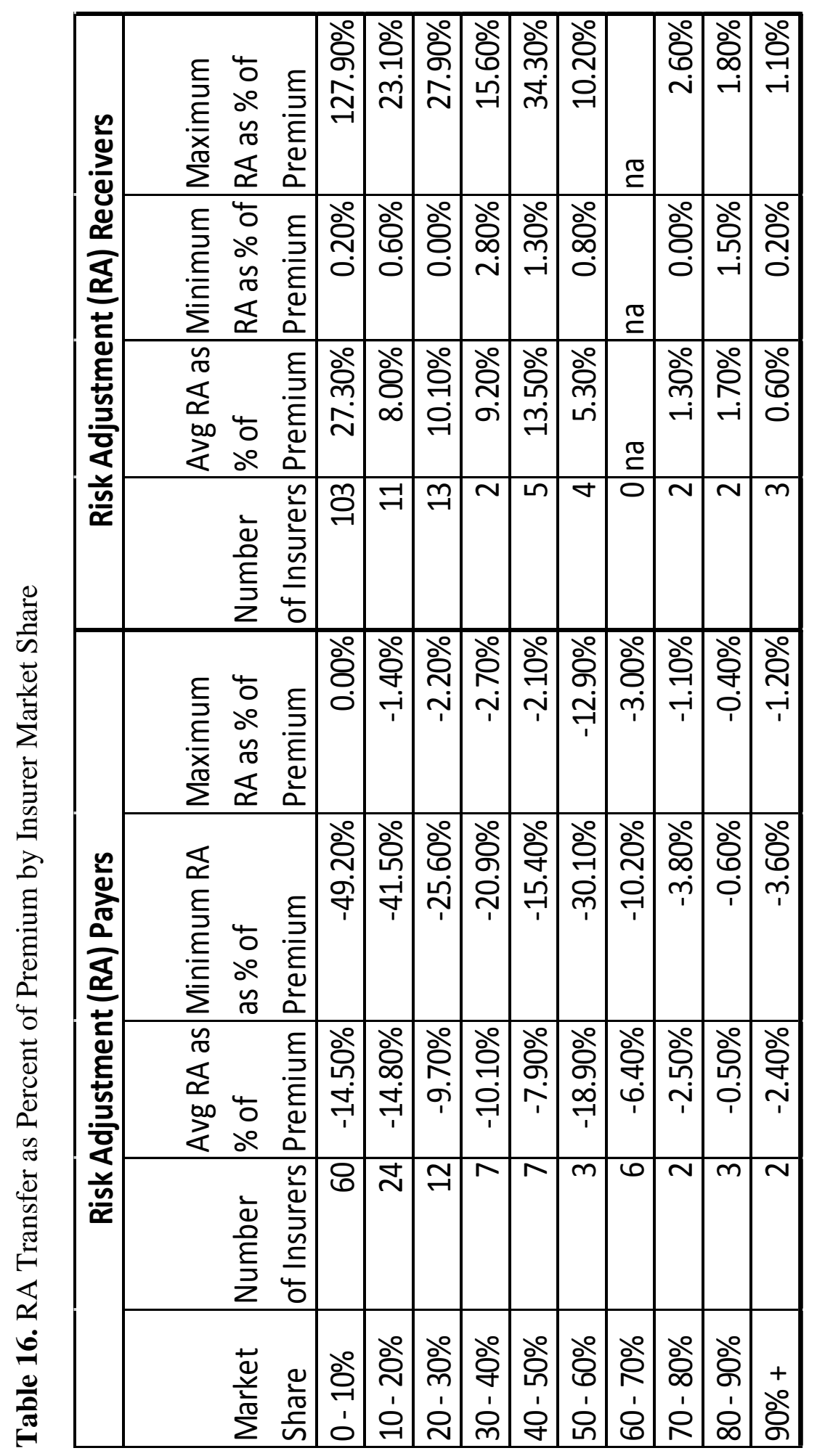


Small insurers are also impacted when large insurers are adversely selected. This means that those small insurers had many of the low-risk, low-cost individuals and the amount some had to pay out in transfer funds could be considered overwhelming (Goldstein, 2016). This situation might dissuade small insurers from participating in providing ACA coverage. The RA program is already being blamed for driving some of the small insurers out of the market (Teichert, 2016). The fear that comes with less insurers participating is that of less competition, resulting in higher pricing of products.

Notice that the largest unpredictability in Table 16 belongs to the insurers with small market share. Those small insurers with healthy members may not have received enough premium revenue to cover their portion of the transfer payment. Conversely, those insurers with the larger market shares that were adversely selected may not receive enough funds through the transfer payment mechanism to cover their claims costs. This situation arises because the transfer formula calculates a percentage of premiums. This can be illustrated through an example as shown in Table 17. Plan A has $70 \%$ of the market share ( 0.7 in the Market share column) and a less healthy population (indicated by a PLRS of 1.2). All else being equal, Plan B must pay out $26 \%$ of their premium per member to Plan A. However Plan A only receives $11 \%$ of their premium per member. This model relies on the PLRS to accurately reflect the incurred costs of the insurer. This is similar to the occurrence in Georgia for the studied insurer as they only received about $\$ 11$ per member to help cover the costs. 
Table 17. Payment Transfer as a Percent of Market Share

\begin{tabular}{|l|r|r|r|r|r|r|r|r|r|r|r|r|}
\hline Plan & Metal & PLRS & ARF & AV & IDF & GCF & $\begin{array}{c}\text { Market } \\
\text { Share }\end{array}$ & $\begin{array}{c}\text { Plan } \\
\text { Liability }\end{array}$ & $\begin{array}{c}\text { Avg } \\
\text { Prem }\end{array}$ & $\begin{array}{r}\text { Transfer } \\
\text { Amount }\end{array}$ & $\begin{array}{c}\text { Mrkt Avg } \\
\text { Prem }\end{array}$ & $\begin{array}{c}\text { \% of } \\
\text { Premium }\end{array}$ \\
\hline Plan A Silver & 1.2 & 1.00 & 1 & 1.00 & 1.00 & 0.7 & $\mathbf{1 1 1 . 1 1}$ & $\mathbf{1 0 0 . 0 0}$ & $\mathbf{1 1 . 1 1}$ & $\$ 100.00$ & $\mathbf{0 . 1 1}$ \\
\hline Plan B & Silver & 0.8 & 1.00 & 1 & 1.00 & 1.00 & 0.3 & $\mathbf{7 4 . 0 7}$ & $\mathbf{1 0 0 . 0 0}$ & $\mathbf{- 2 5 . 9 3}$ & & $\mathbf{- 0 . 2 6}$ \\
\hline
\end{tabular}

The potential number of insurers and the number of eligible enrollees should provide plenty of options so that the phenomenon of adverse selection does not exist. However, other options exists that move enrollees away from ACA RA plans. Specifically, this scenario exists because insurers can continue to offer "grandfathered" and "grandmothered" plans. A grandfathered plan is a plan that was available prior to March 23, 2010. These plans are not ACA-compliant but can exist indefinitely as long as the benefits and costs don't change. Grandmothered plans went into effect after March 23, 2010 but prior to January 1, 2014. These plans expire in 2017. Both of these plans would continue to remain an option for individuals if those plans were cheaper or offered a different set of benefits than those offered through an ACA plan that took effect January 1, 2014 or later. The healthy (or less risk adverse) may find these plans suit them better. By choosing one of these paternal plans an individual has removed herself from the risk pool for risk adjustment.

An unknown population and the use of market scan data to calibrate the 2014 RA model contribute to the inability to price accurately and create the potential to drive adverse selection. Given that many people, prior to 2014, chose not to purchase insurance, it was difficult to determine the health risk of those individuals and simulate their impact on the health insurance market with regards to demand in the form of premiums and impact to claims costs. HHS decided the 2010 Truven MarketScan data 
would be a suitable dataset for calibrating the RA model. Unfortunately, the MarketScan population does not accurately reflect all diagnoses when compared with ACA enrollment. A published MarketScan White Paper lists the following limitations (Adamson, Chang, \& Leigh, 2008):

- The MarketScan data is based on a large convenience sample (not random). This can lead prejudices in the data and may not estimate other populations accurately.

- The data is comprised mostly from large employer claims

In addition one year of claims experience (2010) creates the opportunity to incorrectly estimate the true value of a condition. The cost of chronic conditions could be more accurately reflected utilizing multiple years of data for calibration. Acute conditions can be more unpredictable from one year to the next and may tend to overestimate costs from one year to the next.

Finally, the condition of moral hazard is not a driver of adverse selection. However, as Einav and Finkelstein point out, it could drive a similar correlation between cost and demand resulting in the same downward slopping MC as adverse selection (Einav \& Finkelstein, 2011). Although it is different, moral hazard can be addressed through some of the same mechanisms that will address adverse selection.

\section{Review of Other 2014 RA Conclusions}

Much of the discussion to date about the 2014 RA program is divided in terms of the program's success (or lack of success). There is a lot of discussion about how the inputs into the model need to be revised. Supporters agree, that 2014 was successful but also that the program has room for improvement. Critics have had a strong voice and 
some even stating the program is having a "reverse Robin Hood effect (Goldstein, 2016)." However, the number of discussions around empirical data still remains limited. Oliver Wyman Consulting published a report in 2016 where they indicated that the ACA RA program "contributed positively toward the intended objective of allowing issuers to compete on bases other than risk selection (Giesa, 2016)." The report relies on series of graphs to demonstrate the "positive" contributions of ACA RA. The first graph correlates the ACA temporary Reinsurance payments ${ }^{17}$ to insurers with the riskadjustment payment transfers for those insurers. This data is published by CMS in their yearly Payment notice ${ }^{18}$. Recall that the ACA Reinsurance (RI) program reimburses insurers for claims costs at the enrollee level for claims costs between $\$ 45,000$ and $\$ 250,000$. By definition these members are high cost members and one could infer (without too large of leap) that insurers receiving a large RI payment had a high risk population and would likely to receive a transfer payment through RA. The Wyman report acknowledges that this is not a surprise. The graph, as presented by Oliver Wyman, is illustrated in Figure 38.

Unfortunately, Figure 38 alone, (nor the narrative provided around the graphical analysis) does not provide details around, or infer, the positive contributions of RA. Given that RA is a zero-sum game, it would be surprising if this graph produced results much differently than what is currently being displayed. In this instance it would be helpful to see the RI payments per member per month (PMPM) plotted against Premium PMPM to see if these high cost members paid a high premium. This would allow the EF

\footnotetext{
${ }^{17} \mathrm{PMPM}$ in the graph refers to per member per month

18 The payment notices for RI and RA are published in the same report and are published on June $30^{\text {th }}$ for the previous calendar year.
} 
test for adverse selection to be applied. This particular graph does not necessarily validate that RA is working as intended.

Figure 38. Risk Adjustment Receipts versus Transitional Reinsurance ${ }^{19}$

\section{RISK-ADJUSTMENT RECEIPTS PMPM \\ $\$ 400$}

$\$ 300$

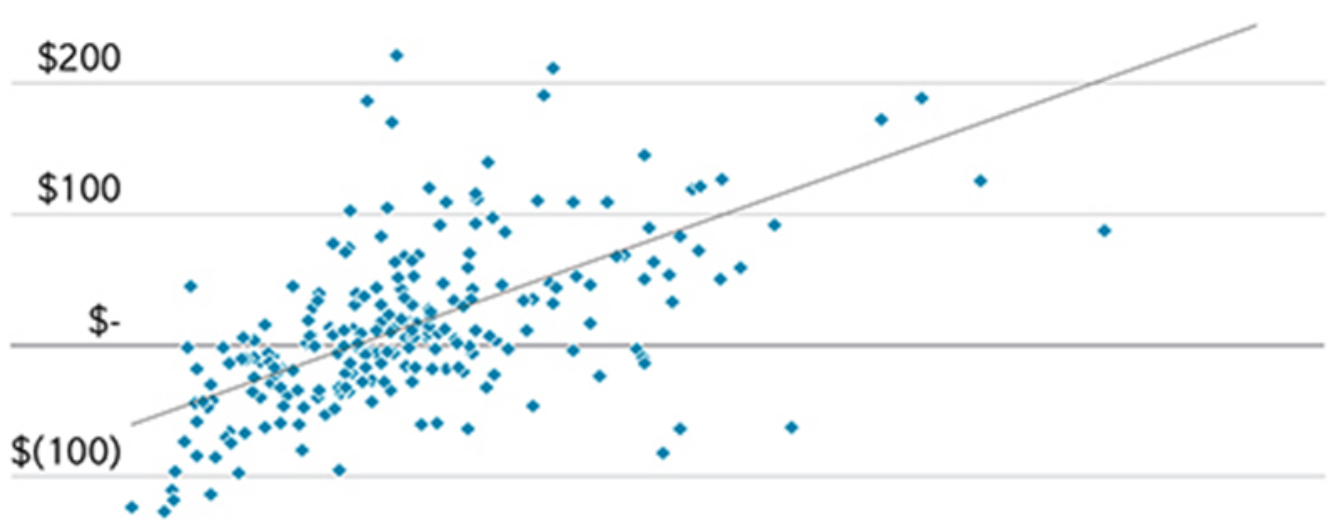

$\$(200)$

\$- $\quad \$ 50 \quad \$ 100 \quad \$ 150 \quad \$ 200 \quad \$ 250 \quad \$ 300 \quad \$ 350$

TRANSITIONAL REINSURANCE RECEIPTS PMPM

In the second graph provided by Oliver Wyman, RA payments are plotted by insurer size based on ACA member months. The Wyman report contends that there was not a "systematic bias based on member months" and attempts to illustrate this in Figure 39. Again, it appears that the requisite premium is needed to validate this analysis. In addition claims costs should also be included to provide a complete picture of the insurer's total costs for the member (claims costs + risk adjustment receipts). The third

\footnotetext{
${ }^{19}$ Oliver Wyman uses the term Risk Adjustment Receipts to refer to the RA transfer payment
} 
Wyman graph, seen in Figure 40, displays transfer payments relative to the statewide average claims. Figure 40 provides some insight into the effectiveness of the payment transfer formula. Unfortunately, the figure does not provide the correlation of the claims costs to the risk scores. Claims cost is a good data element to evaluate when reviewing the RA model. However, a more telling graphical story might be the correlation between risk scores and claims costs. Given that risk scores (and not claims costs) are inputs to the payment transfer, this correlation could contribute to validating the risk scoring methodology. Without this analysis, Figure 40 falls short in validating the contributions of the ACA RA program. At the most simplistic level, the formula to determine effectiveness of RA should be: [Premium - (Costs - Transfer Payment)]. This would be needed to wholly understand the true impact of insurer size on the model. Recall the State of Georgia from the previous chapter. There is clearly a case to be made for insurer size in the RA model when given a state with few options. The simple formula above does not validate if an insurer was adversely selected. The formula does provide insight into how the insurers were impacted financially. 
Figure 39. Risk Adjustment Receipts by Issuer Member Months

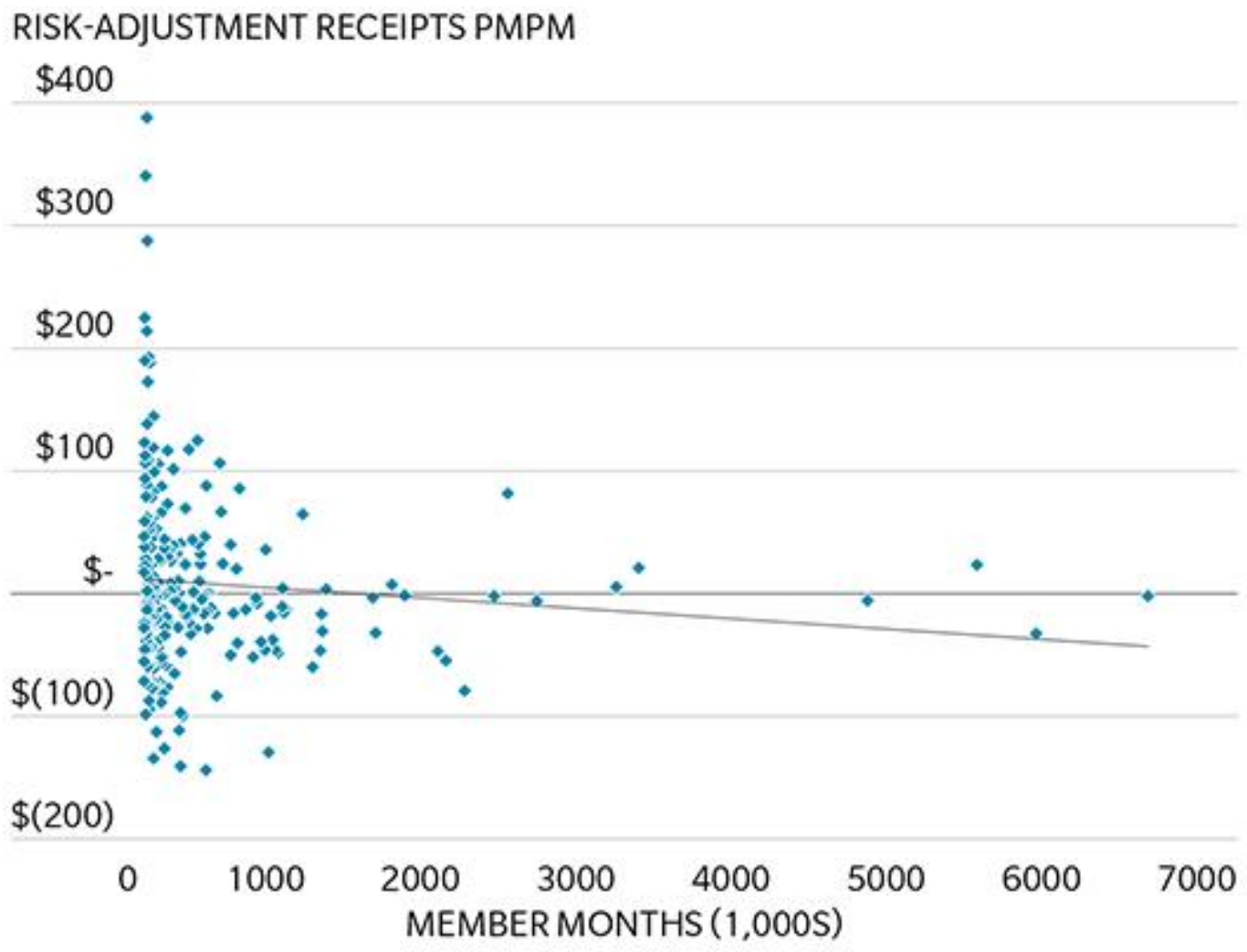

Source: Oliver Wyman analysis

oliverwyman.com

The Oliver Wyman report does provide some useful information at a glance when reviewing the impact of ACA RA in 2014. There are some improvements to be made on their analysis though. Given that adverse selection is relies heavily on pricing and available options, premium must be included where possible. It can be assumed there exists a strong correlation between claims costs and risk scores but those should also be included to strengthen the state-wide claims analysis. An insurer with a low number of member months translates into small insurer population or market share. 
Figure 40. Risk Adjustment Receipts vs Distance from State-Wide Average Claims

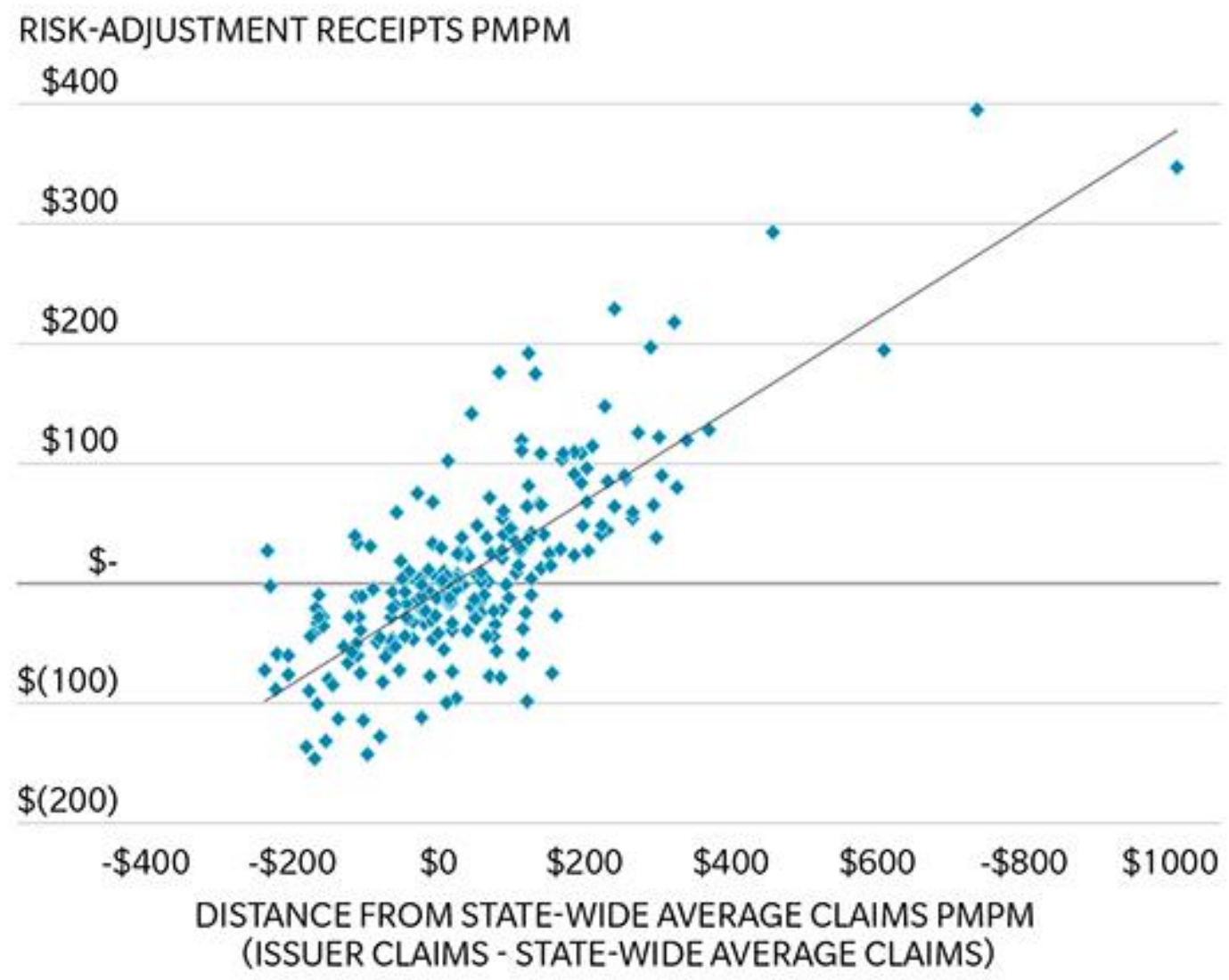

Source: Oliver Wyman analysis

oliverwyman.com

Other issues have been raised regarding the introductory version of the ACA RA program including the scoring of HCCs, the impact of market average premiums, high cost and low cost plans when calculating the transfer formula, and the timing of final risk adjustment determination (CHOICES, 2015).

The Risk Adjustment Payment Transfer Report provided by CMS was delivered on June $30^{\text {th }} 2015$. Until this report was available, insurers did not have visibility into the state markets outside of their enrollees. The payment transfer report provides market averages which, during 2014, were not made available by CMS. The ability to see the 
state average risk scores allows insurers to understand how they compare with the rest of the state. This is important for pricing plans for the next year as well as booking financial accruals for the current year of the program. This particular issue is a recurring topic throughout ACA RA discussions (Perlman \& Liner, 2016). Given that pricing for the next year is required to be submitted to the states prior to June, insurers were unable to price their plans based on their current relative market-share and risk. Unfortunately the 2014 payment transfer data was not useful for 2016 either because many enrollees switched plans within the same insurer or even switched insurers from 2014 to 2015 creating a risk pool mix that, in some cases, was considerably different than that of 2014 . The inability to accurately price plans creates an opportunity for an insurer to be adversely selected. Many of the discussions referenced throughout this chapter are, admittedly, at the distinct disadvantage of only having the ability to use data that has been made available publicly and are unable to validate or audit that data. This dissertation has the distinct advantage of utilizing actual insurer data, albeit for only one insurer. However, the ability to utilize insurer data provides a uniquely quantitative study not readily available elsewhere.

\section{The Case for a Concurrent Model}

The current risk adjustment methodology is based on a concurrent scoring model. This simply means that the individuals are scored during the current calendar year they pay premiums and incur claims. The advantage to the concurrent model is that risk scores more accurately reflect the health status of the individual during the year coinciding with the payment transfer. Additionally, CMS adds that the concurrent model 
more accurately accounts for acute costs (Centers for Medicare and Medicaid Services, 2016). Seth Chandler, in an article published by Forbes, argues that this approach does little to incentivize an insurer to control costs (Chandler, 2016). Instead, he posits, the insurer can pass the costs along to the other insurers via a payment transfer.

The ACA model is different than the Medicare prospective model. The prospective model utilizes previous year's claims data to predict an individual's risk for the current year. The Medicare Risk Adjustment program includes only those members who have purchased a Medicare Advantage (MA) plan through a private insurer. However, these individuals are still Medicare enrollees and CMS can easily track individuals as they move from one plan or insurer to another. Individuals purchasing an ACA plan are enrollees of that insurer, not the government and no personal data (including diagnoses or conditions) is passed on to CMS for risk scoring purposes ${ }^{20}$. This is an important distinction in the two models. Given this difference, enrollees would be impossible to track as they move across the ACA insurer landscape. For this reason alone, implementing a prospective model would impossible.

\section{Impact on Insurers}

CMS, in their 2016 White Paper, says, "Each insurer's premiums should reflect anticipated risk adjustment transfers and therefore in effect the risk of the entire market risk pool, not just the risk of its enrollees." This is a great theory but by making this statement, CMS is indicating that insurers should have complete knowledge of the market risk pool. Insurers may have this capability after participating several years in the ACA

\footnotetext{
${ }^{20}$ Insurers are required to submit enrollees with a unique identifier that is unique to the insurer. No personally identifiable information is submitted to CMS for risk adjustment purposes.
} 
RA program but new insurers wishing to enter the market would be at a disadvantage having not been exposed to the market population. The same is true for small insurers if we are to consider that the smaller insurers attract the high-risk or low risk populations disproportionately to the market average. It might be more difficult for those smaller insurers to understand the true risk of the market in order to price accordingly. Even in a concurrent model, there should be a mechanism to allow for Hierarchical Condition Categories (HCC), at the very least, to move with the enrollee. In order for risk adjustment to avoid adverse selection, individuals need to understand their true health risks. It would be beneficial if the states had some health knowledge of those purchasing insurance. This would allow individuals to be guided to the appropriate metal plans so that they are absorbing the costs associated with health risks. Individuals cannot efficiently sort themselves into the correct plans as evidenced by the results of this study. There should be some effort in the form of public policy to help guide individuals into the correct type of plans. In addition, insurers need to receive more timely information about the market risk pool (not just their risk pool) if CMS is suggesting they should price for the entire market. The cycle of insurers pricing on outdated information and individuals self-selecting into plans (based on old or no data) may result in insurers moving away from offering ACA plans. This leaves fewer options for the consumer and more of a risk for the insurer if they take on more unhealthy individuals.

\section{Strengths of the Study}

The strength of this study relies heavily on the access to data for the insurer being examined. Additionally, confidence of this study can be attributed to the ability to 
examine the price versus cost relationship and to graphically represent the outcome of adverse selection. To date, there does not appear to be any other such research available utilizing actual ACA data in this manner. To validate the findings the bootstrap analysis was conducted and confirmed the results of the study which support the null hypothesis.

\section{Limitations of the Study}

There are limitations to the study conducted in this dissertation. The first limitation is that this study was done in the inaugural year of the ACA Risk Adjustment program. There were no known ways to accurately identify the health mix of those individuals, especially the previously uninsured, coming into the health insurance market. The study would be strengthened by observing the program over several years to determine if insurers have a better understanding of the health risk of the populations within the states they serve and if they are able to stabilize the premiums in those states.

The study could also be strengthened given the ability to incorporate more than one insurer into the research. The ability to see what other insurers experienced in the way of selection patterns would help determine if adverse selection is a systemic problem

or only problematic for certain insurers in certain states. While incorporating more than one insurer into the research would be beneficial, most insurers would be hesitant to share proprietary data that would allow a multiple issuer analysis to be completed.

Lastly, the study described in this dissertation only included paid claims as the as the incurred costs of the insurer. The study may have benefitted from including administrative costs associated with running the risk adjustment program.

Adverse selection did exist prior to 2014 in the health insurance market and to ameliorate this phenomenon the current ACA risk adjustment model was implemented. 
However, the initial year of the program did not, for the states reviewed in this paper, address the issue.

\section{Recommendations for Future Research}

The sole purpose of this paper was to determine if risk adjustment protected one insurer from being adversely selected. However, there are numerous opportunities to extend this study. The research conducted in this dissertation could easily be extended to examine welfare loss and equilibrium as theorized and discussed extensively by Einav and Finkelstein. Another logical extension of the study would be the application of Glazer, McGuire and Shi's methodology to examine equilibrium and efficient sorting. Efficient sorting places individuals the best plan based on their expected costs.

Future research should also include multiple years of risk adjustment data. There are various unknowns that will occur from year to year even for one insurer. The insurer's population is likely to change especially as the insurer tries to correct or align pricing based on the previous year's population. Also, it is unknown what other insurers will do in terms pricing and participation.

The intricacies of the Risk adjustment program, the unknown risk pool, and the difficulties in pricing plans create a difficult environment for smaller insurers and new insurers wanting to participate in the individual marketplace.

\section{Conclusion}

CMS indicated, in its Executive Summary in the 2016 White Paper on Risk Adjustment, that "The Affordable Care Act established a permanent risk adjustment 
program to minimize the negative effects of adverse selection... (Centers for Medicare and Medicaid Services, 2016)." In that same white paper CMS concluded that "the initial findings from benefit year 2014 indicate that, in general, the HHS risk adjustment methodology is working as intended (Centers for Medicare and Medicaid Services, 2016)." The findings in this dissertation provide empirical evidence that the program is not working as expected in all cases. Fortunately, large insurers can overcome adverse selection in some cases by covering their losses in one or more markets through other revenue streams. Smaller insurers do not necessarily enjoy that same advantage. Risk adjustment cannot work as intended if the consumer only has one or two options. There should be enough options to help spread the financial risk of insuring the less healthy enrollees. In addition the program cannot work as efficiently as possible if individuals are not enrolled in the correct plan that aligns with their risks. Public policy is needed to help drive individuals to the correct plans. If individuals are enrolled in the best plan choice based on their health risks, more insurers may be willing to participate in the marketplace. The concurrent model can be used successfully. To sustain this model, CMS should begin utilizing ACA RA data for calibration. If CMS is suggesting insurers set pricing based on the entire risk pool of the market then those enrollees in the market should be used in the calibration of the model. In addition, there should be consideration for the possibility of HCCs to follow enrollees who switch insurers in a calendar year. Finally, in lieu of a timely final payment notice, CMS should provide interim market reports that detail the state average risk scores and state average premiums to allow insurers to price plans accurately for the upcoming year. 
Adverse selection is not the problem in health care insurance; it is the product of information asymmetry and uninformed asymmetry. Risk adjustment may be the right solution but may need more time to mature. Only as the markets mature and insurers understand the market landscape will the MC start to flatten out. They need timely feedback from the government to price their plans accurately. HHS needs more data to calibrate the models accurately. Finally, individuals need more information to make informed decisions about their expected health care costs. Individuals, without some direction, can still make the wrong decision - either purposely or not. However, over time insurers, HHS, and individuals will have more information to make informed decisions. 


\section{REFERENCES}

Adamson, D. M., Chang, S., \& Leigh, H. G. (2008). Health Research Data for the Real World: The MarketScan Databases. Ann Arbor: Thomson Reuters.

Akerlof, G. (1970). The Market for 'Lemons': Quality Uncertainty and the Market Mechanism. Quarterly Journal of Economics, 488-500.

American Academy of Actuaries. (2016). Insights on the ACA Risk Adjustments Program. Washington D.C.: American Academy of Actuaries.

American Academy of Actuaries' Life Valuation Subcommitte. (2008). Credibility Practice Note. Retrieved December 3, 2015, from American Academy of Actuaries:

http://actuary.org/files/publications/Practice_note_on_applying_credibility_theory _july2008.pdf

Andersen, R. M. (1995). Revisiting the Behavioral Model and Access to Medical Care: Does it Matter? Journal of Health and Social Behavior, 36, 1-10.

Buchmueller, T. C. (2006). Consumer Demand for Health Research. Retrieved January 2016, from The National Bureau of Economic Research: http://www.nber.org/reporter/summer06/buchmueller.html

CDC. (n.d.). Classification of Diseases, Functioning, and Disability. Retrieved June 1, 2015, from Centers for Disease, Functioning, and Disability: http://www.cdc.gov/nchs/icd/icd $9 \mathrm{~cm} . h t m$

Centers for Medicare and Medicaid Services. (2012, May 7). Risk Adjustment Payment Transfer Methodolgy. Retrieved August 4, 2013, from CMS: https://www.cms.gov/CCIIO/Resources/Files/Downloads/fm-1d-p-and-c.pdf

Centers for Medicare and Medicaid Services. (2013, August 22). 10 health care benefits covered in the Health Insurance Marketplace. Retrieved March 19, 2014, from HealthCare.gov: https://www.healthcare.gov/blog/10-health-care-benefitscovered-in-the-health-insurance-marketplace/

Centers for Medicare and Medicaid Services. (2014, March 5). Extended Transition to Afforable Care Act - Complaint Policies. Retrieved March 10, 2015, from 
cms.gov: https://www.cms.gov/cciio/resources/regulations-and-

guidance/downloads/transition-to-compliant-policies-03-06-2015.pdf

Centers for Medicare and Medicaid Services. (2015). Health Insurance Marketplace.

Retrieved 8 10, 2015, from Helathcare.gov:

https://www.healthcare.gov/glossary/health-insurance-marketplace-glossary/

Centers for Medicare and Medicaid Services. (2015). The Transitional Reinsurance

Program - Reinsurance . Retrieved 4 4, 2014, from The Center for Consumer Information \& Insurance Oversight: https://www.cms.gov/CCIIO/Programs-andInitiatives/Premium-Stabilization-Programs/The-Transitional-ReinsuranceProgram/Reinsurance-Contributions.html

Centers for Medicare and Medicaid Services. (2016). HHS-Operated Risk Adjustment Methodology Meeting. Balitmore: CMS.

Centers for Medicare and Medicaid Services. (n.d.). Grandfathered health insurance plans. Retrieved Jan 23, 2016, from HealthCare.gov: https://www.healthcare.gov/health-care-law-protections/grandfathered-plans/

Centers for Medicare and Medicaid Services. (n.d.). The 'metal' categories: Bronze, Silver, Gold \& Platinum. Retrieved 6 5, 2015, from How to pick a health insurance plan: https://www.healthcare.gov/choose-a-plan/plans-categories/

Chandler, S. (2016, April 25). Permanent ACA Risk Adjustment Is Permanently Messed $U p$. Retrieved May 2016, from Forbes:

http://www.forbes.com/sites/theapothecary/2016/04/25/risk-adjustment-is-reallyreally-important-to-obamacare-and-its-messed-up/2/\#f8b04661c754

CHOICES. (2015). Technical Issues with ACA Risk Adjustmentand Risk Corridor Programs and Financial Impact on New, Fast-Growing, and Efficient Health Plans. Boston: CHOICES.

Coverage Denied: How the Current Health Insurance System Leaves Millions Behind. (n.d.). Retrieved April 2013, from HealthReform.gov: http://www.healthreform.gov/reports/denied_coverage/index.html

David Cutler, P. E. (2012). Reducing Administrative Costs and Improving the Health Care System. The New England Journal of Medicine, 1875-1878.

Douven, R. (2004). Risk Adjustment in the Netherlands: An analysis of insurers' health care expenditures. The Hague: CPB Netherlands Bureau for Economic policy Analysis. 
Editorial Board. (2013, March 23). Sunday Review | The Opinion Pages: Report Card on Health Care Refrom. Retrieved April 1, 2013, from New York Times: http://www.nytimes.com/2013/03/24/opinion/sunday/report-card-on-health-carereform.html?_r=0

Einav, L., \& Finkelstein, A. (2011). Selection in Insurance Markets: Theory and Empirics in Pictures. Journal of Economic Perspectives, 25(1), 115-138.

Establishing Health Insurance Exchanges: An Overview of State of Affairs. (2012). Retrieved 2013, from Focus on Health Reform: http://www.kff.org/healthreform/upload/8213-2.pdf

Fishburn, P. C. (1968). Utility Theory. Management Science, 335-378.

Focus on Health Reform: Summary of New Health Reform Law. (2010, June 18). Retrieved August 2011, from Kaiser Family Foundation: www.kff.org

Geruso, M., \& Layton, T. (n.d.). Upcoding:Evidence from Medicare On Squishy Risk Adjustment. National Burea of Economic Research.

Geyer, L. (2013). Comparison between Risk Adjustment Methodologies.

Giesa, K. (2016, February 24). A Story in 4 Charts: Risk Adjustment in the Non-Group Market in 2014. Retrieved June 1, 206, from Oliver Wyman Health: http://health.oliverwyman.com/maximizevalue/2016/02/a_story_in_four_char.html

Glazer, J., \& McGuire, T. G. (2000). Optimal Risk Adjustment in Markets with Adverse Selection: An Application to Managed Care. The American Economic Review, 1055-1071.

Glazer, J., McGuire, T. G., \& Shi, J. (2014). Risk Adjustment of Health Plan to Correct Inefficient Plan Choice from Adverse Selection. Cambridge: National Bureau of Econonmic Research.

Goldstein, A. (2016, January 13). Critics say ACA 'risk' strategies are having a reverse Robin Hood effect. Washington Post.

Greenwald, B. C., \& Stiglitz, J. E. (1986, May). Externalities in Economies with Imperfect Information and Incomplete Markets. The Quarterly Journal of Economics, 101(2), 229-264.

Health and Human Services. (2012, 3 23). Patient Protection and Affordable Care Act; Standards Related to Reinsurance, Risk Corridors and Risk Adjustment. Retrieved 4 10, 2015, from Federal Register: 
https://www.federalregister.gov/articles/2012/03/23/2012-6594/patientprotection-and-affordable-care-act-standards-related-to-reinsurance-riskcorridors-and-risk

Health and Human Services. (2013, 7 23). 2014 Benefit Year Risk Adjustment HHSDeveloped Risk Adjustment Model Algorithm Software. The Center for Consumer Information \& Insurance Oversight. Centers for Medicare and Medicad Services.

Health and Human Services. (2013, March 11). Patient Protection and Affordable Care Act; HHS Notice of Benefit and Payment Parameters for 2014. Retrieved March 2013, from Federal Register: The Daily Journal of the United States Government: https://www.federalregister.gov/articles/2013/03/11/2013-04902/patientprotection-and-affordable-care-act-hhs-notice-of-benefit-and-paymentparameters-for-2014\#h-42

Health Insurance Exchanges: Long on options, short on time. (2012, October). Retrieved March 2013, from PriceWaterhouseCoopers: http://pwchealth.com/cgilocal/hregister.cgi/reg/pwc-health-insurance-exchanges-impact-and-options.pdf

HHS. (2013). Patient Protection and Affordable Care Act; Program Integrity: Exchange, Premium Stabilization Programs, and Market Standards; Amendments to the HHS Notice of Benefit and Payment Parameters for 2014. Washginton D.C.: Federal Register.

Kaiser Family Foundation. (2016). State Health Insurance Market Place Types, 2016. Retrieved 2 1, 2016, from State Health Facts: http://kff.org/health-reform/stateindicator/state-health-insurance-marketplace-types/

Kautter, J., Pope, G. C., \& Keenan, P. (2014, Sep 5). Affordable Care Act Risk Adjustment: Overview, Context, and Challenges. Medicare \& Medicaid Research Review, 4(3), p. 11.

Kautter, J., Pope, G. C., Ingber, M., Freeman, S., Patterson, L., Cohen, M., et al. (2014). The HHS-HCC Risk Adjustment Model for Individual and Small Group Markets under the Affordable Care Act. Medicare \& Medicaid Reserach Review, 4(3), E1E46.

Keckley, P., Coughlin, S., Korenda, L., \& Rice, E. (2011). The Impact of Health Reform on the Individual Insurance Market: A Strategic Assessment. Retrieved 2013, from http://www.deloitte.com/assets/Dcom-UnitedStates/Local Assets/Documents/Health Reform Issues 
Briefs/us_chs_HealthReformAndTheIndividualInsuranceMarket_IssueBrief_1010 11.pdf

La Couture, B., \& Booth, A. (2015, January 9). The ACA's Risk Spreading Mechanisms: A Primer on Reinsurance, Risk Corridors and Risk Adjustment. Retrieved October 2015, from American Action Forum:

http://www.americanactionforum.org/research/the-acas-risk-spreadingmechanisms-a-primer-on-reinsurance-risk-corridors-a/

Lambert, J. S., \& Stevens, K. S. (2015). Massachussets Risk Adjustment Program: Executive Summary. Boston: Wakely Consulting Group.

Levitt, L., Claxton, G., \& Damico, A. (2014). How Much Financial Assistance Are People Receiving? . Kaiser Family Foundation.

Moeller, P. (2012). How the Health Insurance Mandate Penalty Will Work. Retrieved from US News: http://money.usnews.com/money/blogs/the-bestlife/2012/07/13/how-the-health-insurance-mandate-penalty-will-work

Newhouse, J. P., Price, M., Willaims, J. M., Hsu, J., \& McGuire, T. G. (2015). How Much Favorable Selection is Left in Medicare Advantage? American Journal of Health Economics, 1-26.

Norris, L. (2016, June 11). Florida Health Insurance Exchange/Marketplace. Retrieved June 2016, 2016, from healthinsurance.org: https://www.healthinsurance.org/florida-state-health-insurance-exchange/

Norris, L. (2016, April 8). Georgia Health Insurance Exchange/Marketplace. Retrieved April 2016, from healthinsurance.org: https://www.healthinsurance.org/georgiastate-health-insurance-exchange/

Norris, L. (2016, June). Michigan Health Insurance Exchange/Marketplace. Retrieved from healthinsurance.org: https://www.healthinsurance.org/michigan-state-healthinsurance-exchange/

Norris, L. (2016, May 16). Mississippi Health Insurance Marketplace. Retrieved May 2016, from healthinsurance.org: https://www.healthinsurance.org/mississippistate-health-insurance-exchange/

Norris, L. (2016, May 18). Texas Health Insurance Exchange/Marketplace. Retrieved May 2016, from healthinsurance.org: https://www.healthinsurance.org/texasstate-health-insurance-exchange/ 
OECD. (2014). OECD.Stat. Retrieved May 2014, from Organization de Cooperation et de Developpement Economiques: http://stats.oecd.org/index.aspx?DataSetCode=HEALTH_STAT

Perlman, D. J., \& Liner, D. M. (2016). Financial Analysis of ACA Health Plan Issuers. Denver: Milliman.

Pope, G. C., Bachofer, H., Perlman, A., Kautter, J., Hunter, E., Miller, D., et al. (2014). Risk Transfer Formula for Individual and Small Group Markets Under the Affordable Care Act. Medicare and Medicaid Reserach and Review, pp. E1-E23.

Roy, A. (n.d.). New McKinsey Survey: 74\% Of Obamacare Sign-Ups Were Previously Insured. Retrieved 3 12, 2015, from Forbes: http://www.forbes.com/sites/theapothecary/2014/05/10/new-mckinsey-survey-74of-obamacare-sign-ups-were-previously-insured/

Sawhney, T. G. (2012). Controlling Indirect Selection under Healthcare Reform. Chicago, IL, USA: University of Ilinois at Chicago.

Susan Mateja, F. M. (2012). Risk Adjustment - A Global Perspective.

Teichert, E. (2016, July 6). Healthy CT crumbles under ACA risk adjustment charges. Retrieved July 8, 2016, from Modern Healthcare: http://www.modernhealthcare.com/article/20160706/NEWS/160709977

The Henry J. Kaiser Family Foundation. (2015, February). State Health Facts. Retrieved November 2015, from State Marketplace Statistics: http://kff.org/healthreform/state-indicator/state-marketplace-statistics/

Von Nuemann, J., \& Morgenstern, O. (1953). Theory of Games and Economic Behavior. Princeton: Princeton University Press.

Weil, A., \& Scheppach, R. (2010). New Roles for States in Health Refrom Implementation. Health Affairs, 1178-1182.

Zhu, J. M., Layton, T., Sinaiko, A. D., \& McGuire, T. G. (2013). The Power of Reinsurance in Health Insurance Exchanges to Improve Fit of the Payment System and Reduce Incentives for Adverse Selection. The Journal of Health Care Organization, Provision, and Financing, 50(4), 255-274. 


\section{GLOSSARY}

Adverse Selection: a phenomenon where individuals who are less healthy and require health care services are the ones who purchase insurance

Community Rating: Pricing of premiums based on geographic location, and age (rather than pricing each individual based on health status or health risk)

Cost: (or Claims costs) - Amount insurer pays out for claims

Cost Share Reduction (CSR): - Subsidy based on income that helps cover an individual's out of pocket expenses

Demand: represented by the amount of money an individual is willing to pay for a service or product - in healthcare the demand is represented by the Premium

Enrollee: usually, this is any individual enrolled in a healthcare plan. For the purpose of this dissertation the Enrollee is the Subscriber.

\section{Patient Protection and Affordable Care Act:}

Premium: Monthly amount paid by an individual (the Subscriber) to maintain health insurance

Risk Pool: Population of insured individuals

Subscriber: The individual who is responsible for payment of the premium

Subsidy: Financial assistance from the government to help pay for a good or service Underwriting: Evaluation of known risk used for the purposes of pricing premiums 


\title{
UNIVERSITY OF LOUISVILLE INSTITUTIONAL REVIEW BOARD DETERMINATION
}

\author{
Human Subjects Protection Program Office \\ UN I VER S I T Y O F
O \\ MedCenter One - Suite 200 \\ $501 \mathrm{E}$. Broadway \\ Louisville, KY 40202-1798 \\ Office: 502.852 .5188 Fax: 502.852 .2164

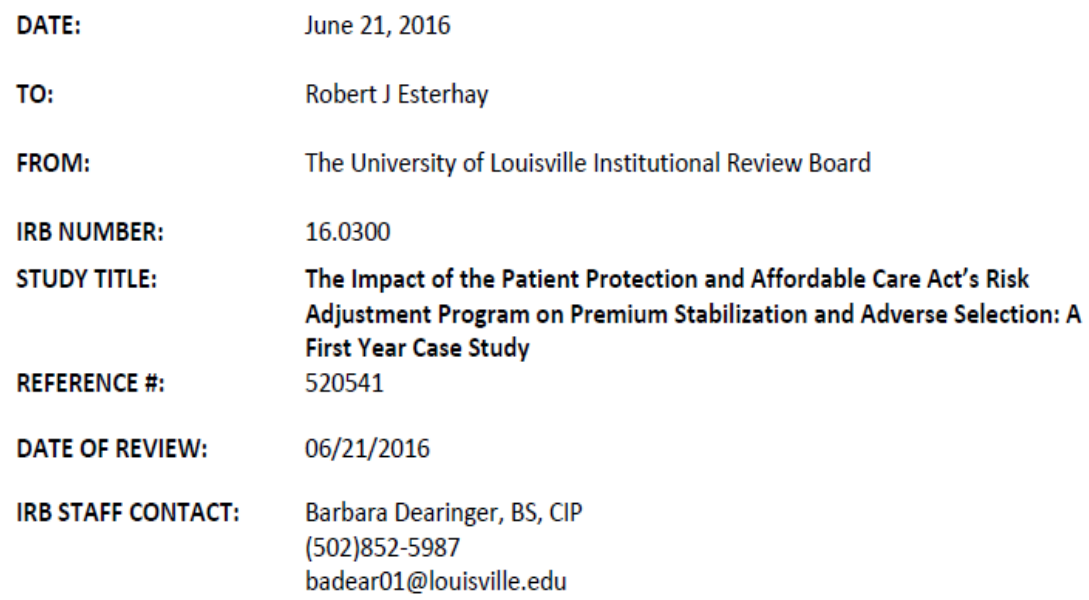 \\ The IRB Chair/Vice-Chair has reviewed your submission and the project described does not meet the "Common Rule" \\ definition of human subjects' research. Therefore, this research project does not require IRB review prior to conducting \\ the research. \\ If you have any questions, please contact the HSPPO office at (502) 852-5188. \\ Thank you for your submission. \\ Sincerely,

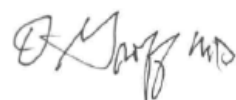 \\ Diller Groff, M.D., Vice Chair \\ Biomedical Institutional Review Board
}




\section{CURRICULUM VITAE}

NAME: $\quad$ Steven Zimmerman

ADDRESS: School of Public Health and Information Sciences 485 Gray Street

Louisville, KY 40202

\section{EDUCATION\&TRAINING}

B.S., Computer Science

Kentucky Wesleyan College

Graduated 1993

M.C.S., Computer Science

Colorado State University

Graduated 2004

Ph.D., Public Health Sciences, Health Management \& Systems Science University of Louisville

August 2016

\section{PROFESSIONAL EXPERIENCE}

2000 - Present Humana, Inc.

Director, Commercial Risk Adjustment

Technology Manager, Medicare Risk Adjustment

Project Manager, Humana Government Services 